\title{
JOINT DESTINATION MARKETING IN THE SOUTH CENTRAL COAST REGION OF VIET NAM
}

\author{
BY \\ LAN THI PHUONG NGUYEN
}

\author{
A thesis \\ submitted to the Victoria University of Wellington \\ in partial fulfillment of the requirements for the degree of \\ Master in Tourism Mangement
}

Victoria University of Wellington

2014 


\section{Abstract}

The tourism industry of Viet Nam has developed rapidly over the last two decades. However, more attention must be given to destination marketing, especially joint destination marketing, if the sector is to continue to expand. To date there has been little research on joint destination marketing, especially in developing countries and transitional economies like Viet Nam. This study attempts to fulfil this gap by examining the joint destination marketing activities of the eight South Central Coast provinces of Viet Nam. The study has three objectives: (1) to examine the nature and extent of current joint destination marketing activities, (2) to analyze the factors that influence joint destination marketing decision-making, and (3) to investigate the destination marketing relationships between local destination marketing organizations(DMOs) of the eight provinces.

The South Central Coast was chosen as the study site as it is the most dynamic tourism development region of Viet Nam. The study triangulated both primary and secondary data. The primary data was collected mainly from semistructured in-depth interviews with DMO representatives. This was complemented by the content analysis of official tourism websites.

Four sets of key findings result from this research. First, the South Central Coast provinces currently conduct destination marketing more individually than jointly. However, all provinces of the region practise a certain mix of both individual and joint marketing activities. Local DMOs also develop competitive and cooperative relationships with other counterpart DMOs. Second, joint destination marketing is an emerging and increasingly common trend in the region and is characterized by different patterns of cooperative behaviour and levels of involvement. Third, joint destination marketing decision-making is influenced by various factors, including preconditions, benefits, drawbacks, motives and barriers. These factors are inter-related, which in turn creates tensions for DMO in their joint destination marketing decision-making. Fourth, in the South Central Coast region, joint destination marketing activities occur 
more commonly at a sub-regional scale than at the scale of the whole region. Furthermore, these sub-region cooperative models involve provinces located in other regions. Decisive factors in destination marketing partnership formation include proximity, convenient transportation, mutual benefits, similar target markets and compatibility of tourism products.

The study concludes by highlighting the need to establish a regional tourism coordinating organization to facilitate joint actions and cooperative interrelationships between provinces. There is also much room left in for further joint destination marketing research.

Key words: joint destination marketing, marketing activities, interrelationships, joint destination marketing decision-making, explanatory factors, data triangulation 


\section{Acknowledgements}

A Master's thesis in tourism is probably one of the most challenging but enjoyable missions I have ever experienced. The thesis could not have been completed without the guidance, support and care of others.

I would like to send big thanks to the New Zealand ASEAN Awards for providing me with an invaluable opportunity to pursue my Master in Tourism Management at Victoria University.

To my supervisor, Prof. Doug Pearce, I would like to express my sincerest thanks for always giving me the best possible guidance with your expertise, passion and determination. I am also very grateful for your experienced advices that are so useful not only for doing research but also for everyday life. I would not have been able to finish the thesis with joy and inspiration without your supervision. I would also like to sincerely thank all members of the Tourism Mangement Group for delivering great tourism lessons and seminars over the past two years.

Thanks so much to my mum, dad and sister Giang for their unconditional love and support no matter what I do or where I go. Special thanks are also sent to Marco - my little family in Wellington - for always loving, making me laugh, keeping me warm and feeding me with pasta and cheese.

To my friends and colleagues in the Masters and Honours room, it is my great pleasure to know you in person and share with you the ups and downs of the Master's journey. Also many thanks to Megan for her great administrative support. Thanks to Beth for her time and effort to proofread this thesis.

Last but not least, I have had two wonderful years of learning and living experiences in Wellington. Thanks again to all people that made that happen and I wish you all the best in the future. 


\section{Table of contents}

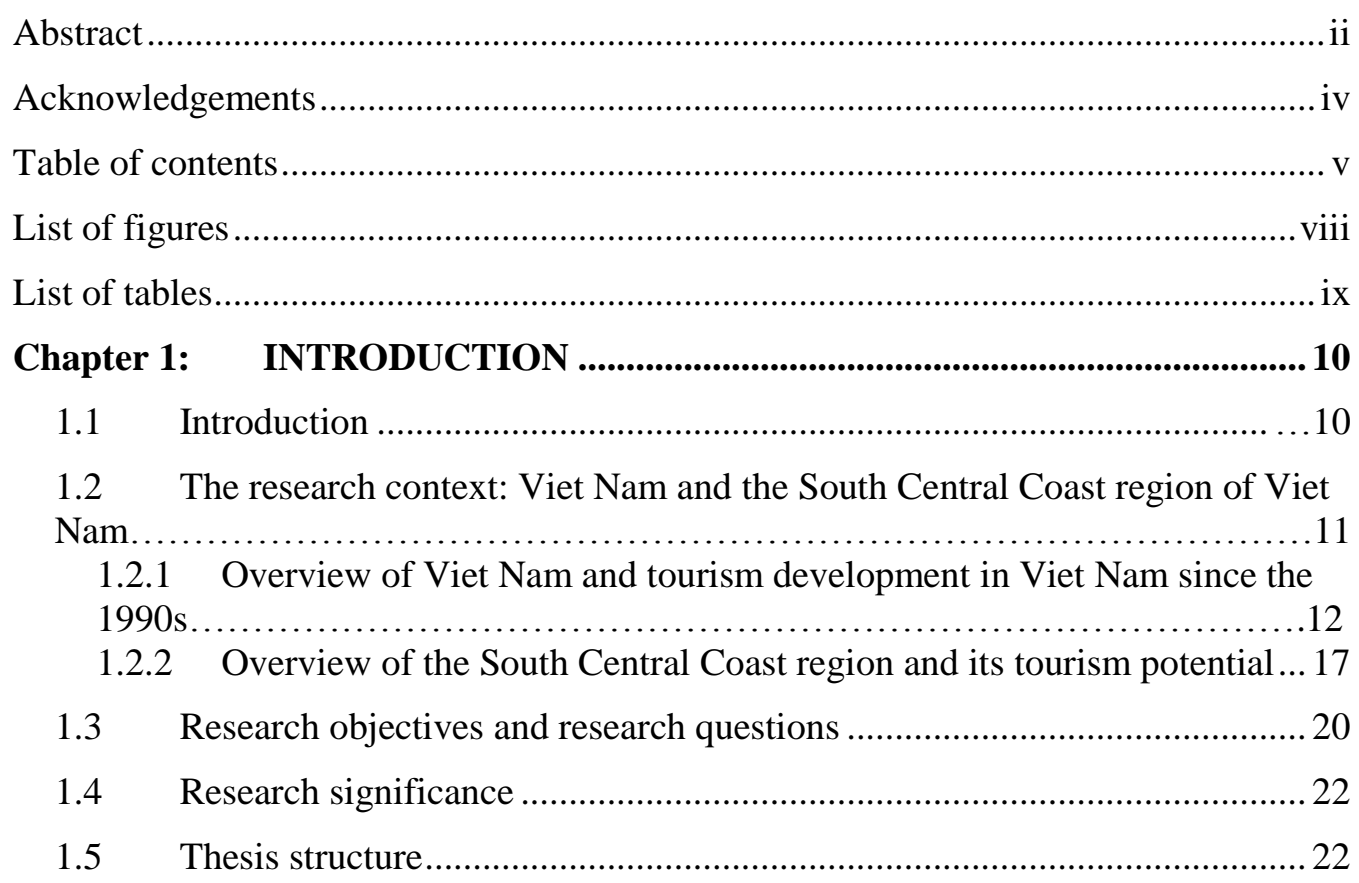

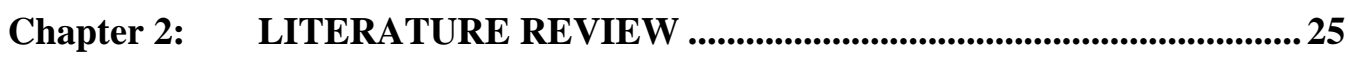

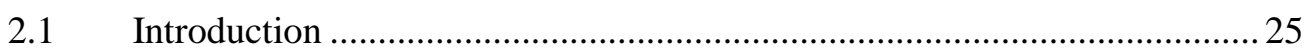

2.2 Defining tourist destinations and destination marketing ............................25

2.3 Destination marketing between tourism organizations...............................28

2.3.1 Destination marketing from perspectives of inter-organizational relations

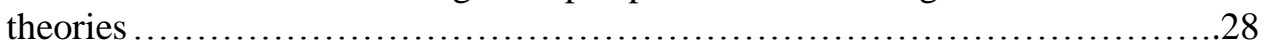

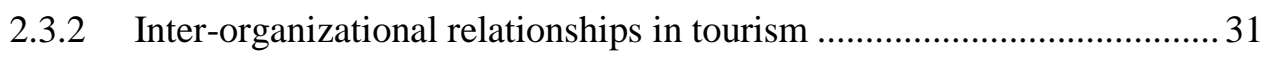

2.3.3 Tourism parnership developmental stages ........................................... 34

2.4 Joint destination marketing activities: Explanatory factors ......................... 35

2.4.1 Preconditions of joint destination marketing .......................................... 35

2.4.2 Motives and barriers............................................................ 36

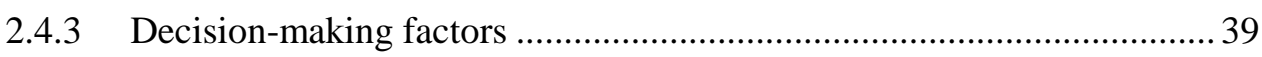

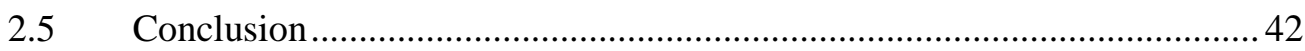

Chapter 3: METHODOLOGY _.........................................................................4

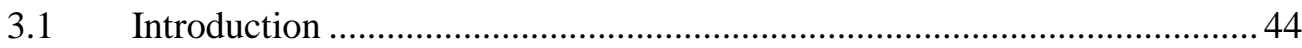

3.2 Selection of study sites and organizations ............................................... 46

3.3 Data collection methods and procedures .................................................. 48

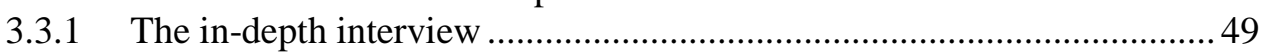

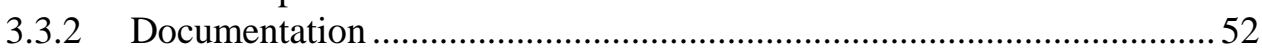

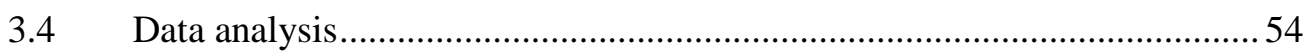

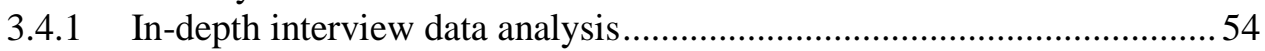

3.4.2 Content analysis of tourism websites and marketing materials...............57

3.5 Data evaluation: Strengths and limitations ................................................5

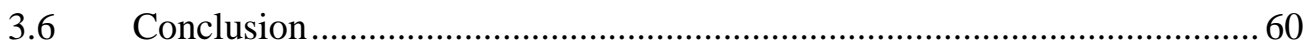




\section{Chapter 4: REGIONAL AND PROVINCIAL DESTINATION}

MARKETING: CONTEXTS OF THE SOUTH CENTRAL COAST REGION .62

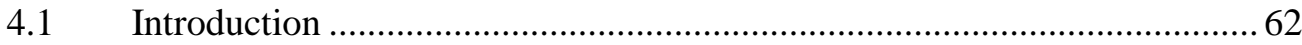

4.2 Regional tourism development and destination marketing context .............62 62

4.3 Provincial tourism development and destination marketing contexts ..........66

4.3.1 Tourism development situations of the eight South Central Coast

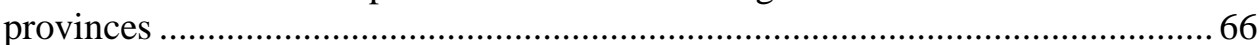

4.3.2 Provincial tourism potential and development orientations ..................... 74

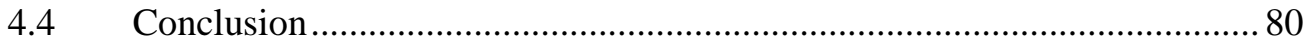

\section{Chapter 5: INDIVIDUAL AND JOINT DESTINATION MARKETING} ACTIVITIES OCCURING IN THE SOUTH CENTRAL COAST REGION......81

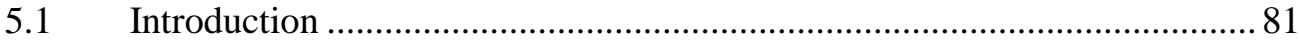

5.2 The role of destination marketing perceived by South Central Coast

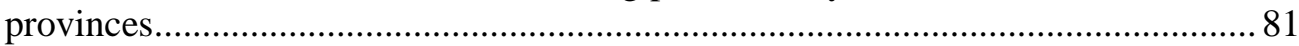

5.3 Joint destination marketing versus individual destination marketing.......... 84

5.3.1 A mix of individual and joint destination marketing activities in South

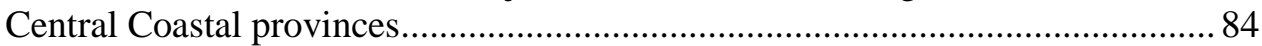

5.4 Joint destination marketing activities of the South Central Coast region....94

5.4.1 Perceptions versus practices of joint destination marketing ................... 94

5.4.2 Whole-region versus sub-region joint destination marketing ............... 100

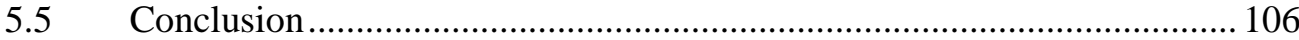

\section{Chapter 6: JOINT DESTINATION MARKETING: FACTORS}

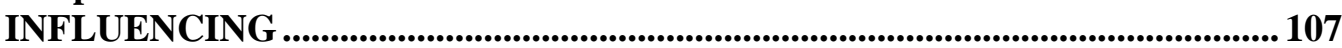

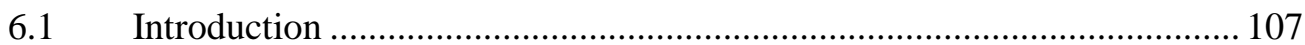

6.2 Conditions favoring joint destination marketing in the region .................. 107

6.3 Benefits and drawbacks perceived from joint destination marketing ........ 113

6.4 Motives for joint destination marketing to South Central Coast

provinces............................................................. 119

6.5 Barriers to implementing joint destination marketing .............................. 122

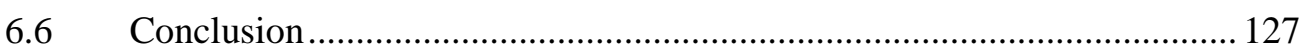

Chapter 7: DESTINATION MARKETING INTER-RELATIONSHIPS OF SOUTH CENTRAL COAST PROVINCES: COOPETITIVE PRESENT AND

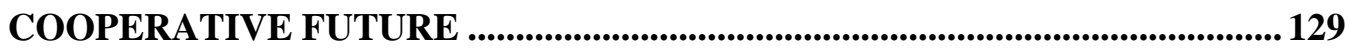

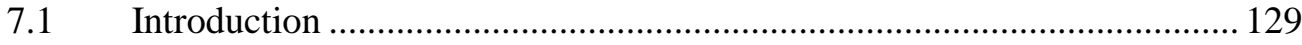

7.2 Destination marketing relationships between South Central Coast provinces: A coopetitive present.

7.3 Destination marketing relationships of the South Central Coast provinces: A

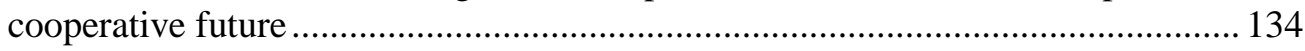

7.4 Joint destination marketing at regional level: What should be done? ....... 137

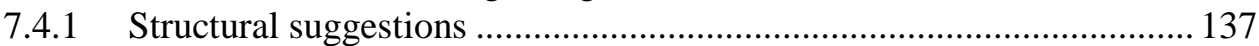

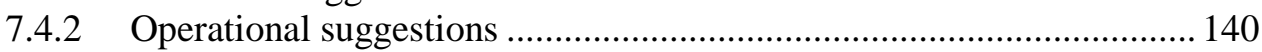

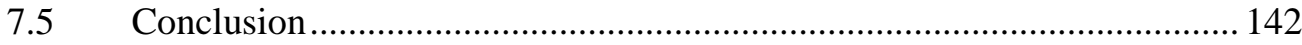


Chapter 8: DISCUSSION, RECOMMENDATIONS AND CONCLUSION ... 143

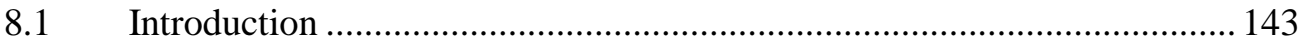

8.2 Joint destination marketing activities of the South Central Coast region.. 144

8.3 Joint destination marketing: Influencing and decision-making factors ..... 146

8.4 Destination marketing interrelationships between South Central Coastal

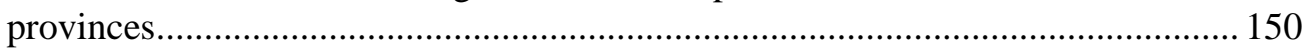

8.5 Implications and recommendations for tourism organizations in Viet Nam

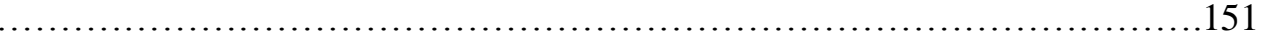

8.5.1 Implications and recommendations for national tourism organizations 151

8.5.2 Implications and recommendations for the regional cooperation

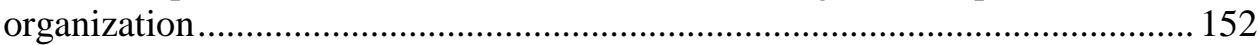

8.5.3 Implications and recommendations for provincial DMOs of South

Central Coast provinces (DCSTs/TIPCs) ......................................................... 153

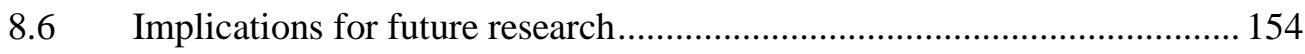

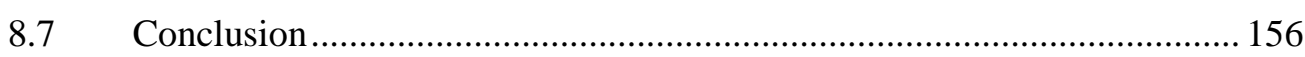

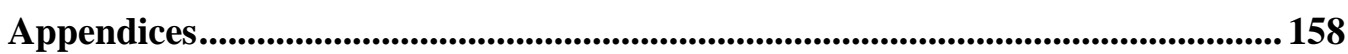

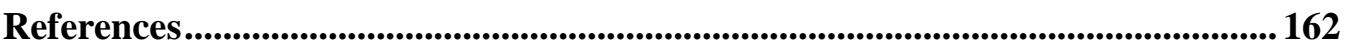




\section{List of figures}

Figure 1.1: Location of Viet Nam in Indochina ...............................................12

Figure 1.2: Tourism receipts of Viet Nam 2005 - 2010 ..................................15

Figure 1.3: Map of the South Central Coast Region ........................................ 17

Figure 2.1: The systematic links between demand and supply, and the influence

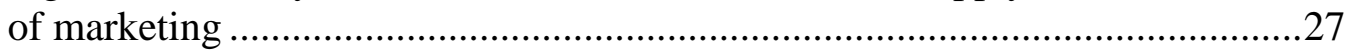

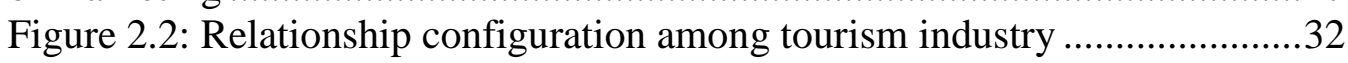

Figure 2.3: Levels of cross-border partnerships in tourism .............................33

Figure 2.4: Continuum of inter-destination relationships ................................. 33

Figure 2.5: Stages of collaboration and level of involvement in collaborative

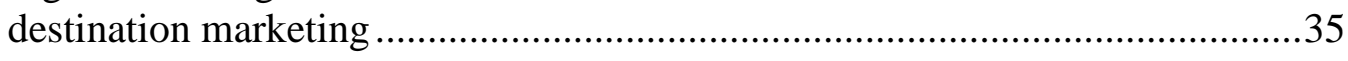

Figure 2.6: Conceptual framework of joint destination marketing ....................41

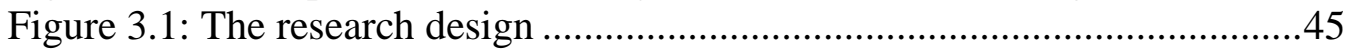

Figure 3.2: Structure of destination marketing organizations in Viet Nam

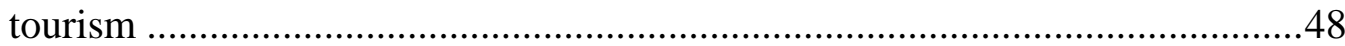

Figure 4.1: Tourist arrivals of the South Central Coast region 2005 - 2012.....63

Figure 4.2: Total tourist arrivals to SCC provinces 2005-2008 and 2011-201266

Figure 4.3: Tourism earnings of South Central Coast provinces in 2008 and

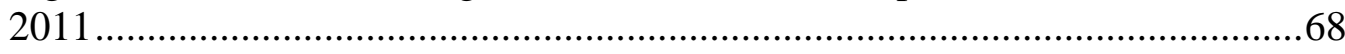

Figure 4.4: Two groups of provinces in the South Central Coast region...........70

Figure 4.5: East-West Economic Corridor (EWEC) ...................................... 74

Figure 5.1: Tourism website of Phu Yen Tourism Information and Promotion

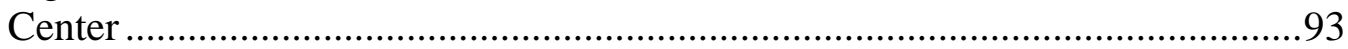

Figure 5.2: Sub-region destination marketing cooperative models .................101

Figure 5.3:Quang Nam's tourism event on Da Nang TIPC's website .............104

Figure 7.1: The destination marketing relationships between South Central

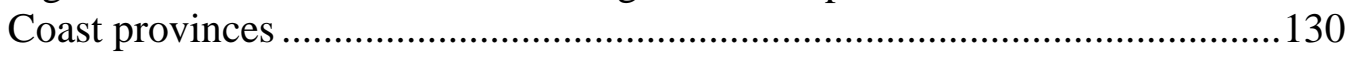




\section{List of tables}

Table 1.1: International and Domestic Tourists of Viet Nam from 1990 to 2012

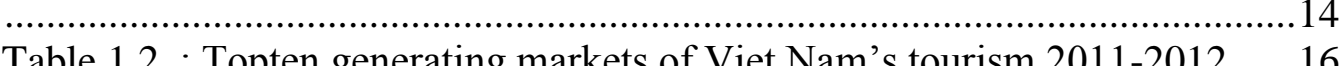

Table 3.1: Analytical framework of provincial and regional destination

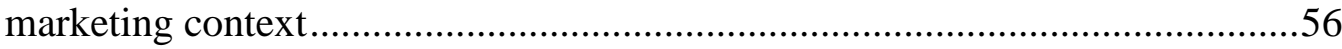

Table 3.2: Analytical framework of joint destination marketing activities .......57

Table 3.3: Content analysis framework of TIPCs' wesbites .............................58

Table 4.1: Tour operators and hotels of South Central Coastal provinces in 2012

Table 4.2: Target tourism markets of South Central Coast provinces .................73

Table 5.1: Individual and joint destination marketing activities occurred in South Central Coast provinces ........................................................................ 85

Table 5.2: Content analysis of Tourism Information and Promotion Centres

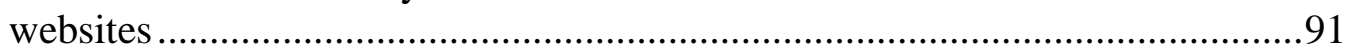




\section{Chapter 1: INTRODUCTION}

\subsection{Introduction}

The tourism sector has contributed substantially to the economic development of many developing and least developed countries. According to the UNWTO Sustainable Tourism - Eliminating Poverty Initiative (ST-EP), tourism is the first or second source of export earnings in 20 of the 48 least developed countries of the world. Also in 2011, emerging markets and developing countries received 459 million international tourists, which accounts for $46.8 \%$ of the market share (UNWTO, 2011).

Of developing countries where the tourism industry has made a big difference, Viet Nam is a typical example. Tourism now accounts for $4.5 \%$ of total GDP of the country and 3.8\% of total employment (WTTC, 2013). Viet Nam tourism achieved an average growth rate of $9.8 \%$ in the past decade (GSO, 2013). The country received 6.8 million international tourists and 32.5 million domestic tourists in 2012, which increased from 2.1 million and 11.2 million respectively in 2000 (VNAT, 2013). In the next ten-year period, Viet Nam is forecasted to rank 16 out of 184 countries in terms of long-term tourism growth (WTTC, 2013).

Although tourism has developed dramatically in developing countries like Viet Nam, little is known about how destination marketing in those countries contributes to the impressive performance of their tourism industries. More studies on destination marketing are conducted in developed countries (Fyall, Leask \& Garrod, 2001; Cox \& Wray 2011; Wang \& Fesenmaier, 2007; Grängsjö \& Gummesson, 2006; Fyall, Oakley \& Weiss, 2000; Augustyn \& Knowles, 2000; Prideaux \& Cooper, 2002; d'Angella \& Go, 2009; Hawes, Taylor \& Hampe, 1991) than in developing countries (Teye, 1988; Wong, Mistilis \& Dwyer, 2010). In addtion, destination marketing between tourism organizations within a single destination (Wang \& Krakover, 2007; Grängsjö, 2003; Palmer \& Bejou, 1995; Soteriades, 2012; Prideaux \& Cooper, 2002) receives more research attention than destination marketing efforts between 
tourism organizations of different destinations (Timothy, 1999; Teye, 1988). These gaps represent challenges for destinations in the context of internationalization and globalization and thus raise the need to study the problem domain of destination marketing between tourism organizations of multiple destinations.

Based on the case study of eight provinces of the South Central Coast region of Viet Nam as a case study, this research aims to explore the nature and extent of joint destination marketing activities between local destinations in a regional context and to investigate factors that contribute to and constrain the practice of those activities. The study seeks to contribute to the inter-destination marketing literature as well as to the limited tourism marketing literature in developing countries.

After the brief introduction, this chapter provides an overview of the research contexts of Viet Nam and the South Central Coast region. More specifically, one section discusses Viet Nam as a transitional economy and its tourism development since 1990s until now. Another section is devoted to background information and tourism potential of the South Central Coast region. The chapter then introduces the research objectives and research questions, which is followed by the significance of the research before ending with the thesis structure.

\subsection{The research context: Viet Nam and the South Central Coast region of Viet Nam}

The South Central Coast region of Viet Nam is one of the seven tourism zones in Viet Nam according to the Viet Nam Tourism Development Strategy to 2020, with the vision to 2030 (VNAT, 2012). Therefore, the section introducing the research context starts with the background information of Viet Nam and Viet Nam tourism development before going into greater detail about the South Central Coast region and its tourism potential. 


\subsubsection{Overview of Viet Nam and tourism development in Viet Nam since the 1990s}

Viet Nam is an S-shaped country lying on the eastern part of the Indochinese peninsula and is located in the Southeast Asian region. Viet Nam shares borders with China in the north, Laos and Cambodia in the west, the East Sea (or South China Sea) in the east and the Pacific Ocean in the east and south. Viet Nam has a very diverse topography, ranging from mountains, hills, deltas, coastlines, karst, islands and archipelagoes (VNAT, 2005). The country has a total area of 331,221 square kilometers and the population is around 92.4 million, $85.7 \%$ of which are Kinh (Viet) people (CIA, 2013).

Figure 1.1: Location of Viet Nam in Indochina

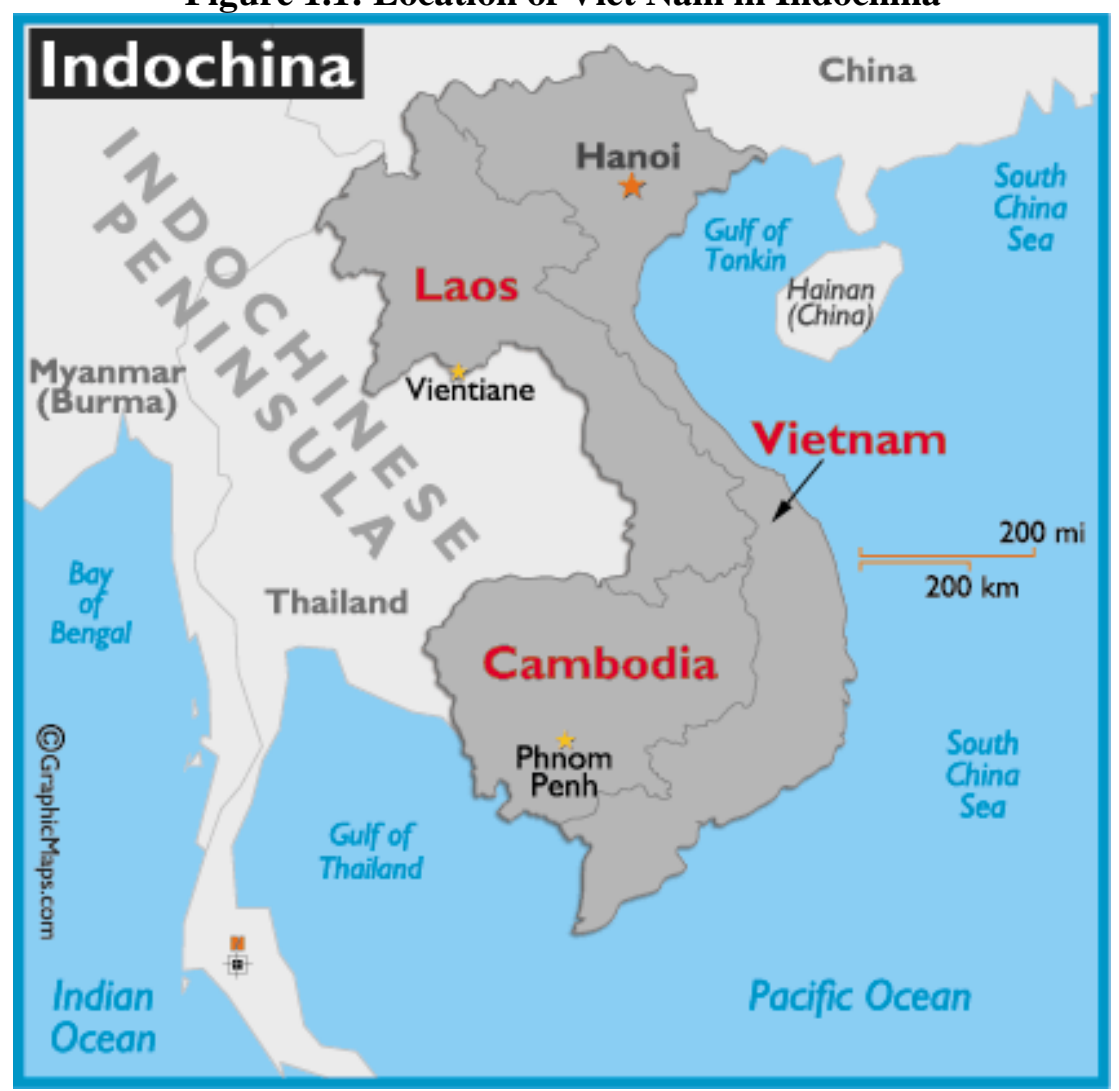

(source: http://www.worldatlas.com)

In 1975, Viet Nam was totally unified after consecutive wars and started rebuilding the country. In 1986, the country initiated the political and economic renovation process called Doi Moi with the main aim of transforming the centrally-planned economy to the socialist-oriented market economy. Doi Moi 
helped Viet Nam to strongly recover from war damage and develop rapidly at an average GDP growth rate of 8.75\% between 1992 and 1997. After the Asian financial crisis during 1997/1998, the economy of Viet Nam grew more slowly but was still one of the fastest-growing countries with an average growth rate of 8\% during 2003-2007 (World Bank, n.d.). The country also has restructured its economy from one based on agriculture towards one based more on industry and service sectors. In particular, agriculture, fisheries and forestry contributed $18.4 \%$ of total GDP in 2013; industry and manufacturing accounted for $38.3 \%$ and services made the biggest contribution of $43.3 \%$. The respective ratios to GDP in 2012 were 19.7\%; 38.6\% and 41.7\% (GSO, 2013). Although having achieved successes in its recovery and development process, Viet Nam's transition to a full market economy is not yet complete. Characteristics of such a transitional economy can still be seen in Viet Nam today, for instance through the centralised structure of organizations. In highly market-oriented fields like tourism and destination marketing, a special focus on market needs is fundamental while a lack of it is a disadvantage. Some findings in later chapters will provide insights into the level of market orientation in the tourism sector in the South Central Coast region.

Being endowed with diverse nature, a rich history and a colorful culture of 54 ethnicities, Viet Nam has great potential to develop tourism. Together with positive changes caused by the open door policy Doi Moi, Viet Nam's tourism industry has developed rapidly and gained important achievements. Table 1.1 shows the development of both the international and domestic tourist markets of Viet Nam during the period 1990-2012. As can be seen, Viet Nam had only 250,000 international tourists and 1,000,000 domestic tourists in 1990. Since then, domestic markets kept increasing to reach 10,000 in 1999 and tripled this number in 2011 before ending the year 2012 with 32.5 million tourists. The international markets increased almost continuously, except for three decreases witnessed in 1998, 2003 and 2009. The number of international arrivals dropped from $1,715,600$ in 1997 to $1,520,100$ in 1998 , which was mainly due to the Southeast Asian economic crisis. A similar drop of 199,253 international tourists occurred again in 2003 when the tourism industries of Southeast Asian 
countries were seriously affected by the Severe Acute Respiratory Syndrome (SARS) epidemic. The world financial crisis in 2009 was also the main reason as to why international tourists to Viet Nam reduced from 4,253,740 in 2008 to $3,772,359$ in 2009. Viet Nam's tourism industry recovered dramatically and welcomed more than 5 million international tourists in 2010, about 6 million in 2011 and 6.8 million in 2012.

Table 1.1: International and Domestic Tourists of Viet Nam from 1990 to 2012

\begin{tabular}{|c|c|c|}
\hline Year & International tourists & Domestic tourists \\
\hline 1990 & 250,000 & $1,000,000$ \\
\hline 1991 & 300,000 & $1,500,000$ \\
\hline 1992 & 400,000 & $2,000,000$ \\
\hline 1993 & 670,000 & $5,100,000$ \\
\hline 1994 & $1,020,000$ & $6,200,000$ \\
\hline 1995 & $1,351,300$ & $6,900,000$ \\
\hline 1996 & $1,607,200$ & $7,300,000$ \\
\hline 1997 & $1,715,600$ & $8,500,000$ \\
\hline 1998 & $1,520,100$ & $9,600,000$ \\
\hline 1999 & $1,781,800$ & $10,000,000$ \\
\hline 2000 & $2,140,100$ & $11,200,000$ \\
\hline 2001 & $2,330,050$ & $11,700,000$ \\
\hline 2002 & $2,627,988$ & $13,000,000$ \\
\hline 2003 & $2,428,735$ & $13,500,000$ \\
\hline 2004 & $2,927,873$ & $14,500,000$ \\
\hline 2005 & $3,477,500$ & $16,100,000$ \\
\hline 2006 & $3,583,486$ & $17,500,000$ \\
\hline 2007 & $4,229,349$ & $19,200,000$ \\
\hline 2008 & $4,253,740$ & $20,500,000$ \\
\hline 2009 & $3,772,359$ & $25,000,000$ \\
\hline 2010 & $5,049,855$ & $28,000,000$ \\
\hline 2011 & $6,014,032$ & $30,000,000$ \\
\hline 2012 & $6,847,678$ & $32,500,000$ \\
\hline
\end{tabular}

Source: Vietnam National Administration of Tourism (2013) 
The tourism industry plays an increasingly significant role in the country's economy. In 2011, tourism directly contributed VND107,318 billion (4.3\% of total GDP), which increased to VND129,969 billion (4.5\% of total GDP) in 2012. The industry directly generated $1,831,500$ jobs and indirectly supported 3,892,000 jobs in 2012 (WTTC, 2013). Tourism receipts have also grown strongly since 2005 despite the global economic downturn, as shown in Figure 1.2 .

Figure 1.2: Tourism receipts of Viet Nam 2005 - 2010 (both international \& domestic tourist markets)

\section{billion VND}

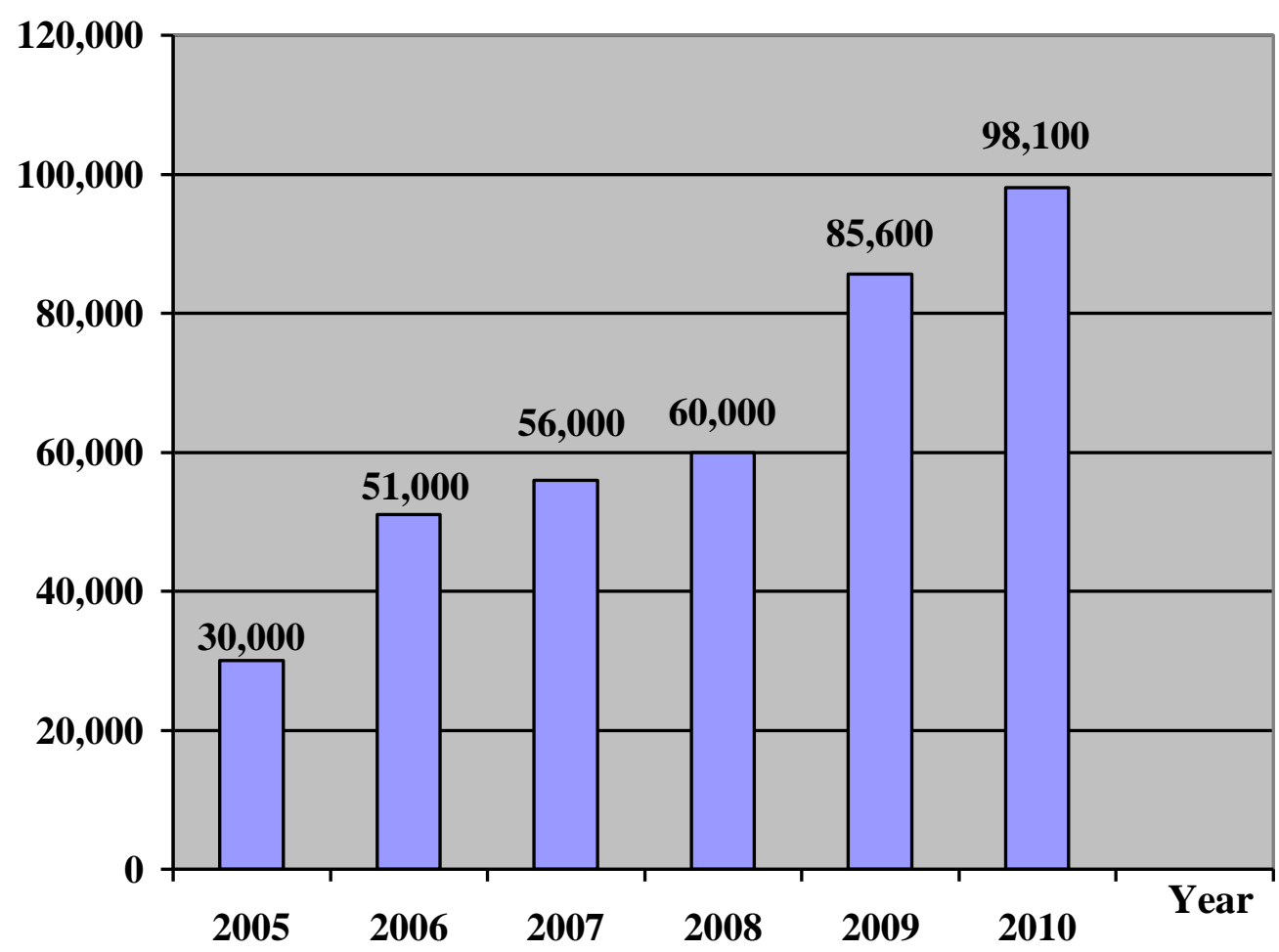

Source: Vietnam National Administration of Tourism (2013)

The top-ten target markets of Viet Nam tourism industry include China, South Korea, Japan, the USA, Taiwan, Cambodia, Malaysia, Australia, Thailand and France. China is the leading origin market of Viet Nam, generating more than 1.4 million foreign tourists to the country in 2011 and 2012. However, the growth rate of this market was much lower $(0.84 \%$ in 2012) compared to other 
Northeast and Southeast Asia countries- Korea (+30.6\%), Japan (+19.7\%), Taiwan (+13.38\%), Malaysia (+28.27\%) and Thailand (+24.23\%) (Table 1.2).

Table 1.2 : Topten generating markets of Viet Nam's tourism 2011-2012

\begin{tabular}{|l|c|c|c|}
\hline \multirow{2}{*}{ Country } & \multicolumn{2}{|l|}{ Number of arrivals } & \multirow{2}{*}{ Growth rate } \\
\cline { 2 - 3 } & 2011 & 2012 & \\
\hline China & $1,416,804$ & $1,428,693$ & $0.84 \%$ \\
\hline Korea & 536,408 & 700,917 & $30.6 \%$ \\
\hline Japan & 481,519 & 576,386 & $19.7 \%$ \\
\hline USA & 439,872 & 443,826 & $0.9 \%$ \\
\hline Taiwan & 361,051 & 409,385 & $13.38 \%$ \\
\hline Cambodia & 423,440 & 331,939 & $-21.6 \%$ \\
\hline Malaysia & 233,132 & 299,041 & $28.27 \%$ \\
\hline Australia & 289,762 & 289,844 & $0.03 \%$ \\
\hline Thailand & 181,820 & 225,866 & $24.23 \%$ \\
\hline France & 211,444 & 219,721 & $3.9 \%$ \\
\hline
\end{tabular}

Source: Vietnam National Administration of Tourism (2012)

In 2013, Viet Nam tourism witnessed a dramatic growth in Russian market from 174,287 tourists in 2012 to 298,126 tourists in 2013 (+ 71.05\%) (VNAT, 2013). Favorite destinations for Russian tourists in Viet Nam are South Central Coastal provinces, especially southern provinces of the region like Khanh Hoa and Binh Thuan.

Despite a rapid growth, Viet Nam's tourism still lags behind many neighbouring countries in Southeast Asia. The successes of Viet Nam's tourism are very modest compared to countries like Malaysia, Thailand and Singapore with respectively 24.7 million, 19 million and 13 million international tourists in 2011 (ASEAN, 2012). Destination marketing is one of the key success factors of these three countries and at the same time is one of the weaknesses of Viet Nam's tourism. By investigating the way in which destination marketing activities are done in eight provinces of the South Central Coast region, the study helps to identify some major problems of destination marketing not just of the region but also of the whole country. 


\subsubsection{Overview of the South Central Coast region and its tourism potential}

The South Central Coast region is the narrow strip of land located in the middle of the country. It consists of eight coastal provinces: Da Nang, Quang Nam, Quang Ngai, Binh Dinh, Phu Yen, Khanh Hoa, Ninh Thuan and Binh Thuan (Figure 1.3). The region has a total area of 44,376.8 square kilometers (GSO, 2012) and a total population of 9,071,000 people in 2012 (CRDF \& DNPPC, 2013). Also in 2012, the region generated 79,778.3 billion VND to the national GDP and all eight provinces had a resonably high economic growth rate. Like all localities of Viet nam, South Central Coast provinces have shifted their economies from mainly agriculture-based to increasingly industrial and services-focused. Services were recorded to be the most important sector in the economy of Da Nang, Khanh Hoa and Binh Thuan in 2012 with its share of $54.42 \%$ in Da Nang and $41.6 \%$ in Khanh Hoa and $45.7 \%$ Binh Thuan (CRDF \& DNPPC, 2013).

Figure 1.3: Map of the South Central Coast Region

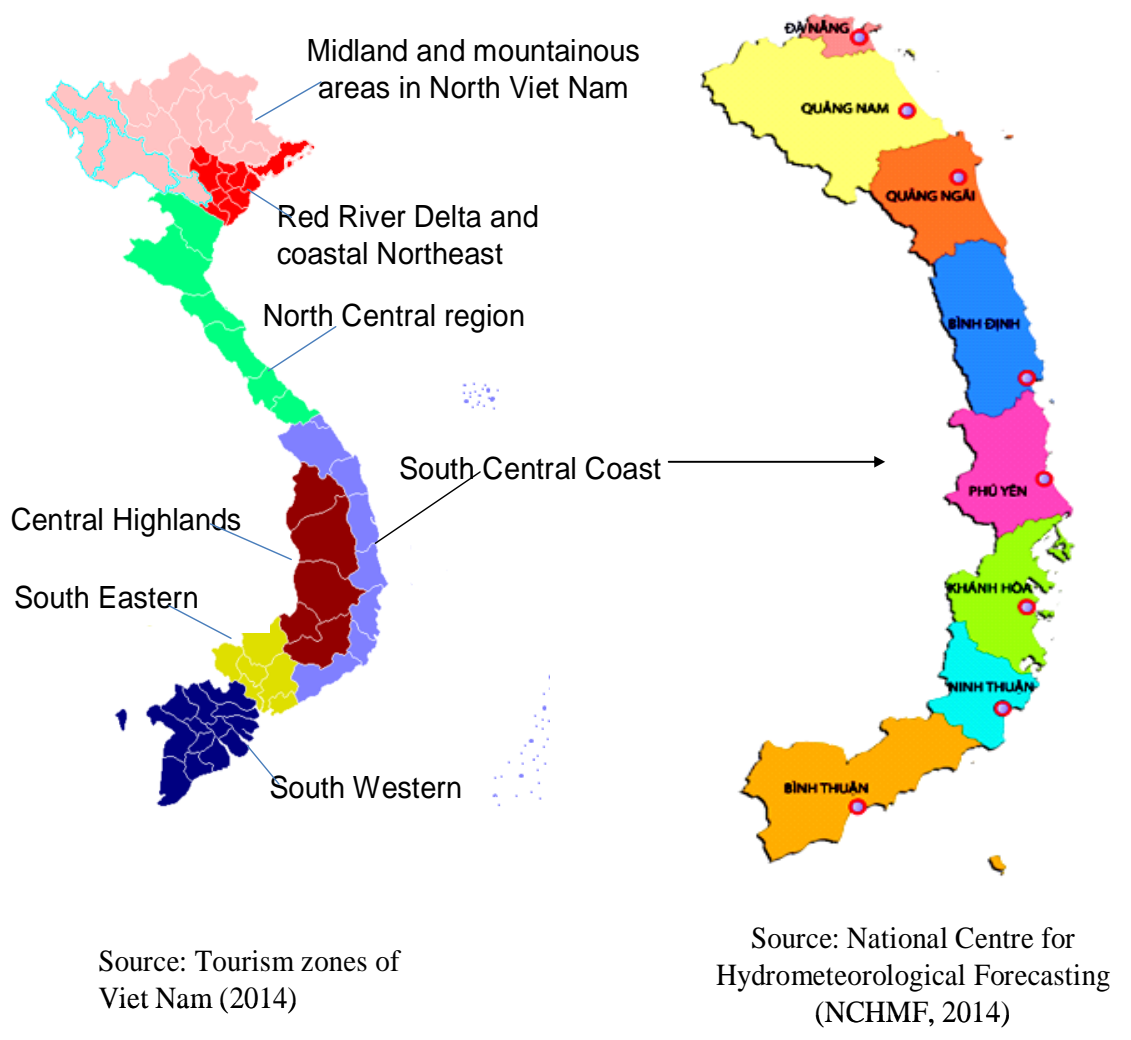

Note: Name and order of South Central Coastal provinces (from north to south)
1. Da Nang
2. Quang Nam
5. Phu Yen
3. Quang Ngai
6. Khanh Hoa
4. Binh Dinh
7. Ninh Thuan
8. Binh Thuan 
All provinces in the region have coastlines with a total length of $1310 \mathrm{~km}$, accounting for $40.18 \%$ of the total national coastline $(3260 \mathrm{~km})$. The region is famous for beaches like Da Nang beach - one of the six most luxurious beaches in the world (Forbes, 2005); An Bang (Quang Nam) - CNN's list of 100 best beaches in the world (CNN, 2013); Nha Trang Bay - one of the most beautiful bays in the world (World-bays, n.d.). Besides beaches, the region also possesses islands and peninsulas that have much potential to develop tourism such as Son Tra peninsula (Da Nang), Cham island (Quang Nam), Ly Son island (Quang Ngai), Hon Tre island (Nha Trang), Phu Quy island (Binh Thuan), two archipelagoes, namely the Paracel islands in Da Nang and the Spratly islands in Nha Trang. In general, the region is especially rich in maritime resources and this is the foundation for the region to develop coastal tourism. It is important to note here that the term "beach or sea tourism" is translated literally from Vietnamese. However, it implies all tourism activities that are based on marine resources, not just beaches. To be clearer, thus, this study uses the terms “coastal or marine tourism”, instead of beach tourism.

The region's advantages also come from the special location facing both the East Sea in the east and the Truong Son mountain range in the west. The range has with it the high-biodiversity ecosystem of waterfalls, springs, caves, primeval forests and a wide variety of rare plants and animal species that are named in the Red Book of Viet Nam and the world (CRDF \& DNCCP, 2013). The region now has two national parks, Nui Chua and Phuoc Binh, which were established in 2003 and 2006 respectively from two nature reserves. These natural conditions provide additional tourism potential for the region, especially in terms of eco-tourism activities.

In addition to coastal and eco-tourism potential, the region is rich in cultural and historical heritage. The region is the cradle of Sa Huynh culture- one of the three earliest centres of civilization in Viet Nam - which thrived about 2,500 years ago. The Cham people who are possibly the descendants of Sa Huynh people lived and built their Champa kingdom throughout the region until the $19^{\text {th }}$ century. This explains why Champa relics can be found in almost every 
province of the South Central Coast such as My Son sanctuary, Chien Dan Tower, Da Nang museum of Cham Sculpture, Banh It Towers, Ponagar Tower, Po Klong Garai Towers and so on. The region is also the intersection of cultures of Vietnamese, Cham, Chinese, Japanese when Hoi An (Quang Nam) was an important trading port of the Southeast Asia in the $16^{\text {th }}$ and $17^{\text {th }}$ centuries. Hoi An ancient town and My Son sanctuary were listed as the world cultural heritages sites by UNESCO in 1999 (UNESCO, n.d.). In addition, all eight South Central Coast provinces have well-known landscapes with outstanding cultural, historical and spiritual values. Some typical sites include the Marble Mountains, Dien Hai citadel in Da Nang; the capital of Tra Kieu, Sa Huynh Culture museum in Quang Nam; Son My memorial, Truong Luy rampart in Quang Ngai; Quang Trung museum, Emperor citadel in Binh Dinh; Ghenh Da Dia (Rapids of stone plates), Numberless ships in Vung Ro bay in Phu Yen; Ponagar tower, Dien Khanh citadel, Institute of Oceanography in Khanh Hoa; Ong Nui pagoda, Ca Du Mount historic relic in Ninh Thuan and Duc Thanh School, Ke Ga light house in Binh Thuan (CRDF \& DNPPC, 2013).

In terms of intangible cultural heritages, the South Central Coast region possesses unique traditions, customs, festivals, traditional handicraft villages and cuisine. The region possesses special festivals which cannot be found in other regions, for example - Nghin Ong (Whale worshipping) festival, Hoang Sa Soldier Feast and Commemoration festival, traditional martial arts festival and Kate festival. The marine culture also brings differences to this region's cuisine. Along with fresh and tasty seafood, each locality has its own specialities, including rolled pork paper cake (Da Nang); Cao Lau noodle, Mi Quang noodle (Quang Nam); Tra river's goby fish (Quang Ngai); Nem Huyen (Binh Dinh); Dried beef (Phu Yen); Salanganes' Nest (Khanh Hoa); Phan Rang chicken rice (Ninh Thuan); and Phan Thiet fish sauce (CRDF \& DNPPC, 2013).

In short, the South Central Coast region has diverse tourism potential and favorable conditions to develop various types of tourism, especially coastal and cultural tourism. 


\subsection{Research objectives and research questions}

As can be seen from the previous section, the coastal and cultural tourism potential of the region is scattered over eight provinces. Accordingly, the Viet Nam Tourism Development Strategy to 2020, with the vision to 2030 (VNAT, 2012) has identified the tourism orientation for the whole region, not for individual provinces. This clearly requires the eight localities in the region to work together. However, it is unclear whether this is happening? Do the provinces work jointly for regional tourism development or not? To what extent do they actually conduct tourism activities together? What factors influence this? And what is the destination marketing relationships between destination marketing organizations (DMOs) of multiple provinces in the region? Linking these unexplored questions with research gaps identified earlier, this study investigates joint activities between eight South Central Coast provinces in the specific area of destination marketing. In order to reach that goal, the study aims to:

- Examine the nature and extent of current destination marketing activities that occur jointly between the eight South Central Coast provinces of Viet Nam

- Analyze the factors that influence joint destination marketing decisionmaking in the South Central Coast region

- Investigate the destination marketing relationships between local DMOs of the eight provinces in the region

These objectives are to be achieved by answering the following primary and secondary research questions:

1) What is the nature and extent of joint destination marketing activities in the South Central Coast region of Vietnam?

- What is the destination marketing context of each South Central Coast province and of the whole region? 
- Do South Central Coast provinces do more individual or joint destination marketing?

- What joint destination marketing activities are currently done by South Central Coast provinces?

2) What are the factors that contribute to and constrain the practice of joint destination marketing in the context of the South Central Coast region?

- What conditions, benefits, motives and barriers of joint destination marketing perceived by representatives of local DMOs?

- Which of these are the most important factors in making decisions about joint destination marketing?

3) How do tourism representatives of provincial DMOs perceive the destination marketing relationships they have with counterpart DMOs in the region at present and in the future?

The tourism development situation and destination marketing contexts of the region and of individual provinces are examined first. This is because these contextual factors may affect the ways in which provinces conduct their destination marketing as well as influence joint destination marketing decisions. The study then investigates which of the two approaches - individual or joint marketing - is mainly practised in the South Central Coast region. Current joint marketing activities and their characteristics are examined next in the third secondary questions. Joint destination marketing activities of the region are then explained in terms of preconditions, benefits, drawbacks, motives and barriers perceived by tourism representatives. The most important factors that influence joint destination marketing decisions of the eight South Central Coast provinces are drawn. Finally, the study investigates the destination marketing relationships between DMOs of the eight provinces in order to shed light on destination marketing relationships between multiple destinations, which is identified as a research gap in existing destination marketing literature. 


\subsection{Research significance}

By meeting its objectives, this thesis can make three important contributions to the current destination marketing literature and to the cooperative activities of the tourism industry of Viet Nam in general and of the South Central Coast region in particular. First, it contributes to the limited literature on destination marketing in developing countries. Second, by investigating joint marketing activities and relationships between neighbouring local destinations in a regional context, the study contributes to the inter-destination marketing literature which has not yet attracted much research attention. Third, it provides destination marketing organizations at local, regional and national levels with an evidence-based understanding of the nature and extent of actual joint marketing activities. Consequently, provinces, the region and the nation can develop appropriate policies and actions to facilitate joint destination marketing effectively and beneficially to multiple stakeholders in the tourism industry.

\subsection{Thesis structure}

This thesis consists of eight chapters. This first chapter has introduced the research topic and presented it as an appropriate topic to fulfil the gaps being found in the current destination marketing literature. It has then described the research contexts of Viet Nam and the South Central Coast region. In particular, contextual information on tourism development in Viet Nam since the 1990s and on the tourism potential of the South Central Coast region was provided. This information forms the foundation on which joint marketing activities are analyzed. The chapter then presented the research objectives, research questions and explained the ways in which the research makes both theoretical and practical contributions.

Chapter Two reviews several key themes within the tourism and destination marketing literature in order to develop a theoretical background and then a conceptual framework for the research. The chapter firstly reviews some definitions of tourism destinations, the role of destination marketing in the tourism system and a definition of destination marketing from the DMOs' perspective. Destination marketing between multiple tourism organizations is 
then discussed from four inter-organizational relations theories, namely resource dependency theory, transaction cost theory, strategic management theory and network theory. Previous studies that examine the relationships between tourism organizations are then reviewed through two aspects: forms of inter-organizational relationships and development stages of tourism partnerships. The chapter continues discussing factors that may influence the organizations' decisions for entering tourism partnerships, including preconditions, benefits, drawbacks, motives and barriers. Finally, the chapter reviews factors that affect tourism partnership decisions of tourism organizations.

Chapter 3 discusses the research design and methodology of the study. The chapter introduces a comparative approach and justifies it as an appropriate research method for the study. The choice of study sites and organizations is also justified before different sources of data (in-depth interviews, documentation and secondary data) and the data-collection procedures are explained in detail. The steps of the interview data analysis and content analysis are then presented, followed by data evaluation to outline the strengths and limitations of the study.

The study's results are presented in four findings chapters. Chapter Four provides a general overview of the tourism development and destination marketing contexts of the region and its member provinces. The chapter begins with a section discussing the tourism development situation and orientation of the region in association with regional tourism potential that has been presented in the research context in Chapter One. Similarly, the tourism development status and marketing contexts of the eight provinces are discussed in a comparative manner in terms of tourist arrivals, tourism infrastructure, target markets, tourism strengths and weaknesses, development goals and typical tourism products.

Chapter Five presents findings related to destination marketing activities that have occurred in the South Central Coast region. The chapter first discusses the 
role of destination marketing perceived by DMOs representatives. Second, individual and joint destination marketing activities are reviewed based on semi-structured in-depth interviews and the content analysis of official tourism websites. The comparison between joint marketing in perceptions versus in practices as well as between whole-region versus sub-region scales indicate several patterns of the current joint destination marketing activities in the region.

Chapter Six focuses on examining factors that affect the joint destination marketing decisions made by South Central Coast provinces. Drawing from the literature review, factors that are examined included preconditions, benefits, drawbacks, motives and barriers perceived by interviewed tourism representatives. The chapter then draws conclusions regarding which are the most important factors in making joint marketing decisions in the case of the South Central Coast provinces.

Chapter Seven investigates the perceived destination marketing relationships between provincial DMOs in the region by using a continuum representing forms of inter-organizational tourism relationships drawn from the literature. Some future patterns of the region's joint destination marketing are also explored and presented together with structural and operational suggestions made by DMOs representatives to guide the region to achieve its common goals.

Chapter Eight summarizes findings and refers them to previous studies. Being the final chapter, it also discusses implications and recommendations for DMOs at national, regional and provincial levels. Opportunities for future research in joint destination marketing are then included before the conclusion on the thesis' theoretical and practical contributions is presented at the end. 


\section{Chapter 2: LITERATURE REVIEW}

\subsection{Introduction}

After the first chapter which provided a general introduction, this chapter reviews relevant studies in the field of tourism and destination marketing in order to contextualize the study within the existing literature.

To examine the nature and extent of joint destination marketing in the chosen region, it is critical to understand different perspectives from which tourist destinations and destination marketing are defined. Several studies on typical characteristics of destination products and destination marketing then explain the interdependences and thus provide the rationale for multiple stakeholders to work with each other. The study mainly focuses on exploring and explaining the current destination marketing activities that are conducted jointly between a number of destination marketing organizations (DMOs) of neighbouring provinces. Therefore, several commonly-used theories of inter-organizational relations (IOR) are reviewed and discussed. Furthermore, the literature on variable forms of inter-relationship between multiple tourism organizations guides the introduction of the relationship continuum which is then used to investigate the current inter-destination relationship configuration of South Central Coast provinces. A discussion on process-oriented studies of tourism partnership formation is also fundamental to acknowledge the current stage that the eight study provinces are in. The final section of the literature review discusses possible factors that influence the formation of tourism partnerships such as preconditions, motives, barriers and decision-making factors.

\subsection{Defining tourist destinations and destination marketing}

A tourist destination is a complex and multidimensional concept (Pearce, 1989; Buhalis, 2000; Murphy, Prichard \& Smith, 2000). Destinations are perceived differently from the perspectives of suppliers and consumers. From tourists' perspectives, a tourist destination is perceived as a unified product which provides tourists with integrated experiences and thus enables them to compare one destination with others (Buhalis, 2000; Grängsjö, 2003). From the 
suppliers' point of view, tourist destinations are made up of multiple product components offered by multiple suppliers (Wang, 2008). Therefore, although producers of destination product components are autonomous organizations, they are dependent on each other in order to offer tourists with integrated tourism products. Generally from a stakeholder's perspective, d'Angella and Go (2009) define a destination "as an open-social system of interdependent and multiple stakeholders" (p. 429).

According to the World Tourism Organization (2007):

A local tourism destination is a physical space in which a tourist spends at least one overnight. It includes tourism products such as support services and attractions and tourist resources within one day's return travel time. It has physical and administrative boundaries defining its management, and images and perceptions defining its market competitiveness. Local destinations incorporate various stakeholders often including a host community, and can nest and network to form larger destinations. Destinations could be on any scale, from a whole country (e.g. Australia), a region (such as the Spanish 'Costas') or island (e.g. Bali), to a village, town or city, or a self-contained centre (e.g. Center Parc or Disneyland).

This definition is appropriate for the present study which looks at multiple destinations at the provincial level and their joint destination marketing at a regional level.

In the process of creating integrated experiences for tourists, marketing plays a role in connecting the demand side representing the tourists with the supply side representing all tourist-service providers at the destinations (Middleton \& Clarke, 2001). Marketing links the fragmented components of the tourism system together (Figure 2.1). 
Figure 2.1: The systematic links between demand and supply, and the influence of marketing

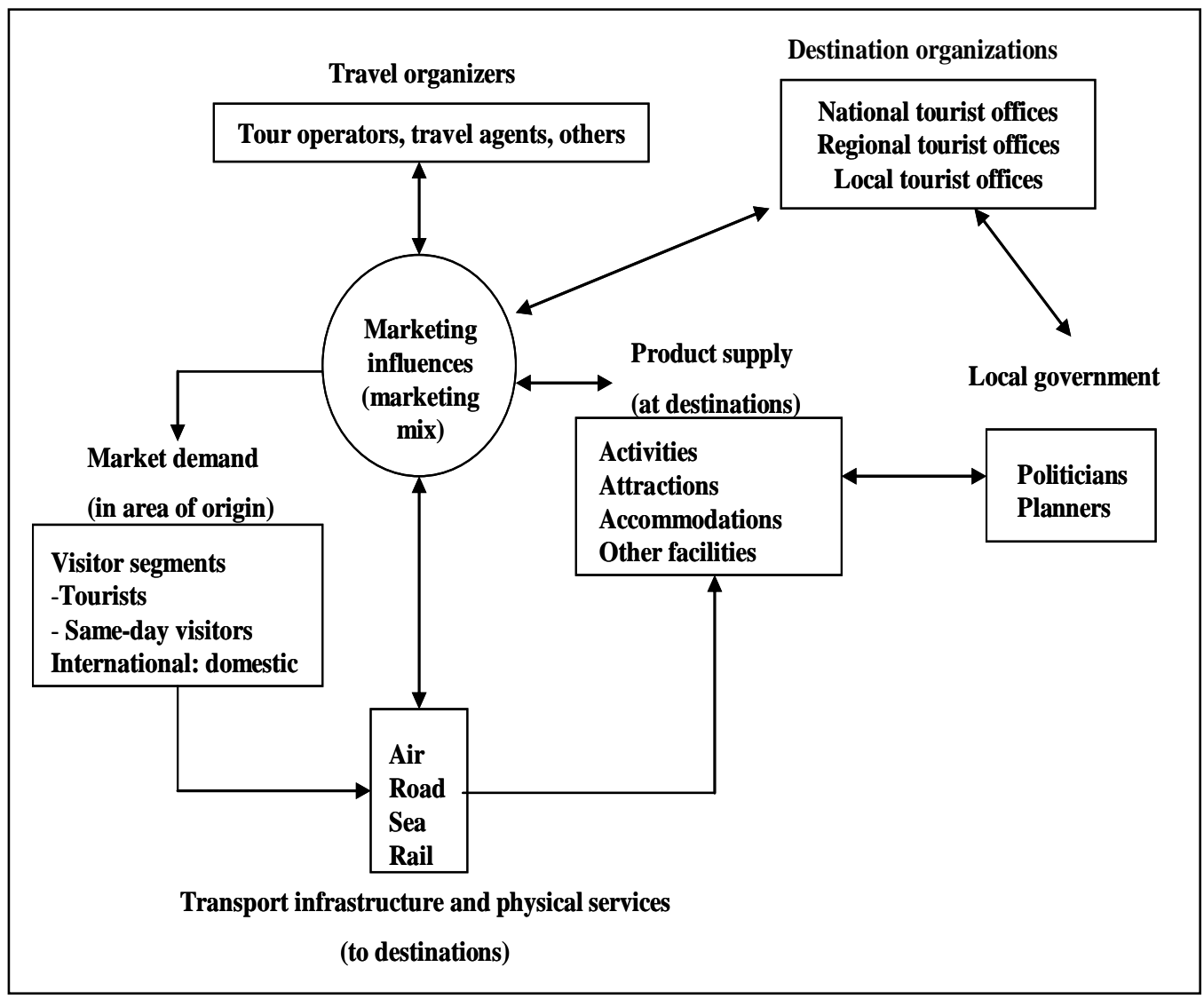

Source: Middleton, 1998, cited in Fyall and Garrod, 2005

Destination marketing lies at the very heart of tourism marketing given the important role of destination in the tourism system (Hsu et al., 2008). While various tourism-related organizations and companies are involved in tourism marketing, the responsibility of marketing a destination often lies with destination marketing organizations (Pike, 2008). Therefore, the definition of destination marketing from a DMO perspective is critical in this study. Such a definition has been recently provided by Morrison (2013, p.9):

Marketing is a continuous, sequential process through which a destination management organization (DMOs) plans, researches, implements, controls and evaluates programmes aimed at satisfying traveller's needs and wants as well as the destination's and DMO's vision, goals and objectives. To be most effective, the DMO's marketing programs depend upon the efforts of many other organizations and individuals within and outside the destination. 
The definition emphasizes the process-oriented dimension and the necessity of networking in destination marketing given the interdependence of multiple tourism stakeholders to provide unified travel experiences for tourists.

The fragmented nature of the tourism industry makes destination marketing extremely complex. Fyall and Leask (2006) rank "complexity" as the very first challenge to destination managers and marketers. That complexity is said to be "not in dispute" (p.53) because of a wide variety of suppliers involved in delivering the integrated travelling experiences for tourists. A destination product is not just fragmented in components but also in ownership. Consequently, no single producer or organization has total control over the marketing of a destination product (Baker \& Cameron, 2008). Horner and Swarbrooke (1996) discuss another interesting feature of destination marketing, which is the absence of a pricing mechanism and that is also associated with the involvement of multiple suppliers in the tourism industry.

Furthermore, destination marketing has also changed over time. Traditionally, destination marketing concentrated on creating and promoting destination images in order to attract an increasing number of visits (Cox \& Wray, 2011). Marketing also used to treat tourism like other commodities (Buhalis, 2000), which is not appropriate in today's context. Destination marketing now aims at adopting a more sustainable approach where the needs of both tourists and residents are satisfied. In other words, destination marketing today has dual functions which are to develop destinations in a sustainable manner and to provide high-quality experiences for tourists (Cox \& Wray, 2011).

\subsection{Destination marketing between tourism organizations}

\subsubsection{Destination marketing from perspectives of inter-organizational relations theories}

In the tourism literature, the concept of inter-organizational relations (IOR) is widely used in efforts to understand dynamics and relationships between organizations (Selin \& Beason, 1991; Gray, 1985; Wood \& Gray, 1991; Jamal \& Getz, 1995; Fyall, Oakley \& Weiss, 2000; Wang \& Fesenmaier, 2007). 
Organizations strategically seek to "incorporate the perspective of interorganizational domains" (Jamal \& Getz, 1995, p.189) when they face complex problems which are out of their capabilities to solve individually. Importantly, IOR is well explained by a variety of theoretical paradigms. Among these, resource dependency theory, transaction cost theory, strategic management theory and networking theory seem to be the most commonly used.

One of the most common theories used to explain relations between multiple organizations is resource dependency theory. According to this theory, partnerships are established between organizations when they perceive strategic interdependence with other organizations (Wang \& Xiang, 2007). The interdependence between organisations is again due to the fact that no individual actors have control over all resources (Fyall \& Garrod, 2005; Jamal $\&$ Getz, 1995). In the tourism context, many types of tourism resources are public goods like forests, beaches and thus no single organization has full access to these resources. However, it is also true that certain types of tourism resources are owned by only some organizations like location or qualified human resources (Fyall, Garrod \& Wang, 2012). Under these paradoxical circumstances, organizations tend to form alliances in order to acquire better accessibility to their desired resources. Wang and Xiang (2007) also note that higher interdependence between organizations leads to higher incentives to combine resources through cooperation. Resource dependency theory is useful for explaining whether organizations decide to compete or cooperate with others and why they do so but it is not good at addressing cooperation from a process-oriented perspective (Wang \& Xiang, 2007; Fyall, Oakley \& Weiss, 2000).

As the name implies, transaction cost theory focuses on minimizing the transactional costs for organizations through cooperative arrangements (Selin \& Beason, 1991; Wood \& Gray, 1991). Cooperation can help to reduce transactional costs by sharing the costs with other organizations or helping the organization achieve a better performance (Fyall, Garrod \& Wang, 2012). Beside its strength in explaining inter-organizational relationships well, 
transaction cost theory tends to focus too much on the cost minimization and ignore the joint benefit maximization (Zajac \& Olsen, 1993).

IOR is also commonly examined from the perspective of strategic management theory, which provides strategic explanations as to why organizations enter alliances. According to this theory, organizations may form partnerships with other organizations in order to achieve certain goals, "which may include: obtaining access to needed assets; learning new skills beyond firm boundaries; maintaining parity with competitors; exploring economies of scale and scope; and entering new markets" (Wang \& Xiang, 2007, p.76). This theory is similar to resource dependency theory with respect to the motivational aspects of resource scarcity and collective problems (Wong, Mistilis \& Dwyer, 2009). In addition, the theory emphasizes the means which help organizations minimise external threats and maximise external opportunities through cooperating with others (Fyall, Oakley \& Weiss, 2000).

Network theory is said to be more important in tourism than in other industries of many countries (Scott, Cooper \& Baggio, 2008). This is because a large number of small actors in the tourism industry with limited resources find it difficult to survive and prosper sustainably unless they work and support each other in certain forms of network. Noticeably, based on the network theory, "the destination as a strategic network could be defined as an interorganizational, goal-oriented network embedded in the destination, comprising value-creating activities that are linked to each other through tourism business relationships, and that require the resources of tourism companies or other organizations." (Meriläinen \& Lemmetyinen, 2011, p.26). Also using network theory, Scott, Cooper and Baggio (2008) analyzed the destination organizations as networks through three elements of actors, relationships and resources of four case destinations in Australia, namely the Gold Coast, Southern Downs, Legends, Wine and High Country, and Great Ocean Road. Each one has different structures and some are more effective than others. The Great Ocean Road is a more centralized network than the Legends, Wine and High Country 
one and that structure enhances formal coordination between stakeholders in the region.

As can be seen, the abovementioned theories have both strengths and weaknesses and thus should be combined in order to provide more holistic explanations of destination cooperation (Wang \& Xiang, 2007).

\subsubsection{Inter-organizational relationships in tourism}

Research shows relationships between tourism organizations exist at different levels and in different forms (Timothy, 1999; Grängsjö, 2003; Wang \& Krakover, 2007; Watkins \& Bell, 2002). Accordingly, these authors suggest a relationship continuum (Wang \& Krakover, 2007; Watkins \& Bell, 2002) or typology (Timothy, 1999) to describe the variations.

In their study examining the managers' experiences of business relationships between tourism organizations, Watkins and Bell (2002) suggest a continuum consisting of three categories of experiences, namely competition, cooperation and collaboration. Based on responses of interviewed tourism managers, meanings of three categories were clarified. Firstly, competition refers to the business relationships in which organizations gain market share at the expense of other organizations. Notably, some tourism managers who acknowledge competing and supporting each other can exist at the same time in loosely formalised arrangements. Secondly, tourism organizations that work together to "share information and engage in joint activities" are in the relationship of cooperation. This type of relationship can either be informal through exchanging information/ideas or more formal through commitments to attend certain projects. The third category of experiences is collaboration which is more formalized and is characterized by a longer commitment between participants in order to achieve benefits for the industry and the region (Watkins \& Bell, 2002).

Wang and Krakover (2007) also indicate that tourism organizations can adopt competition, cooperation or coopetition behaviour in destination marketing 
efforts. Competitive behaviour is used when tourism organizations only focus on maximizing their own interests. In contrast, cooperative behaviour is adopted when organizations share the interest of achieving common goals. Coopetition consists of both competitive and cooperative behaviours as a result of attempting to fulfill both conflict and common interests.

Figure 2.2: Relationship configuration among tourism industry

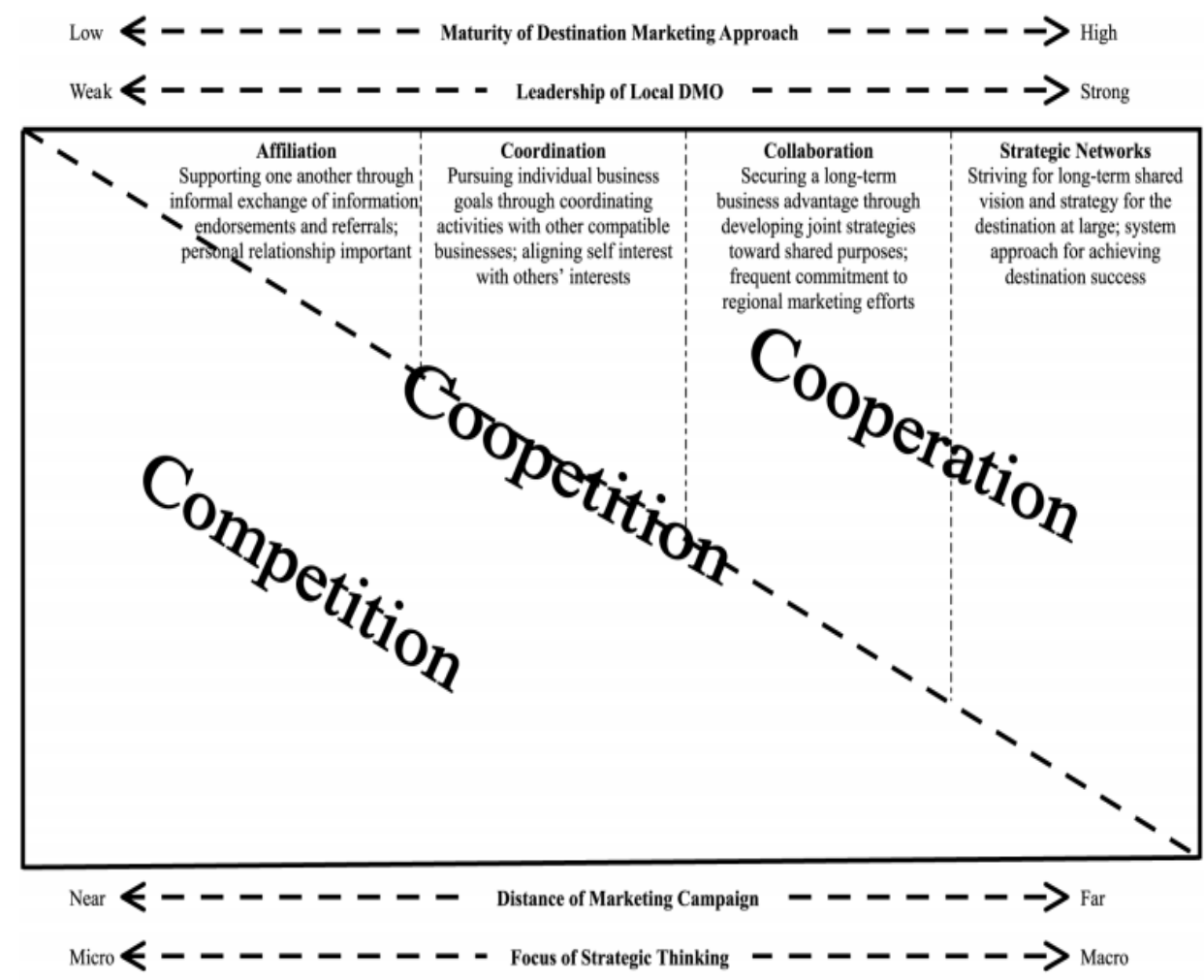

Source: Wang and Krakover (2007)

These two authors argue that cooperative relationships can be different from each other in terms of formalization, integration and structural complexity. From low to high degrees of these criteria, four forms of cooperative relationships include affiliation, coordination, collaboration and strategic networks.

As can be seen, the above studies propose a continuum to describe the business relationships between tourism organizations within a destination. Few studies in tourism literature have examined the relationship continuum between tourism 
organizations in different destinations. One exception is the study of Timothy (1999). Based on a typology (Figure 2.3), the study examines the partnership level of various areas (management frameworks, infrastructure development, human resources, conservation, promotion and border concessions) in three national parks along the US-Canada border.

Figure 2.3: Levels of cross-border partnerships in tourism

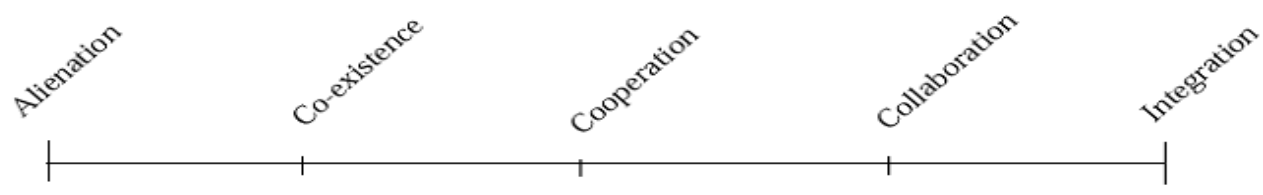

Source: Timothy, 1999

His typology consists of five partnership levels, starting from alienation which means that no partnerships exist between countries. Next, co-existence implies minimum partnerships in which two nations coexist but are not yet willing to work together. With cooperation, neighbouring countries start making efforts to solve common problems. If cooperative relations become stable with wellestablished joint efforts, nations enter the collaboration level. The final partnership level is integration which occurs when both sides are merged and under the same management. Interestingly, different areas of all three national parks have different partnership levels. In terms of promotional activities, two sides of three national parks cooperate with each other in producing joint tourism literatue like brochures, in suggesting tourists visit both sides and in sharing equal views towards the other.

Sharing some similarities with the three papers analyzed above, this study proposes a continuum that contains four different forms of inter-organizational relationships: competition, coopetition, cooperation and collaboration.

Figure 2.4: Continuum of inter-destination relationships

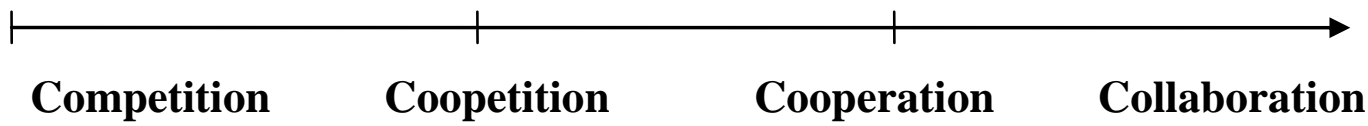


Based on previous studies, the four configurations are defined as follows:

- Competition is defined as gaining benefits at the competitors' expenses (Watkins \& Bell, 2002).

- Coopetition is the form of relationships when organizations compete and cooperate at the same time (Bengtsson \& Kock, 2000). These two authors argue that this form of relationship should be the most advantageous one because it allows involved organizations to fulfill self-interests through competition and to achieve common goals through cooperation. Indeed, Grängsjö (2003) agrees that it is difficult to separate cooperation and competition and one needs to be balanced against the other.

- Cooperation means "working together to some end" (Jamal \& Getz, 1995, p.187).

- Gray (1989, p.227) defines "collaboration as a process of joint decision making among key stakeholders of a problem domain about the future of that domain". Wood and Gray (1991) further explained that "collaboration occurs when a group of autonomous stakeholders of a problem domain engage in an interactive process, using shared rules, norms and structures, to act or decide on issues related to that domain."

\subsubsection{Tourism parnership developmental stages}

Inter-organizational domains progress through developmental stages (McCann, 1983; Gray, 1985). These authors suggest that multiple stakeholders engage to solve a shared problem domain through three processes, namely problemsetting, direction-setting and structuring. In the problem-setting phase, stakeholders acknowledge the problem domain existing among themselves and start initial steps to work together like appreciating the interdependence and negotiating legitimate issues. In the direction-setting phase, agreements among stakeholders on shared values and ends are achieved, which then in turn sets direction for action. The third stage, structuring, concerns two fundamental issues which are functional roles and responsibilities of stakeholders and the appropriate structural arrangement to regulate their partnerships. In spite of being a developmental model, it is important to note that the three stages discussed above belong to an open-ended system because the social contexts in which the problem domains emerge are complex and dynamic (McCann, 1983). Also, in the study of collaboration in tourism policy making, Parker (1999) 
finds that the move from one stage to the next can occur without the ending of the earlier stage.

Specifically in the collaborative destination marketing domain, Wang (2008) suggests a five-stage model (Figure 2.5) describing how local tourism industry's stakeholders collaborate in implementing marketing projects at the destination level.

Figure 2.5: Stages of collaboration and level of involvement in collaborative destination marketing

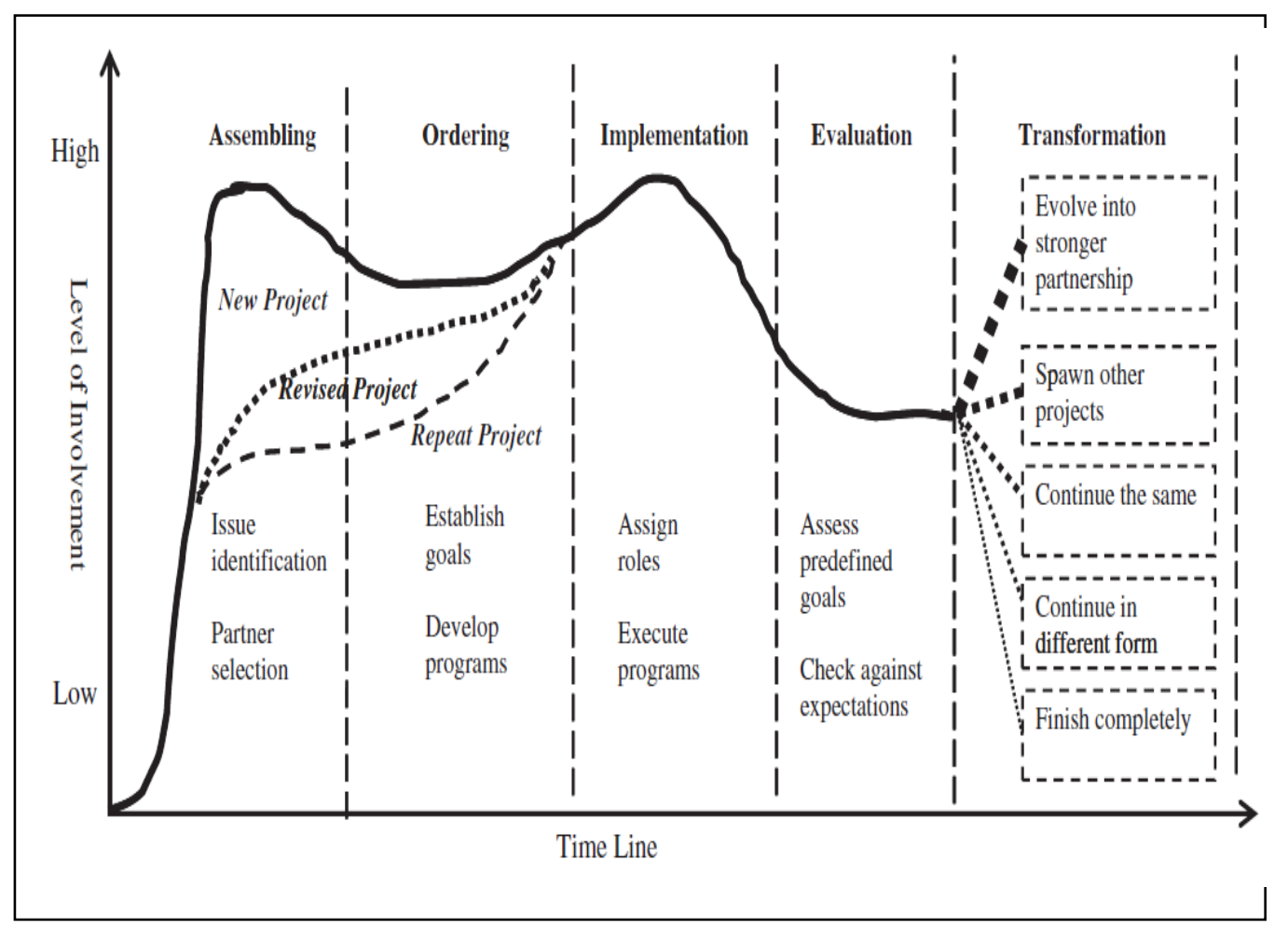

Source: Wang (2008)

\subsection{Joint destination marketing activities: Explanatory factors}

\subsubsection{Preconditions of joint destination marketing}

Cooperative relationships, including joint destination marketing, are formed by certain environmental factors which are also known as preconditions (Wang \& Fesenmaier, 2007). The convention and visitors bureaus (CVBs) in Elkhart County, Indiana enter marketing alliances with each other on the basis of four important conditions, namely crisis, competition, organization support and technology support. Gray (1985) also notes that the cooperation between 
organizations tends to increase when they have to face crises. Similarly, the increasing environmental turbulence encourages organizations to work collectively rather than individually (Jamal \& Getz, 1995).

Some characteristics of the tourism industry and destinations form the bases for strategic alliances between organizations. The tourism industry clearly consists of many enterprises which produce complementary products. A unified tourist product from the perspective of customers is constructed by many single products and services provided by individual producers (Grängsjö, 2003). The combination of fragmentation and interdependence call for cooperation in tourism regions (Augustyn \& Knowles, 2000). With a process-oriented approach, Jamal and Getz (1995) notice that there are different facilitating conditions for community-based tourism collaboration in different stages of the collaboration model. Conditions like "recognition of interdependence, shared access power, perceptions of legitimacy among stakeholders" are important in facilitating the first stage of problem-setting. Meanwhile, the second stage of direction-setting is facilitated by conditions such as "coincidence of values and dispersion of power". The final stage of implementation is under the effects of external mandates and contextual environment. One thing in common is that these conditions can come from both the micro- and macro-environment of organizations participating in the inter-organizational relationships.

\subsubsection{Motives and barriers}

Motives and barriers have attracted much research attention in the literature of tourism alliances and partnerships (Jamal \& Getz, 1995; Saxena, 2005; Wang \& Fesenmaier, 2007; Naipaul, Wang \& Okumus, 2009). It is clear that comparison between motives and barriers that organizations perceive from cooperative activities plays an important role in their decision of whether or not they form alliances with other organizations.

Studies that attempt to explain the motivation for partnership formation discuss three rationales: strategic, transaction costs related, and learning related. Strategic considerations involve using partnership to enhance a business' 
competitive advantage through market power or efficiency (Saxena, 2005); gain access to critical external resources (Fyall, Oakley \& Weiss, 2000); deal with rapid technical changes in an industry (Wang \& Xiang, 2007); enter markets rapidly (Fyall \& Garrod, 2005; Grängsjö, 2003); or to share risk or uncertainty with their partners (Prideaux \& Cooper, 2002). Naipaul, Wang and Okumus (2009) also concluded that targeting the same or similar target market is an important factor that facilitaties partnerships among destinations.

Transaction cost explanations view partnership formation as a means to reduce the production and transaction costs for the businesses concerned or to exploit economies of scale and scope (Palmer, 2002). Cost reduction and maximizing marketing budgets have proven to be the major motivational factors encouraging neighbouring destinations to work together. In particular, destinations with complementary tourism products have big advantages in broadening and diversifying the product portfolio in the regional destination because their resources can be exchanged and exploited effectively and efficiently. More stakeholders create more promotional impacts on potential markets than individual efforts because collective resources are pooled (Palmer \& Bejou, 1995).

Learning explanations view partnerships as a means to learn or absorb critical skills or capabilities from working partners (Saxena, 2005), and to access or internalize new technologies and know-how beyond firm boundaries (Wang \& Fesenmaier, 2007). These objectives are especially important for destination marketing where the knowledge, expertise, capital, and other resources of the various tourism organizations need to be brought together in order to offer products that are unique, inimitable, and difficult to substitute (Fyall \& Garrod, 2005).

Besides the strategy-related, transaction-cost related and learning-related motives, Wang and Feisenmaier (2007) identify two more categories of motivations for cooperation: cluster competitiveness and community responsibility. Cooperation also helps to increase the competitiveness of the 
whole region because tourists can have holistic experiences which are provided by complementary products of a range of tourism organizations and enterprises. Also, community responsibility is expressed through cooperative activities, especially for the benefits of the local people.

Tourism organizations are not just motivated to cooperate but also may be hindered in their attempts to do so by a number of barriers. Fyall and Garrod (2005) identify several barriers to destination collaboration such as mistrust and suspicion among collaborating partners; inability of stakeholders to work together due to excuses of a political, economic and administrative nature; and cases where particular stakeholders fail to recognise the real value of collaboration. Moreover, partners of the cooperative relationships may not always agree on the directions of marketing efforts (Naipaul, Wang \& Okumus, 2009). Naipaul, Wang and Okumus (2009) observe the inhibiting factors both within destination marketing organizations (the convention and visitor bereaus CVBs in the USA) and from other stakeholders. Within CVBs, disagreement among directors or limited human and financial resources are challenges to regional collaborative efforts. Industry stakeholders like hotels and attractions may also hesitate to collaborate as the result of not recognizing the real values of collaboration.

Futhermore, Palmer and Bejou (1995) note that the benefits of tourism destination marketing partnership are not universal. Some recognize potential benefits which are perceived to be worthy of entering partnerships, others may perceive too few benefits. Another possibility is that stakeholders in "hot" destinations may see no need to cooperate with other actors. A "honey pot" attraction, for example, Edinburgh Castle may think colloborating with other attractions is not important because most of its visitors have satisfactory experiences within the place (Palmer \& Bejou, 1995).

Selin and Chavez (1995) concluded that tourism partnerships are built on dynamic but fragile collective efforts. Its fragility is the result of competition, bureaucratism as well as geographic and organizational fragmentation. 
Hierarchical decision-making is another constraint to collective action (Selin \& Chavez, 1995).

\subsubsection{Decision-making factors}

As reviewed above, marketing relationships between different stakeholders exist in various forms such as competition, coopetition, cooperation or collaboration. This also implies that there are factors influencing tourism organizations to choose one configuration or a certain level of combined configurations over the other.

After identifying three configurations of marketing relationships among tourism businesses (competition, coopetition and cooperation), Wang and Krakover (2007) discussed factors affecting choices of the tourism businesses in their study. They concluded the configurations and even the levels of those configurations are affected by four factors, namely strategic thinking, maturity of destination marketing approach, distance of marketing campaign and leadership of local DMOs. In terms of strategic thinking, the two authors compare the micro versus the macro organizational perspectives taken by tourism businesses. Organizations with micro thinking run business with the main objective to generate profits for themselves and therefore they see competition as a common strategy to reach their goals. In contrast, businesses with macro strategic thinking tend to cooperate for common benefits and interests. Another factor affecting the level of cooperative relationships is the distance of the marketing campaign. In the study of Wang and Krakover, tourism businesses tended to cooperate more with each other when they attended marketing campaigns organized in other places and in order to compete with other destinations. Thirdly, tourism businesses show more cooperative behaviour when the destination marketing approach becomes more mature as a result of the learning process. Finally, two towns in the study showed different levels of cooperative activities among the local industry and this was attributed to the leadership of local DMO.

Taking another perspective, Hill and Shaw (1995) examined the possibility of forming strategic alliances between two countries at the industry level when 
they both aim to target a particular third country. Their study showed that the tourism industry of two destination countries prefer to become cooperative partners if they share the following features: a close proximity to each other compared with their proximity to the origin markets; en route air service connections; compatible tourist attractions; similar standards in tourism products; and many multinational tourism enterprises. Their findings support cooperation between New Zealand and Australia in targeting any origin markets given these two countries satisfy all of the above criteria.

For tourism organizations in general, domain consensus and geographic proximity have been tested to be positively related to the degree of cooperative relations (Selin \& Beason, 1991). To destination marketing organizations, very few studies have been found to directly answer the question of what factors explain the variations in marketing relationship decisions of DMOs. One exception is the study of Naipaul, Wang and Okumus (2009). These authors found several important factors to DMOs partnerships, namely common operating philosophy; homogeneous target markets; complementary tourism products; geographic structure and the broadening of destination domain; good personal relationships and constant communication; fair share of benefits and responsibilities. However, being categorized as facilitating factors in general, it is unclear whether or not they are also the decisive factors affecting DMOs' decision to enter the partnership. Therefore, futher investigation on destination marketing relationship decision-making factors of DMOs is needed.

Drawing from the previous studies discussed above, a conceptual framework (Figure 2.6) is proposed to bring key themes within the literature together and to shape the research design of the present study. To examine the destination marketing activities that currently occur in destinations, it is crucial to understand the contexts in which destination marketing activities take place (Bennett, 1999). Considering interaction between neighbouring destinations belonging to a region, destination marketing can be implemented individually, jointly or simultaneously. In other words, individual destinations as well as the region might practise individual destination marketing activities or joint destination marketing activities or a mix of both. On one hand, previous studies 
indicate the decisions of entering a tourism partnership or not are influenced by various factors such as preconditions, benefits, drawbacks, motives and barriers of working together (Gray, 1985; Jamal \& Getz, 1995; Saxena, 2005; Wang \& Fesenmaier, 2007; Fyall, Oakley \& Weiss, 2000; Palmer \& Bejou, 1995). On the other hand, the mix of activities may enable one to place at certain positions along the continuum, which represents various forms of destination marketing interrelationships between tourism organizations. These interrelationship forms include competition, coopetition, cooperation and collaboration, which are defined by degree of formalization, integration and structural complexity (Wang \& Krakover, 2007; Timothy, 1999).

Figure 2.6: Conceptual framework of joint destination marketing

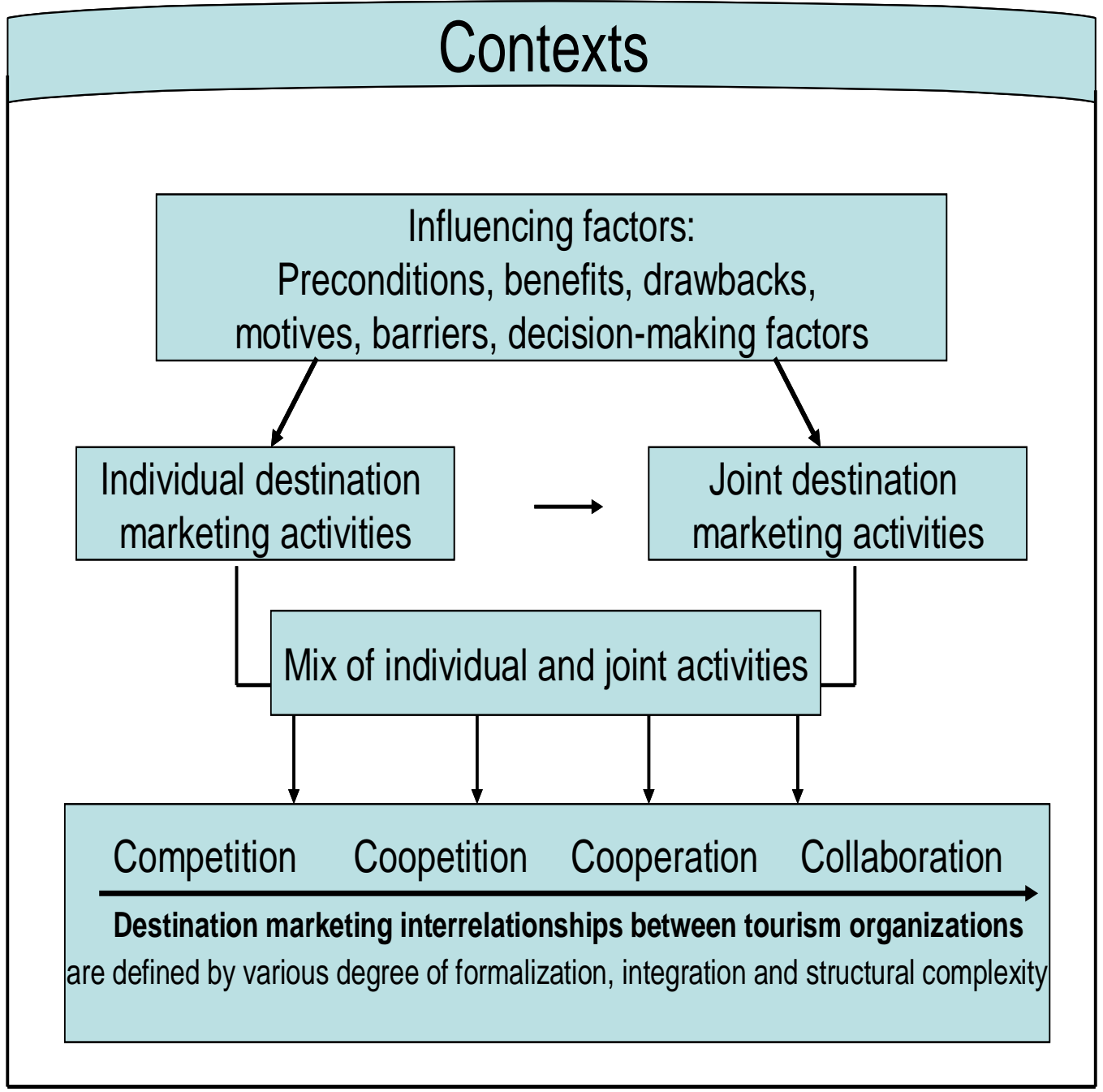


Different destinations in the region conduct a mix of individual and joint destination marketing activities and therefore are perceived at different positions along the continuum. Also, the shift from competition to cooperation to collaboration represent progressively joint ways of conducting activities. In this framework, two key themes from the existing literature - influencing factors and interrelationships between tourism organizations - are brought together and correlated through a mix of individual and joint destination marketing. The framework also guides the researcher to find answers for research questions by systematically examining three aspects of destination marketing: (1) the current destination marketing activities; (2) factors that influence decisions of destination marketing activities and (3) the interrelationships in destination marketing between tourism organizations (DMOs in this case).

\subsection{Conclusion}

By reviewing a number of previous studies that are relevant to the topic of joint destination marketing, this chapter set up the theoretical background for the study. Furthermore, the process also helped to identify several research gaps that deserve more academic attention. First, there is clearly a lack of research on the activity aspect of destination marketing, especially from the perspective of destination marketing organizations. This is a surprise because DMOs are mainly responsible for destination marketing activities (Pearce, 1992; Pike, 2008). Second, research has called for tourism stakeholders to shift from a conventional (individualistic) destination marketing approach to a more modern (cooperative) marketing approach (Teye, 1985; Buhalis, 2000; Fyall \& Leask, 2006; Bennett, 1999). However, whether destinations actually make this shift or not and why they do or do not are issues that remain unclear. Third, although factors like preconditions, motives, barriers of tourism partnerships have been reasonably well-documented (Wang \& Fesenmaier, 2007; Selin \& Beason, 1991; Naipaul, Wang \& Okumus, 2009), the factors that have a decisive role in the partnership decision-making process have not yet been examined. 
This study aims to fulfil the mentioned research gaps by examining destination marketing activities between the eight South Central Coast provinces of Viet Nam, the destination marketing interrelationships among them and factors that explain their decisions. This chapter also provided the conceptual framework based on which the research methodology is proposed and discussed in Chapter Three. 


\section{Chapter 3: METHODOLOGY}

\subsection{Introduction}

The review of relevant studies in the previous chapter provided guidance for the appropriate research design and methodology of the study, which are discussed in-depth in this chapter. The chosen research method is first presented and explained, followed by a discussion of selecting particular study sites and organizations. The chapter then describes the data collection methods used in the study, including in-depth semi-structured interviews and documentation and the analysis of the data collected. The generated data are then evaluated in terms of strengths and limitations of research methodology before findings are drawn and presented in the following chapters.

The research design of this study is presented in Figure 3.1. Starting with research gaps identified in Chapter One and the existing literature reviewed in Chapter Two, three objectives of the study were formulated. Three primary research questions were then designed to find the answers to the research problem and thus achieve the objectives. In this study, three primary questions are concerned with gaining a thorough understanding of destination marketing activities that are conducted jointly by the eight provinces in the South Central Coast region; of the factors that influence the joint destination marketing decisions; and of the destination marketing interrelationships between provinces perceived by local DMOs.

In order to answer those questions, an identified set of information was searched for. In particular, data needs included data that contains information about tourism development and the destination marketing context of each province; destination marketing activities that the eight provinces have conducted both individually and jointly; their inter-destination marketing relationship with other provinces; and factors that influence the joint destination marketing decisions. 
Figure 3.1: The research design

\begin{tabular}{|c|}
\hline $\begin{array}{l}\qquad \text { Research Gaps } \\
\qquad \text { - Lack of research in destination marketing in developing countries } \\
\text { - Marketing relationships within a single destination have received much more research } \\
\text { attention than marketing relationships between multiple destinations. }\end{array}$ \\
\hline $\begin{array}{l}\qquad \text { Research Objectives } \\
\text { - To examine the nature and extent of current destination marketing activities that occur } \\
\text { jointly between the eight South Central Coastal provinces of Viet Nam } \\
\text { - To analyze the factors that influence joint destination marketing in the South Central } \\
\text { Coast region. }\end{array}$ \\
\hline $\begin{array}{l}\text { Primary Research Questions } \\
\text { - What is the nature and extent of joint destination marketing activities in the South } \\
\text { Central Coast region of Viet Nam? } \\
\text { - What are the factors that contribute to and constrain the practice of joint destination } \\
\text { marketing in the context of the South Central Coast region? }\end{array}$ \\
\hline $\begin{array}{l}\text { Needed Data } \\
\text { - Data on tourism development and destination marketing context: tourist statistics, tourism } \\
\text { infrastructure statistics, marketing strategy, marketing plans, tourism marketing events (tourism } \\
\text { fairs, road shows, exhibitions, cultural tourism events) } \\
\text { - Data on individual and joint destination marketing activities: what activities, who are } \\
\text { organizers, which organizations are involved in, the individual versus joint destination marketing } \\
\text { experiences, the provinces' contribution to joint activities } \\
\text { - Data on, inter-destination marketing relationship with other provinces: form of inter- } \\
\text { relationships with other provinces, level of engagement, competitor-partner relationships, proposed } \\
\text { structures to facilitate joint destination marketing } \\
\text { - Data on factors that influence the joint destination marketing decisions: benefits vs } \\
\text { drawbacks of individual and joint destination marketing activities, favorable conditions, motives, } \\
\text { barriers for South Central Coastal provinces to conduct destination marketing jointly }\end{array}$ \\
\hline $\begin{array}{l}\qquad \text { Research Methodology } \\
\text { Comparative appoach adopted for the South Central Coast Region which consists of eight } \\
\text { neighbouring provinces }\end{array}$ \\
\hline $\begin{array}{l}\text { Data Collection } \\
\text { - Primary data: in-depth semi-structured interviews } \\
\text { - Documentation (secondary data, tourism websites \& marketing materials) }\end{array}$ \\
\hline $\begin{array}{l}\text { Data Analysis } \\
\text { - Interview data analysis: Coding interview transcripts. Group codes by themes } \\
\text { - Content analysis of provincial DMO's websites and marketing materials }\end{array}$ \\
\hline
\end{tabular}


Regarding the specific research method, this study chose the comparative approach given the following reasons. First, the notion of joint destination marketing activities allowed the researcher to examine the interactions between destinations and to compare dimensions of their destination marketing to understand the nature of joint destination marketing activities and the extent to which those activities are conducted jointly. Second, being different provinces in the same region, South Central Coast provinces clearly share similarities but also have their differences. Of a wide range of research methods, the comparative approach is suggested to be useful for exploring similarities and differences (Warwick \& Osheron, 1973, as cited in Pearce, 1993, p.21) as well as for focusing on the diversity (Ragin, 1994) of research phenomena. Furthermore, the comparative approach enables researchers "to go beyond description (what? when? how?) towards the more fundamental goal of explanation (why?)" (Hague \& Harrop, 1982). In other words, the comparative approach is a suitable tool to meet the research objectives which aims to understand not only whether or not there are joint destination marketing activities among eight provinces of the region but also why those activities happen or not. The comparative approach guides not only the formulation of research questions but also the selection of the study site, the collection and analysis of the data as well as the presentation of the findings. These areas, except for the findings, are futher discussed in the following sections.

\subsection{Selection of study sites and organizations}

As explained in Chapter One, the study aims to contribute to the limited literature of destination marketing in developing countries and to contribute to describe and explain joint destination marketing between multiple provinces in a regional context. In order to make this intended contribution, a suitable study site is needed. The South Central Coast region of Viet Nam was chosen for two good supporting reasons. Firstly, as outlined in Chapter One, Viet Nam is widely known as one of the fastest-growing economies in the world and the South Central Coast region is the most dynamic region in Viet Nam in terms of tourism development activities. Secondly, eight South Central Coast provinces belong to the same region but have autonomous destination management and 
marketing organizations. This enables destination marketing in these provinces to be examined both individually and jointly.

The South Central Coast region consists of eight localities, of which there is one centrally governed city, Da Nang, and seven provinces (Quang Nam, Quang Ngai, Binh Dinh, Phu Yen, Khanh Hoa, Ninh Thuan and Binh Thuan) (Figure 1.1). Like all provinces in Viet Nam, each South Central Coast province has a Department of Culture, Sport and Tourism (DCST) which is a specialized agency helping the provincial People's Committee to implement their statemanagement tasks in the field of culture, family, sports and tourism (Ministry of Home Affairs, 2005). Therefore, the DCST of each province is the main organization responsible for state management activities of tourism, including destination marketing activities. Most provinces in Vietnam also have a Tourism Information and Promotion Center (TIPC) which is under the management of the DCST and specializes in providing tourism information and organizing tourism promotion activities for the locality. So in the Viet Nam context, DCSTs/TIPCs play the role of destination marketing organizations (DMOs) at the provincial level.

At the national level, the Viet Nam National Administration of Tourism (VNAT) which is under the management of Ministry of Culture, Sport and Tourism (MCST) is mainly responsible for marketing the country as a destination. Currently, there is no regional tourism organization which lies beween VNAT and DCSTs. In 2011, a regional organization was established called the Central Region Research and Development Fund (CRDF), which coordinated to organize several tourism events. However, this organization does not specialize in tourism. Instead, its role is to raise and manage funds to provide financial support for socio-economic development activities of the Central region of Viet Nam.

Figure 3.2 shows the structure of destination marketing organizations of Viet Nam's tourism industry. 
Figure 3.2: Structure of destination marketing organizations in Viet Nam tourism

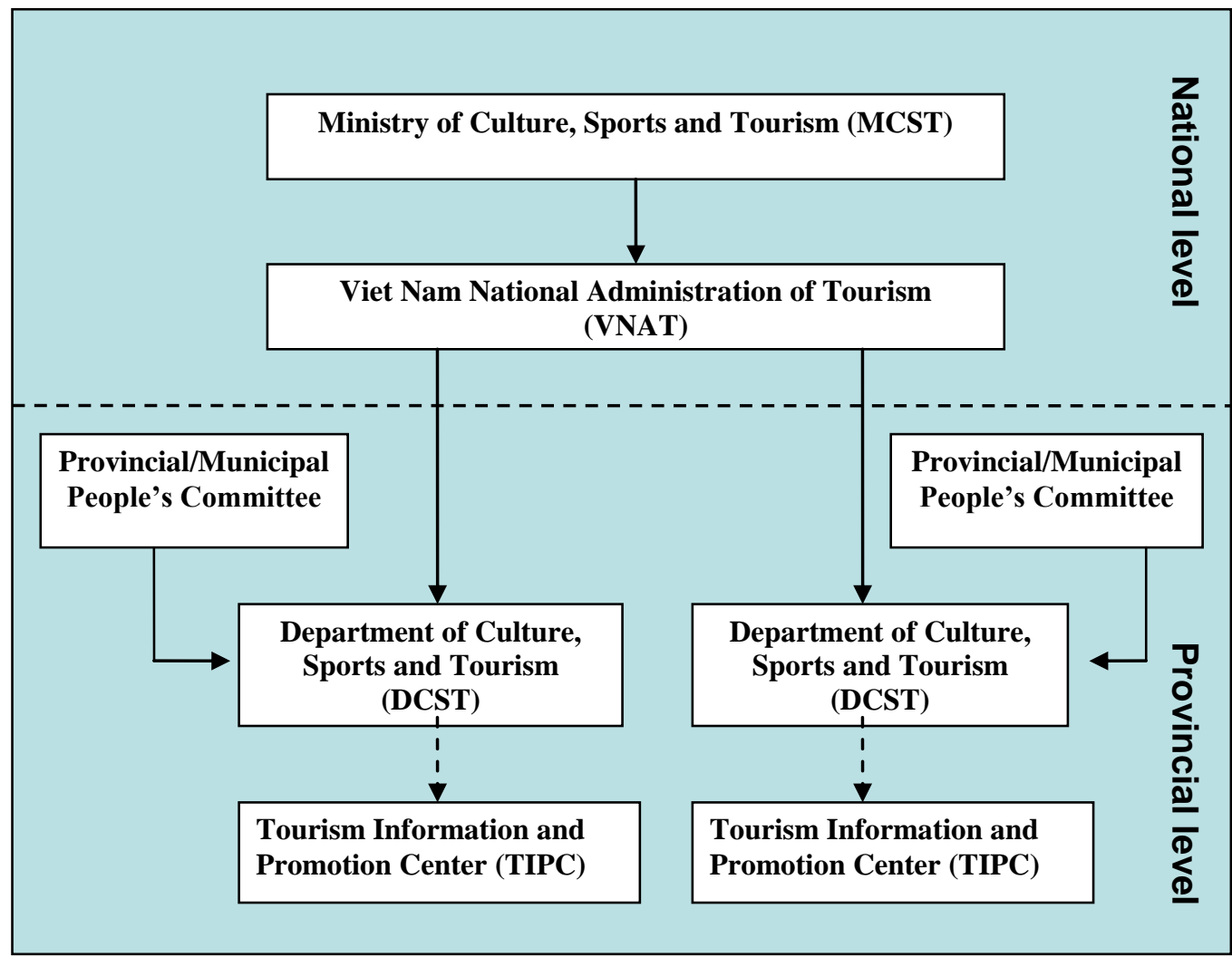

Note: Some provinces may not have a TIPC $\left(\begin{array}{l}1 \\ 1 \\ \nabla\end{array}\right)$

This thesis examines destination marketing mainly from the perspective of provincial destinations, so the DCSTs and TIPCs are chosen as suitable study organizations. The study also examines how destination marketing is done in the whole region, so holistic perspectives are required. Because Viet Nam does not have regional tourism organizations, such a holistic perspective is sought from the national tourism organizations like VNAT and the Vietnam Institute for Tourism Development Research (ITDR).

\subsection{Data collection methods and procedures}

In comparative case-study research, multiple sources of evidence are recommended. The most important advantages of multiple sources of evidences are data triangulation and corroboration, which make the study findings more convincing and accurate (Yin, 2009). This means the researcher can corroborate the findings with information collected from multiple sources. Yin (2009) also suggests six different sources of evidence, including documentation, archival 
records, interviews, direct observations, participant observation and physical artifacts. This study used two sources in searching for primary data: interviews and documentation. In-depth interviews provided insights into experts' perspectives of joint destination marketing activities that occur among provinces of the region. Tourism websites of eight provinces and selective marketing materials were also accessed and analyzed for evidences of cooperative marketing activities between the provinces. Some secondary data were also sourced from collected documentation and presented in the study when appropriate.

\subsubsection{The in-depth interview}

Guest, Namey and Mitchell (2013) believe in-depth interviews help researchers to go beyond the basic facts and gain insights into "processes, norms, decision making, belief systems, mental models, interpretations, motivations, expectations, hopes, and fears" (p.116). In fact, the in-depth interview is one of the most common research methods used in social research (Travers, 2010). The literature on destination marketing relationships also shows that the indepth interview is a commonly-used data collection method (Naipaul, Wang \& Okumus, 2009; Prideaux \& Cooper, 2002; Timothy, 1999; Wang \& Fesenmaier, 2007). Noticeably, in their study which explores how small neighbouring destinations can collaborate, Naipaul, Wang and Okumus (2009) use focus group interview together with the in-depth semi-structured interviews with senior executives of convention and visitors bureaus of three counties in Northeast Ohio, USA. With a similar subject (destination marketing occuring jointly between neighbouring destinations), this study also chose in-depth semistructured interviews as the main method for collecting primary data.

The semi-structured in-depth interview provided a good fit for gaining a comparable set of qualitative data needed in this comparative research. Following a set of common questions in each interview, this type of interview helps one to obtain similar data like, in this case, tourism development status, typical tourism products, motives and barriers to joint destination marketing 
activities. Semi-structured interviews also create spaces where participants can discuss the topic in their own ways and present their own views.

The potential interviewees are representatives of destination management organizations and destination marketing organizations at the provincial and national levels. Therefore, the semi-structured in-depth interviews questions were designed to fit two mains groups of interviewees: (1) the representatives of DCSTs/TIPCs and (2) the representatives of national tourism organization(s). In the final in-depth interview protocols, there were 26 questions for representatives of DCSTs/TIPCs (Appendix 1) and 19 questions for representatives of national tourism organiztions (Appendix 2).

The question list for the representatives of DCSTs/TIPCs consisted of three parts. The first five questions explored the tourism development and destination marketing context in each province. The second part (from question 6 to question 19) went in depth into the joint destination marketing activities through a variety of dimensions, including comparison between individual and joint marketing; current marketing activities each South Central Coast province conducts jointly with other provinces; preconditions, motives, barriers of joint destination marketing. The third part of the interview (from question 20 to question 26) explored the destination marketing relationships between DMOs of the eight provinces in the region. Questions for representatives of national tourism organizations were designed similarly except for the first part in which the destination marketing activities of the whole region are examined.

All in-depth interviews were to be done in Vietnamese - the first language of potential interviewees. Therefore, after designing the interview questions in English, the researcher translated the questions into Vietnamese. To minimize the translated-related problems, the researcher asked one Vietnamese Masters colleague to translate the questions again from Vietnamese into English for cross-checking. The two English versions of the interview questions were then compared and proved to be reasonably consistent. 
The human ethics application for the research was approved by the Human Ethics Committee of Victoria Management School on $2^{\text {nd }}$ May 2013.

A cover letter, introductory letter from the researcher's supervisor and an information sheet were sent directly to eighteen potential interviewees before the field work started. After two weeks, interviewees were then approached again, firstly through emails. However, very few people responded to emails, so phone-calls were made and proved to be more effective in setting up interview appointments. Another issue that occurred during the data collection procedure was related to arranging interview appointments. The face-to-face interviews with representatives of DCSTs/TIPCs of eight provinces required the researcher to make follow-up calls to set up interview appointments about two weeks in advance. Interviewees agreed for meetings on phones, however, their working schedule is often fixed on a weekly basis. Consequently, two representatives could not participate in the interviews as planned and had to assign their staff to attend the interviews.

After about two weeks spent for arrangements, representatives of six DCSTs and seven TIPCs agreed to participate in the interviews. One additional interview was done with the representative of Hue's TIPC, which was motivated by the fact that Hue belongs to the North Central Coast region but its cooperation with Da Nang and Quang Nam is the first cooperative model established in the Central region and appears to be the most successful one mentioned by interviewees. Data gained from this interview is only used for analyzing the three-province cooperation, not for the joint destination marketing of the South Central Coast region. From the national perspective, the representative of the Institute for Tourism Development Research (ITDR) was approached successfully (ITDR is one professional body of VNAT, being responsible for researching and developing tourism strategies, plans, managerial policies and mechanisms to support the implementation of state-management tasks on tourism). In total, fifteen interviews were conducted, fourteen interviews reflect the provincial perspectives (from DCSTs/TIPCs representatives) and one reflects the national as well as regional perspective 
(from ITDR representative). In two interviews, consent was only given for notes to be taken; the other interviews were recorded.

At the time of each interview, the researcher described the main points of the study to interviewees. The information sheet and the consent form were then explained and provided. Any concern of participants about the purpose of the interview and the data confidentiality was answered before the interview started with participants' agreement.

\subsubsection{Documentation}

This study uses a range of documents which were mainly accessed from three sources: the internet, actual fields visit and a tourism fair and conference. Based on the data needs, prior to the field visits, thorough internet searches were conducted and provided useful contextual information. For example, most of the tourism statistics of Viet Nam (tourist arrivals since 1990, tourism receipts, top-ten international tourist markets) are available on the official website of the the Viet Nam National Administration of Tourism. The Viet Nam Tourism Development Strategy to 2020, with a vision toward 2030, is also available on the website of the Institute for Tourism Development Research. Some socioeconomic and tourism statistics of South Central Coast provinces were also accessed directly from websites of DCSTs/TIPCs. The internet search also helped to find the official web portal of the Central Coast region (www.vietccr.vn) run by the Central Region Research and Development Fund, providing updated information associated with the cooperation initiative from Hue to Binh Thuan. In general, statistical information accessed from official websites of national and provincial tourism management and marketing organizations are reliable and useful in providing the understanding of the national and regional development contexts in which joint destination marketing activities occur.

Official tourism websites of South Central Coastal provinces are also an important source of information. Tourism websites run by the DCSTs/TIPCs and selective marketing materials were used as another source of evidence for 
joint destination marketing activities between provinces. In some provinces, like Khanh Hoa and Phu Yen, DCSTs and TIPCs have developed and used one tourism website. In other provinces where DCSTs and TIPCs have different websites, the websites of TIPCs are used for website evaluation because they focus more on marketing destinations rather than on informing statemanagement tasks. So seven websites were evaluated (Table 3.3) because Quang Ngai does not yet have its own tourism websites run by its DCST (Quang Ngai is also the only province in the region that does not have a TIPC).

During field visits to nine provinces, the researcher collected marketing materials of each province as well as other regional materials that are available in some provinces. Most of the collected marketing materials are guidebooks, brochures, leaflets, tourist maps and tourism event calendars. The researcher also attended the conference "Development of tourism products of Central Coastal Region of Vietnam" organized on $9^{\text {th }}$ June within the Nha Trang International Tourism Sea Tourism Fair 2013. The tourism fair and conference was a good chance to observe how joint marketing activity is organized and to collect marketing materials displayed in the tourism fair and proceedings of the conference. The documents collected include:

- The Viet Nam Tourism Development Strategy until 2020, vision to 2030 (VNAT, 2012)

- Conference proceedings of "Investment Promotion for the Central Coastal Region of Viet Nam" (Central Region Development Fund \& Da Nang People's Committee, 2013)

- Conference proceedings of "Development of tourism products of Central Coastal Region of Viet Nam" (Central Region Development Fund \& Khanh Hoa People's Committee, 2013)

- Tourism development plan of Da Nang (Da Nang People's Committee, n.d.)

- Tourism product development plan of Quang Nam (Quang Nam People's Committee, 2013) 
- Tourism development master plan of Khanh Hoa to 2010, vision 2020 (Khanh Hoa Department of Culture, Sports and Tourism, 2009)

- The first joint destination marketing material of nine provinces "A journey through the Central Coastal Region" (Central Region Development Fund, 2013)

- Joint brochure of tourism events of Hue, Da Nang and Quang Nam (prepared by TIPCs of Hue, Da Nang and Quang Nam)

- The cooperation agreement on socio-economic development between six provinces of Lam Dong, Khanh Hoa, Ninh Thuan, Binh Thuan, Dak Lak and Phu Yen (Provincial People's Committees, 2013)

- Individual marketing materials of nine provinces: tourist guidebooks, brochures, leaflets, tourist maps, CDs. (provided by DCSTs/TIPCs of provinces)

- Tourism-related information posted on the page of the Viet Nam Central Coastal Region (www.vietccr.vn)

- Online articles discussing about issues related to the tourism cooperation of central coastal provinces

At the end of the data collection stage, the researcher had a variety of qualitative data to be used for the next step of data analysis. The collected raw data (interviews, documentation) require certain preparation and processing, which is discussed in detail in the data analysis section that follows.

\subsection{Data analysis}

\subsubsection{In-depth interview data analysis}

Qualitative data contain rich descriptions and explanations of processes but are often not immediately ready for analysis (Miles \& Huberman, 1994). Instead, they need to be processed through a data analysis process which consists of sequential analytic tasks of data preparation, code development and data coding, description, comparison, categorization, conceptualization and theory development (Hennink, Hutter \& Bailey, 2011). These authors emphasize that these analytic tasks allow researchers to immerse themselves in data and therefore enables them to develop interpretations and to draw findings that are 
"evidence-based and well-rooted in the data" (p.205). Following suggested practices, the process of analyzing in-depth interview data in this study is presented and explained as follows.

The data preparation of this study included two specific tasks of transcribing and translating the data. In particular, 15 interviews were transcribed word by word before being translated from Vietnamese into English. After having the full text of transcripts, the researcher coded the whole set of data through basic steps suggested by Rubin and Rubin (1995):

(1) Prepare a list of potential codes based on the research objectives, interview questions and interview transcripts.

(2) Read the interview transcripts while at the same time underlining words, phrases or paragraphs and noting with appropriate codes in the margin.

(3) Add new codes if any part of the transcripts does not fit the listed codes. In that case, the data might need to be recoded. This process helps to guarantee that continously-updated coding categories provide a good fit to the data.

During data coding, issues in the data were identified and compared so that complex data were simplified and differentiated from each other. Twenty five codes emerged from the interview transcripts and the codes sharing certain charasteristics were grouped together in the four broad coding categories: (1) Regional destination marketing context, (2) Provincial tourism development and destination marketing context, (3) Joint destination marketing activities and (4) Inter-destination marketing relationships. In other words, individual codes were linked at a more abstract level, which led to a broader conceptual understanding of destination marketing issues. One example is illustrated in Table 3.1. 
Table 3.1: Analytical framework of provincial and regional destination marketing

\begin{tabular}{|c|c|c|c|c|c|c|}
\hline \multirow[b]{2}{*}{ Provinces } & \multicolumn{6}{|c|}{ Provincial and Regional Destination Marketing Contexts } \\
\hline & $\begin{array}{l}\text { Tourism } \\
\text { development } \\
\text { status }\end{array}$ & \begin{tabular}{|l} 
Strengths for \\
tourism \\
development
\end{tabular} & $\begin{array}{l}\text { Weaknesses } \\
\text { for tourism } \\
\text { Development }\end{array}$ & \begin{tabular}{|l|} 
Typical \\
tourism \\
products
\end{tabular} & $\begin{array}{l}\text { Marketing } \\
\text { orientations }\end{array}$ & $\begin{array}{l}\text { Target } \\
\text { markets }\end{array}$ \\
\hline Da Nang & & & & & & \\
\hline Quang Nam & & & & & & \\
\hline Quang Nga & & & & & & \\
\hline Binh Dinh & & & & & & \\
\hline Phu Yen & & & & & & \\
\hline Khanh Hoa & & & & & & \\
\hline Ninh Thuan & & & & & & \\
\hline Binh Thuan & & & & & & \\
\hline $\begin{array}{l}\text { The SCC } \\
\text { Region }\end{array}$ & & & & & & \\
\hline
\end{tabular}

As can be seen, the destination marketing context of each province and of the whole region were conceptualized through different but interconnected codes, namely tourism development status, strengths and weaknesses for tourism development, marketing objectives, typical tourism products and target markets. These six dimensions reflect the tourism development and marketing context of each province horizontally. At the same time, certain dimensions can be compared across eight provinces and with the whole region vertically.

Similarly, the category of joint destination marketing activities was constructed from individual codes which not only describe what destination marketing activities were done jointly between provinces but also explains why those joint destination marketing activities occurred or did not occur through analysis of favourable conditions, benefits, drawbacks, motives and barriers (Table 3.2). 
Table 3.2: Analytical framework of joint destination marketing activities

\begin{tabular}{|c|c|c|c|c|c|c|}
\hline \multirow[b]{2}{*}{ Provinces } & \multicolumn{6}{|c|}{$\begin{array}{l}\text { Joint Destination Marketing Activities occur } \\
\text { in South Central Coast provinces and in the whole region }\end{array}$} \\
\hline & $\begin{array}{l}\text { Joint } \\
\text { Destination } \\
\text { Marketing } \\
\text { Activities }\end{array}$ & Preconditions & Benefits & Drawbacks & Motives & Barriers \\
\hline Da Nang & & & & & & \\
\hline Quang Nam & & & & & & \\
\hline Quang Ngai & & & & & & \\
\hline Binh Dinh & & & & & & \\
\hline Phu Yen & & & & & & \\
\hline Khanh Hoa & & & & & & \\
\hline Ninh Thuan & & & & & & \\
\hline Binh Thuan & & & & & & \\
\hline $\begin{array}{l}\text { The SCC } \\
\text { Region }\end{array}$ & & & & & & \\
\hline
\end{tabular}

Also, with this analytical framework, the researcher was able to draw a multifaceted picture of joint destination marketing for the individual provinces and for the region as well as to make comparisons among the eight provinces to thoroughly understand the research problem from different provincial perspectives.

\subsubsection{Content analysis of tourism websites and marketing materials}

This study used content analysis on official websites of TIPCs and on other marketing materials to search for evidences of any joint marketing effort between South Central Coast provinces. Considering that TIPCs websites contain lots of information, a list of criteria were developed in order to meet the analysis purpose identified above. Then the TIPC website of each province was checked vertically in terms of the existence or absence of the seven criteria (Table 3.3). The framework also allows certain criteria across the seven websites to be compared horizontally. 
Table 3.3: Content analysis framework of TIPCs' wesbites

\begin{tabular}{|c|c|c|c|c|c|c|c|}
\hline \multirow[b]{2}{*}{ Criteria } & \multicolumn{7}{|c|}{ Official tourism websites used for content analysis } \\
\hline & DNTIPC & QNTIPC & BDTIPC & PYTIPC & KHTIPC & NTTIPC & BTTIPC \\
\hline \multicolumn{8}{|l|}{$\begin{array}{l}\text { (1) Having links to tourism } \\
\text { websites of other provinces in } \\
\text { the region }\end{array}$} \\
\hline \multicolumn{8}{|l|}{$\begin{array}{l}\text { (2) Having links to national } \\
\text { tourism websites }\end{array}$} \\
\hline \multicolumn{8}{|l|}{$\begin{array}{l}\text { (3) Updating tourism events of } \\
\text { the whole region or of other } \\
\text { provinces in the region }\end{array}$} \\
\hline \multicolumn{8}{|l|}{$\begin{array}{l}\text { (4) Updating news of joint } \\
\text { tourism activities between } \\
\text { provinces in the region }\end{array}$} \\
\hline \multicolumn{8}{|l|}{$\begin{array}{l}\text { (5) Introducing tourism products } \\
\text { of other provinces in the region }\end{array}$} \\
\hline \multicolumn{8}{|l|}{$\begin{array}{l}\text { (6) Providing travel information } \\
\text { of the whole region or other } \\
\text { provinces in the region } \\
\text { (brochures/ } \\
\text { travel tips/ images/maps/ } \\
\text { suggestions) }\end{array}$} \\
\hline \multicolumn{8}{|l|}{$\begin{array}{l}\text { (7) Publicizing tourism-related } \\
\text { opportunities to other provinces } \\
\text { (job opportunities, call for event } \\
\text { participation) }\end{array}$} \\
\hline \multicolumn{8}{|l|}{ Note: } \\
\hline \multicolumn{8}{|c|}{ DNTIPC: Da Nang Tourism Information and Promotion Center, www.danangtourism.gov.vn } \\
\hline \multicolumn{8}{|c|}{ QNTIPC: Quang Nam Tourism Information and Promotion Center, http://www.quangnamtourism.com.vn } \\
\hline \multicolumn{8}{|c|}{ BDTIPC: Binh Dinh Tourism Information and Promotion Center, http://dulichbinhdinh.com.vn } \\
\hline \multicolumn{8}{|c|}{ PYTIPC: Phu Yen Tourism Information and Promotion Center, http://www.phuyentourism.gov.vn/ } \\
\hline \multicolumn{8}{|c|}{ KHTIPC: Khanh Hoa Tourism Information and Promotion Center, http://www.nhatrang-travel.com } \\
\hline NTTIPC: Ninh Thuan Tourism & Information & and Promo & on Center, & ttp://www. & inhthuante & rist.com & \\
\hline
\end{tabular}

For other marketing materials, the analysis process was more straightforward. Among the marketing materials collected during field visits, there only two examples of joint materials: the guidebook "A journey through the Central Coastal Region" (prepared by the CRDF and a joint brochure of tourism events of Hue, Da Nang and Quang Nam (prepared by TIPCs of Hue, Da Nang and 
Quang Nam). Publishing joint guidebooks and brochures are examples of joint destination marketing activities and the interpretations of these activities will be incorporated with interviews data and presented in the findings chapters. It is important to note that findings from the content analysis were to be used in a complementary manner with the ones from in-depth interviews.

\subsection{Data evaluation: Strengths and limitations}

Before presenting the data that have been analyzed, it is critical to provide some data evaluation. The data used in this research are evaluated from three aspects: types of data that were collected; the data-collection methods; and the quality of the data based on the data-need section specified earlier (Figure 3.1).

In terms of strengths, different types of data have been collected and used in this study. Primary data from in-depth interviews with tourism representatives of provinces and the nation provides reliable information on destination marketing. The study also triangulated primary data from other two sources: official tourism websites of the seven TIPCs and selective marketing materials collected during field visits. In addition to the primary data, secondary data were sourced from governmental documents (national tourism development strategy, provincial tourism master plans); from official websites of national and regional organizations; from conference proceedings and from marketing materials published by DCSTs/TIPCs. Such data triangulation is useful to enhance validity, reliability and objectivity of a research project (Decrop, 1999). In the present study, data from various sources were used to complement each other. For example, comments of some tourism representatives about the rapid tourism development of their provinces can be reconfirmed through statistical data like tourist arrivals and tourism growth rate. Another strength is that the collected data met the data needs. Again different sources of data increase the chance of finding what is actually needed.

On the other hand, the study is not without its limitations. Firstly, in Viet Nam, DCSTs/TIPCs are the main but not the only type of organizations that are involved in destination marketing. Clearly, enterprises and their associations 
(hotel and tour-operator associations) may contribute to destination marketing in marketing their own products and services. However, given the time and budget constraints, this study did not look at how enterprises in the eight provinces were involved in joint destination marketing activities and how their marketing relationships with other provinces' enterprises were compared to the destination marketing relationships between DCSTs/TIPCs. Another limitation resulted from the fact that interviewees are the representatives of their tourism organizations. With such positions, interviewees tended to answer some interview questions in "a diplomatic style", especially to the questions asking about their relationships with other provinces in destination marketing. However, the method of conducting interviews with each province's representative individually (rather than a focus group) helped to increase the candidness of responses.

\subsection{Conclusion}

This chapter has described and explained in depth about the research methodology. The research method, comparative approach, was firstly justified to be appropriate given the research objectives of examining joint destination marketing between the eight provinces of the South Central Coast region. Consisting of eight neighbouring provinces with dynamic tourism development contexts, the South Central Coast region is a suitable case study and DMOs of the eight provinces named DCSTs/TIPCs in Viet Nam are the most suitable study organizations. To limit possible biases and enhance the study's reliability and validity, triangulation of data and data-collection methods were optimized. As the main method for collecting data, in-depth semi-structured interviews with representatives of DCSTs/TIPCs helped gain insights into the nature and extent of joint destination marketing activities between the examined provinces and provided explanatory reasons for the phenomenon. Furthermore, official tourism websites of provinces and other marketing materials were analyzed to complement on interviews data about joint destination marketing activities of the eight provinces. Secondary data were also collected from official sources and used effectively to meet the data needs of the study. The study then analyzed data with recommended data analysis process for in-depth interviews 
and with content analysis for websites and other marketing materials. Suitable analytical frameworks were developed and helped to not only conceptualize but also compare the joint destination marketing between eight provinces. In general, an appropriate research methodology has been developed and presented in this chapter. 


\section{Chapter 4: REGIONAL AND PROVINCIAL DESTINATION MARKETING: CONTEXTS OF THE SOUTH CENTRAL COAST REGION}

\subsection{Introduction}

Understanding the context in which destination marketing activities occur is fundamental for investigating the nature and extent of joint marketing efforts made by multiple destinations. Therefore, this chapter aims to set the scene for the subsequent findings chapters by presenting and discussing contextual factors of the South Central Coast region as well as its provinces. More specifically, such factors as the tourism development situation, the strengths and weaknesses for tourism development, marketing objectives, typical products and target markets are discussed in order to uncover the respective marketing contexts, which in turn drive the ways in which marketing activities are implemented both individually and jointly by the eight provinces in the region.

\subsection{Regional tourism development and destination marketing context}

With bountiful tourism potential (discussed in Chapter 1), the tourism industry of the South Central Coast region has grown significantly and played a major role in the economy (Nguyen \& Le, 2013). As can be seen from Figure 4.1, the total number of tourists visiting the region in 2005 was about 5 million with 3.63 million domestic tourists and 1.37 million international tourists. For eight consecutive years since 2005, the domestic market grew strongly and continuously to reach 11.1 million tourists in 2012. At the same time, the region also received an increasing number of international tourists -1.5 million and 2.1 million tourists in 2006 and 2008 respectively. There was a slight decrease in international arrivals in 2009, which was in line with the reduced number of international tourists visiting Vietnam in that same year. The year 2010 instead marked the recovery of this market which then reached the number of $2,755,143$ tourists (up 17.8\%) in 2011 and 3,151,537 tourists (up 14.4\%) in 2012. 
Figure 4.1: Tourist arrivals of the South Central Coast region 2005 - 2012

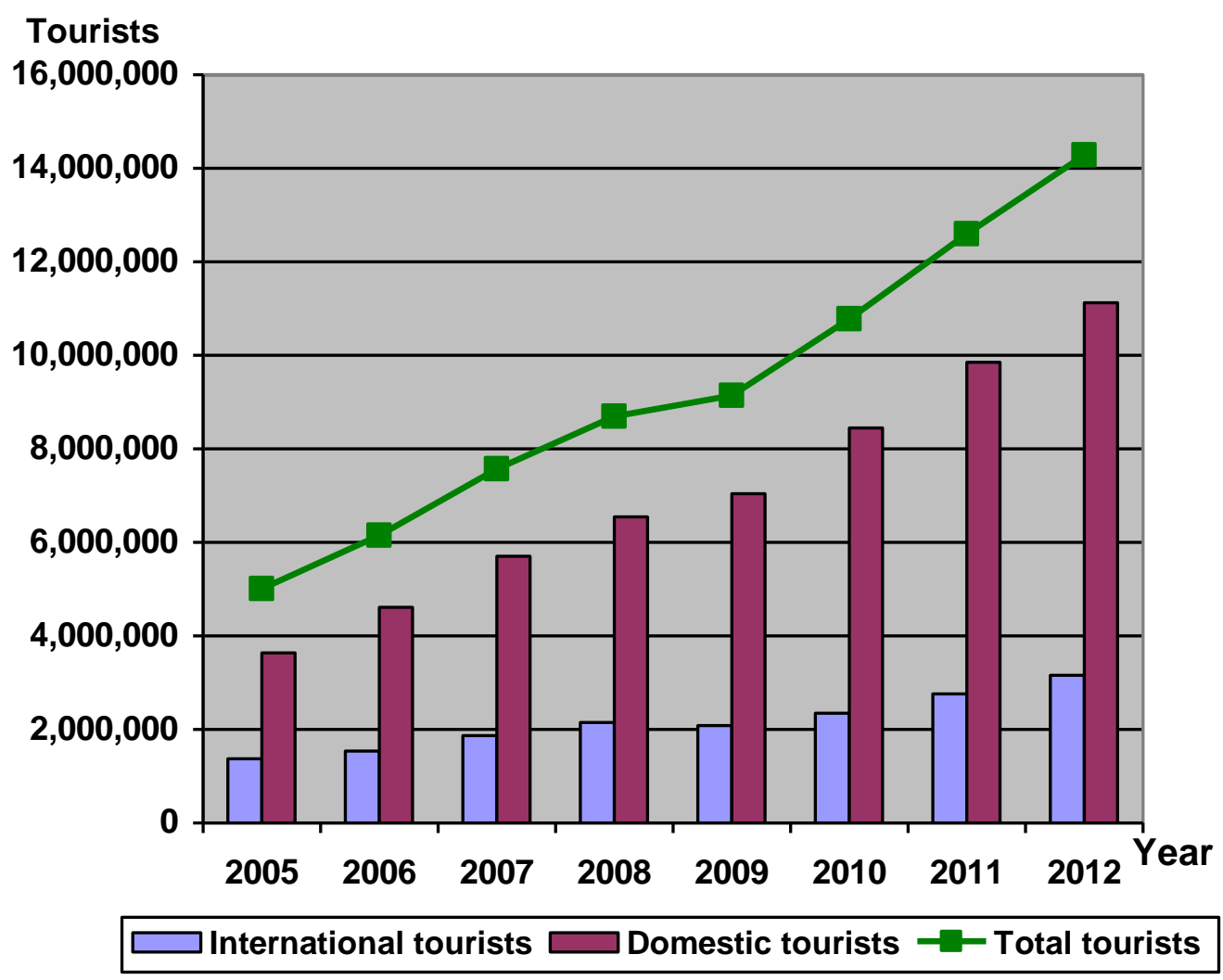

Source: Viet Nam Central Coastal Region (www.vietccr.vn)

Together with the growth of tourist arrivals, the tourism revenue of the region increased dramatically. Tourism activities generated VND2,260 billion in revenue in 2005 and 6,875 billion in 2010, which then doubled in 2012 with VND12,876 billion.

According to interviewees' responses, traditional international markets for the region include Australia, the USA, Japan, France and Germany. The region also aims to attract emerging markets such as South Korea, Thailand, Laos and especially Russia. In 2012, 174,000 Russian tourists visited Viet Nam and the South Central Coast region was their main destination. According to a tourism survey conducted in April 2013, the Russian market accounted for approximately $38.8 \%$ of foreign tourists in the Central Coastal provinces, followed by Europe (27.3\%), Australia (16.5\%), America (8.3\%) and Asia (7.2\%) (Tran \& Consultative group, 2013). In terms of domestic markets, Ha 
Noi and Ho Chi Minh city are the two major markets of South Central Coastal provinces.

The tourism infrastructure has been improved over the years along with dynamic tourism development in the region. Regional statistics in 2012 showed that the whole region has 379 travel businesses, including 85 international travel companies, 201 domestic ones and 93 travel agents or branches of large foreign and domestic tour operators. In addition, the region has 22 accommodation units ranked as 5-star, 153 units ranked as 3-4 star and 768 units as 1-2 star (Tran \& Consultative group, 2013).

Besides, the eight provinces are well connected by the national highway $1 \mathrm{~A}$. The region also connects with four neighbouring countries, namely Myanmar, Thailand, Laos and Cambodia and further with South Asian countries, Southwest China through the East-West Economic Corridor and national highways No.9, 14, 19 and 27. The region has two international airports in Da Nang and Cam Ranh (Khanh Hoa) and three domestic airports in Quang Nam, Binh Dinh and Phu Yen. There are 13 seaports along the coastline of the region, however, only Tien Sa seaport of Da Nang and Nha Trang seaport of Khanh Hoa province are able to receive big cruise ships. Recently, these two ports have welcomed 5-star cruise ships like the Queen Elizabeth II, Superstar Gemini Cruise, Diamond Princess Cruise and Seven Seas Cruise (Tran \& Consultative group, 2013).

The South Central Coast region has a clear orientation for tourism development, which has been identified in the Viet Nam Tourism Development Strategy to 2020 and was mentioned by the representative of the Institute for Tourism Development Research (ITDR) as follows:

...the Central Coast region will become the most dynamic region for tourism development in the whole country with the direction of developing sea tourism together with marine culture and heritages. Aspects like sea culture, sea cuisine, sea ecology should be exploited for regional tourism development. The region should also exploit 
cultural values in proximity areas to diversify products and prolong tourists' holidays.

This vision statement indicates that eight provinces of the South Central Coast region need to work together in order to achieve the common goal of developing tourism to become the key industry of each province/city and of the region as a whole. Following the region-based approach of VNAT, the South Central Coast provinces have started making joint efforts to develop the region as a single destination in the past few years. In 2011, leaders of seven provinces including Thua Thien Hue (a city in the North Central Coast) and six provinces of the South Central Coast from Da Nang to Khanh Hoa signed the Central Coast Cooperation Agreement to cooperate in various socio-economic fields, including tourism. In 2012, the two southern-most provinces of the South Central Coast region - Ninh Thuan and Binh Thuan - joined the cooperation initiative. Since 2011, there have been three tourism-themed conferences organized to connect these nine provinces. The ITDR representative evaluated the cooperative efforts of the South Central Coast provinces as follow:

...for the South Central Coast region, the tourism industry has a very important role in the economic structure of provinces; the leaders from the highest level have recognized and paid attention to tourism development activities, including destination marketing. So compared with other regions, the joint destination marketing of the region is better.

However, the national tourism representative also said that the destination marketing efforts of the region are still limited compared with its potential. This assessment is consistent with opinions of most provincial representatives who stated that their provinces do destination marketing more individually than jointly. The tourism development status and current destination marketing contexts of individual provinces are provided in the next section, which in turn explains why the national organization's representative stated that cooperative actions of the region do not yet match its potential. 


\subsection{Provincial tourism development and destination marketing contexts}

\subsubsection{Tourism development situations of the eight South Central Coast provinces}

Due to their influence on destination marketing practices, the tourism development situations of the eight provinces need to be understood. Despite different starting points and development levels, the tourism industry has developed rapidly in all South Central Coastal provinces. As shown in Figure 4.2, the number of tourists (both international and domestic) visiting South Central Coastal provinces kept increasing during the periods 2005-2008 and 2011- 2012.

Figure 4.2: Total tourist arrivals to SCC provinces 2005-2008 and 2011-2012

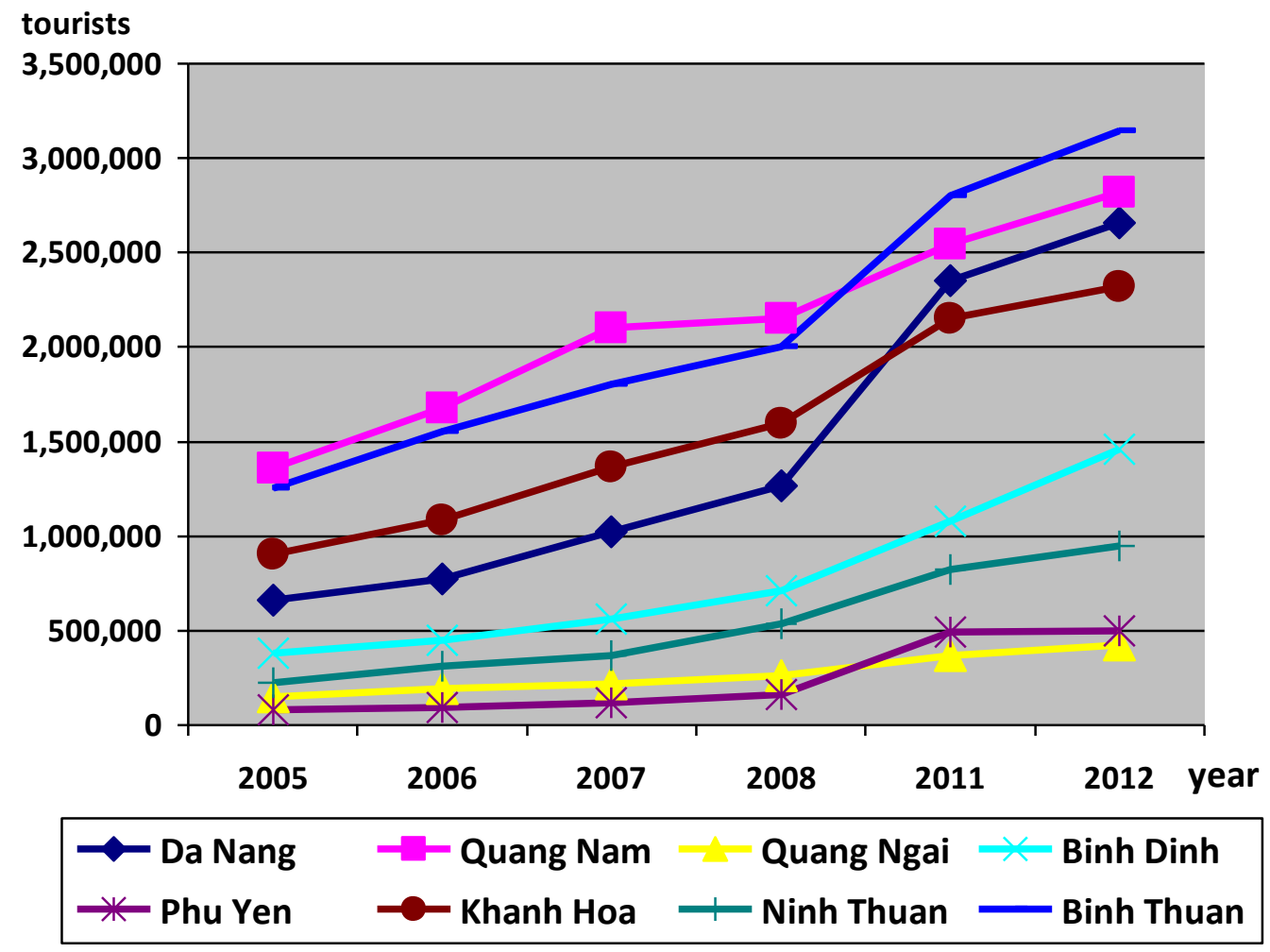

Source: ITDR (2012)

In 2005, there were only two provinces in the region, namely Quang Nam and Binh Thuan, that received more than 1.2 million tourists. Unlike the period 2005-2008 when Quang Nam was always the leading province in terms of total number of tourists, in 2011 and 2012 Binh Thuan jumped to first ranking with 
3,144,650 tourists. However, Quang Nam still attracted many more international tourists $(1,384,342$ in 2012) than Binh Thuan (341,160 in 2012). A similar situation happened with Khanh Hoa and Da Nang. There were 1,269,150 tourists visiting Da Nang in 2008 and this number increased to 2,659,553 in 2012; meanwhile Khanh Hoa welcomed a bigger number of tourists $(1,597,200)$ in 2011 but a smaller number in $2012(2,318,071)$. Four other provinces - Quang Ngai, Binh Dinh, Phu Yen and Ninh Thuan - also witnessed increases in total tourist arrivals but generally at a slower rate. Until 2012, these provinces received less than one million tourists, except for Binh Dinh whose tourism industry achieved that milestone in 2011.

The tourism representatives of the provinces being researched also confirmed that tourism has developed and contributed positively to the provincial/municipal economy in different ways.

...Based on the diverse tourism potential, in the past few years Khanh Hoa tourism has had big progress which contributes very positively to the socio-economic development of the locality. In 2012, Khanh Hoa welcomed 2.3 million tourists, of which about 530,000 were international tourists. The success of the tourism industry not only helps to implement national tourism action programs but also helps to shift the province's economic structure with increasing contribution from tourism and services. Tourism development also affects strongly the development of other industries. (Khanh Hoa TIPC)

...In the past 3-4 years, Binh Dinh Tourism has developed quite quickly in terms of tourism planning, state management and tourism promotion activities. (Binh Dinh TIPC)

...According to the evaluation of the action plans from 2005 till now, the province's tourism has developmental signals, which are proven through statistics of tourist arrivals and revenue. The tourism revenue in that period increased by $25 \%$. The tourism infrastructure has increasingly developed; heritage in the province received annual funding for conservation activities. (Binh Dinh DCST) 
Although constant tourism growth was recorded in the eight provinces, a development gap exists between them. There are basically two groups of provinces: more tourism-developed provinces (Da Nang, Quang Nam, Khanh Hoa and Binh Thuan) and less tourism-developed provinces (Quang Ngai, Binh Dinh, Phu Yen and Ninh Thuan). In relation to the number of tourist arrivals, this classification can be seen clearly in Figure 4.2. A similar conclusion, even a clearer one, is drawn when tourism earnings of provinces are compared (Figure 4.3). Although tourism earnings in all provinces increased, four provinces Quang Ngai, Binh Dinh, Phu Yen and Ninh Thuan - lagged way behind their counterparts.

Figure 4.3: Tourism earnings of South Central Coast provinces in 2008 and 2011 billion VND

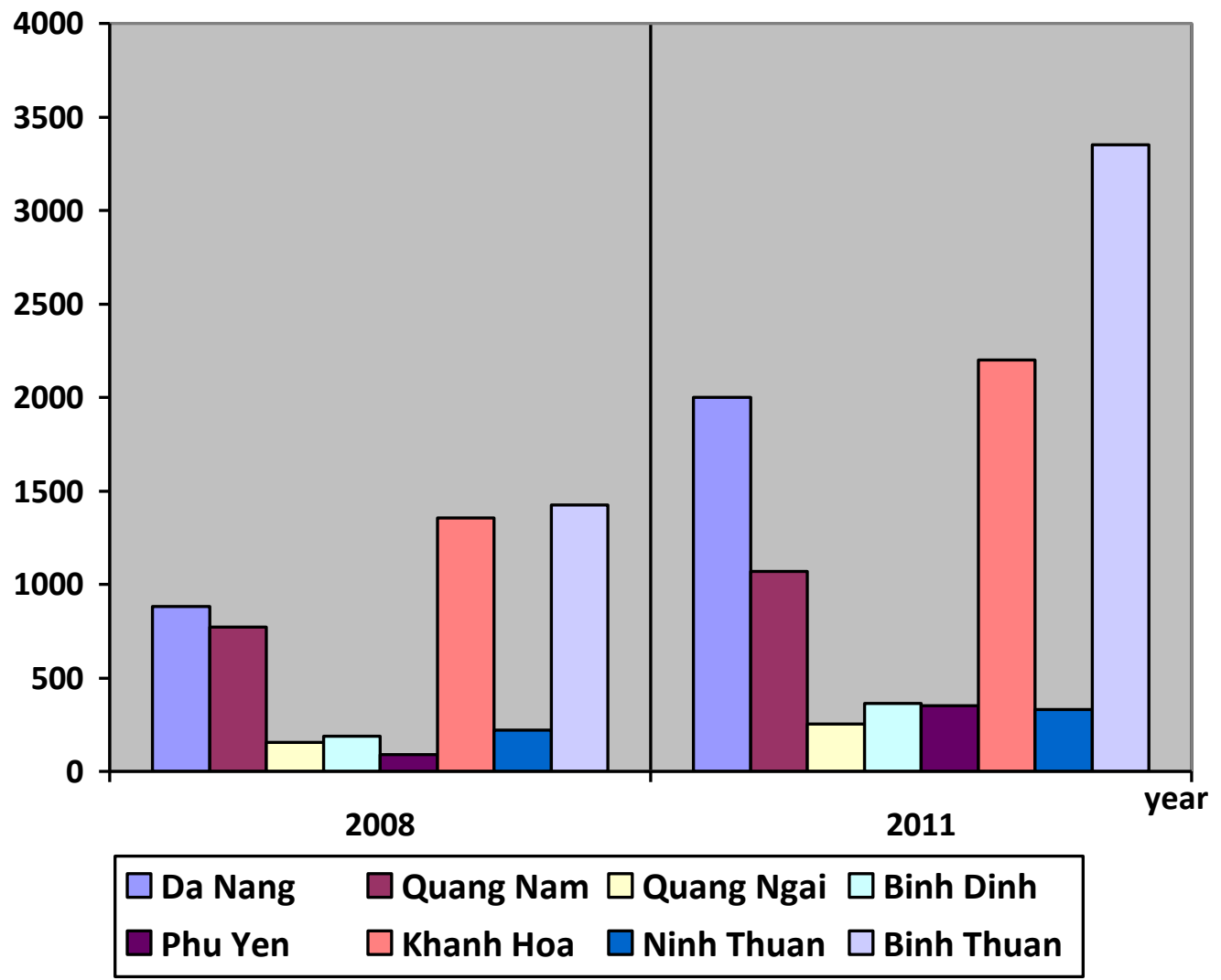

Source: ITDR (2012)

The tourism infrastructure also reflects different development stages and the distance between the two groups of provinces. As Table 4-1 shows, four provinces - Da Nang, Quang Nam, Khanh Hoa and Binh Thuan account for 
336 out of 379 tour companies operating in the region. Twenty two five-star hotels in the region and 136 out of 153 three and four-star hotels are all located in these four provinces. One and two-star hotels are the dominating type of accommodation in the less-developed provinces (192 hotels) but this number is only one third of the same-category hotels in the more developed provinces. Similarly, 336 out of 379 tour operators operating in the region are located in Da Nang, Quang Nam, Khanh Hoa and Binh Thuan.

Table 4.1: Tour operators and hotels of South Central Coastal provinces in 2012

\begin{tabular}{|c|c|c|c|c|c|c|c|c|c|}
\hline Items & $\begin{array}{l}\mathrm{Da} \\
\text { Nang }\end{array}$ & $\begin{array}{l}\text { Quang } \\
\text { Nam }\end{array}$ & $\begin{array}{l}\text { Quang } \\
\text { Ngai }\end{array}$ & $\begin{array}{l}\text { Binh } \\
\text { Dinh }\end{array}$ & $\begin{array}{l}\text { Phu } \\
\text { Yen }\end{array}$ & $\begin{array}{l}\text { Khanh } \\
\text { Hoa }\end{array}$ & $\begin{array}{l}\text { Ninh } \\
\text { Thuan }\end{array}$ & $\begin{array}{l}\text { Binh } \\
\text { Thuan }\end{array}$ & $\begin{array}{l}\text { Whole } \\
\text { region }\end{array}$ \\
\hline \multicolumn{10}{|c|}{ Tour Operators } \\
\hline Total & 138 & 36 & 11 & 14 & 10 & 90 & 8 & 72 & 379 \\
\hline International & 41 & 11 & 2 & 4 & 0 & 22 & 1 & 4 & 85 \\
\hline Domestic & 54 & 22 & 8 & 9 & 9 & 64 & 7 & 28 & 201 \\
\hline Agency & 43 & 3 & 1 & 1 & 1 & 4 & 0 & 40 & 93 \\
\hline \multicolumn{10}{|l|}{5 star hotels } \\
\hline $\begin{array}{l}\text { Number of } \\
\text { hotels }\end{array}$ & 8 & 4 & - & - & 1 & 6 & & 3 & 22 \\
\hline $\begin{array}{l}\text { Occupancy } \\
\text { rate }\end{array}$ & $45-50$ & 56 & - & - & 25 & $50-55$ & - & 58 & \\
\hline \multicolumn{10}{|l|}{ 3-4 star } \\
\hline $\begin{array}{l}\text { Number of } \\
\text { hotels }\end{array}$ & 45 & 22 & 7 & 5 & 3 & 38 & 2 & 31 & 153 \\
\hline $\begin{array}{l}\text { Occupancy } \\
\text { rate }\end{array}$ & $40-65$ & $54-65$ & $40-50$ & $40-45$ & 45 & $60-65$ & 45 & 67 & \\
\hline \multicolumn{10}{|l|}{$1-2$ star } \\
\hline $\begin{array}{l}\text { Number of } \\
\text { hotels }\end{array}$ & 273 & 40 & 10 & 75 & 40 & 204 & 67 & 59 & 768 \\
\hline $\begin{array}{l}\text { Occupancy } \\
\text { rate }\end{array}$ & $35-42$ & 60 & $55-60$ & $35-40$ & 60 & $45-50$ & 60 & 55 & \\
\hline
\end{tabular}

Source: Tran and Consultative group (2013) 
After reviewing three tourism indicators - tourist arrivals, tourism earnings and tourism infrastructure, it is clear that the eight provinces of the South Central Coast region are classified into two groups: the more tourism-developed provinces and the less tourism-developed provinces (Figure 4.4).

Figure 4.4: Two groups of provinces in the South Central Coast region

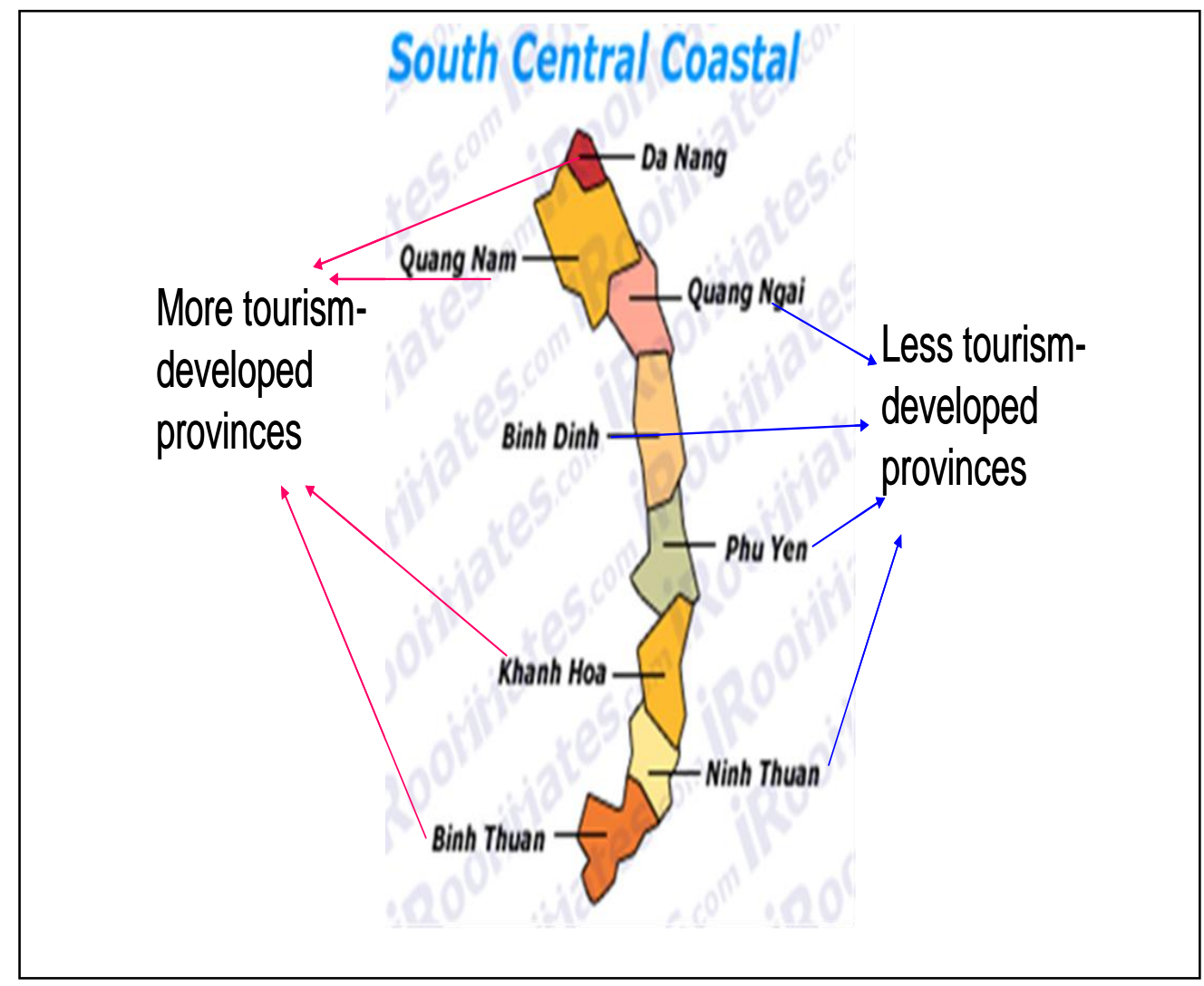

Also, the South Central Coastal provinces are at different stages in their tourism development life cycle (Butler, 1980). Of the eight provinces, perhaps Da Nang, Quang Nam, Khanh Hoa and Binh Thuan are now at the development stage where they are known reasonably widely by tourists. The tourism representatives of Quang Nam and Da Nang stated:

... Quang Nam's destinations, especially Hoi An and My Son, have been widely known by both domestic and foreign tourists. Hoi An is frequently chosen as one of the favourite destinations by many travel magazines, and websites. (Quang Nam TIPC)

...In the list of ten outstanding events in Viet Nam in the year 2012, Da Nang was chosen as one of the localities that made breakthroughs in tourism development. Da Nang has become a 
highlight in the tourism map of the Central region and the whole country. (Da Nang DCST)

These provinces are also capable of making big investments to organize international festivals or attend tourism fairs/promotional events abroad. Binh Thuan has organized an international windsurfing race, international sailing festival and international hot-air balloon festival. Khanh Hoa has an international sea tourism fair organized within the annual Nha Trang Sea festival. The international fireworks competition has become a brand attached with Da Nang and, similarly, Quang Nam has a well-known heritage festival and unique Viet Nam International Choir Competition. Aiming to attract both international and domestic tourists, the representatives from these provinces attend important tourism events such as an International Travel Expo held in Ho Chi Minh city; Vietnam International Travel Mart held in Hanoi; Leisure tourism trade fair in Russia; and KOTFA world travel fair in Korea.

Conversely, Quang Ngai, Binh Dinh, Phu Yen and Ninh Thuan appear to be at the "introduction stage" of their life cycle. Tourism representatives of these provinces agreed on several characteristics. Firstly, the tourism industry of these less developed provinces has just been started in the past few years. The Ninh Thuan tourism representative emphasized: “...Ninh Thuan is a poor province where tourism development has just been started". In the case of Phu Yen, "from 2008 till now, [its] tourism has developed quickly, especially after the National Tourism Year 2011...”. Similarly, Binh Dinh's representative noted: “...our sea tourism cannot be compared with provinces like Da Nang, Nha Trang, Binh Thuan because they have developed long before us with big investments".

Secondly, three provinces - Binh Dinh, Phu Yen and Ninh Thuan - have just established their TIPCs to enhance destination marketing activities, while Quang Ngai does not yet have one. Thirdly, while the more developed provinces invest in large-scale tourism activities, the less developed provinces focus on improving their tourism infrastructure and calling for more 
investments. Attracting infrastructure investment seems to be the current priority of less tourism-developed provinces.

... Phu Yen tourism has just started being known, many destinations in Phu Yen still require more investment....The province needs to invest more for tourism infrastructure, accessibilities of destinations as well as destination promotion. (Phu Yen DCST)

... the infrastructure of Ninh Thuan is still very weak...Ninh Thuan still meets many difficulties in tourism infrastructure investment. (Ninh Thuan DCST)

... To coastal tourism, we focus on developing the route Quy Nhon - Nhon Ly - Cat Tien - Di Pass - Tan An. There are many big projects that have been started along this route, for example the Hai Giang tourism area, Vinh Hoi, Hon Ngoc Viet, Trung Luong. (Binh Dinh TIPC)

The two groups of provinces also aim to attract different target markets (Table 4.2). The target markets of Da Nang, Quang Nam, Khanh Hoa and Binh Thuan are both international and domestic. In terms of international markets, countries like Australia, the USA, Japan, France and Germany are traditional foreign markets. There are also some emerging international markets, which are becoming increasingly important such as Russia, Korea, Thailand and Laos.

Conversely, attracting domestic markets is the main focus of the less developed provinces. Specifically, Binh Dinh and Phu Yen aim to attract tourists from $\mathrm{Ha}$ Noi, Ho Chi Minh city and Central Highlands provinces. Ninh Thuan focuses on Ho Chi Minh city and the Southeast provinces of Viet Nam. The representatives of Phu Yen and Ninh Thuan stated:

... Actually now Phu Yen sets priority for domestic markets because the budget does not allow us to implement promotional activities abroad. (Phu Yen TIPC)

... If you have a product but customers do not know about it, no one is using it. It is the same for tourism. Knowing that Ninh Thuan dares not to invest for destination marketing activities because the expense is too much. (Ninh Thuan DCST) 
Table 4.2: Target tourism markets of South Central Coast provinces

\begin{tabular}{|c|c|}
\hline Provinces & Target markets \\
\hline Da Nang & $\begin{array}{l}\text { Near markets: China, Korea, Japan, ASEAN, Thailand } \\
\text { - Far markets: Russia, the USA, Germany, Europe } \\
\text { - Domestic markets }\end{array}$ \\
\hline Quang Nam & $\begin{array}{l}\text { Two main domestic markets are Ha Noi and Ho Chi Minh city. } \\
\text { - Australia, France, Germany, Japan, Korea, Russia. Indian and the } \\
\text { Middle East are also potential markets }\end{array}$ \\
\hline Quang Ngai & $\begin{array}{l}\text { - Domestic markets } \\
\text { - Near foreign markets: Laos, Thailand }\end{array}$ \\
\hline Binh Dinh & $\begin{array}{l}\text { Ha Noi, Ho Chi Minh and Central Highlands } \\
\text { - Target Thailand and Laos through cooperation with Central Highlands }\end{array}$ \\
\hline Phu Yen & $\begin{array}{l}\text { - Ho Chi Minh, Ha Noi, Da Nang, Central Highlands } \\
\text { - Attract selectively Russian tourists } \\
\text { - Laos, Thailand } \\
\text { - Attract international tourists who arrive through Ho Chi Minh city and } \\
\text { Ha Noi }\end{array}$ \\
\hline Khanh Hoa & $\begin{array}{l}\text { - Traditional target markets: the USA, Australia, Japan, China } \\
\text { - ASEAN markets, especially Thailand through caravan tours } \\
\text { - Emerging markets: Russia, Korea }\end{array}$ \\
\hline Ninh Thuan & $\begin{array}{l}\text { Ho Chi Minh city and Southeast provinces; In the near future will attract } \\
\text { Russian and Japanese tourists }\end{array}$ \\
\hline Binh Thuan & $\begin{array}{l}\text { - International markets: Russia, Germany, China, Korea, } \\
\text { - Domestic markets }\end{array}$ \\
\hline
\end{tabular}

For all provinces, Ha Noi and Ho Chi Minh city are the most important domestic markets, which is easy to understand. Firstly, Ha Noi and Ho Chi Minh city generate the biggest number of domestic tourists who also stay longer and spend more on travelling than tourists from other places within Viet Nam. Secondly, they are the two main gateways that welcome the majority of international tourists visiting Viet Nam. Some provinces located in the centre of the country and have their own domestic airports like Binh Dinh and Phu Yen have made efforts to attract international tourists from Ha Noi and Ho Chi Minh by attending the International Travel Expo and Viet Nam International Travel Mart respectively organized in Ho Chi Minh city and Hanoi annually. 
Three provinces of Quang Ngai, Binh Dinh and Phu Yen have recently paid some attention to attract nearby foreign markets like Thailand and Laos by enhancing their relationship with Da Nang and Kon Tum. Da Nang is the final city in the East-West Economic Corridor connecting Myanmar-Thailand-LaosVietnam (Figure 4.5) and Kon Tum is one Central Highlands province that has an international border gate with Laos and Cambodia.

Figure 4.5: East-West Economic Corridor (EWEC)

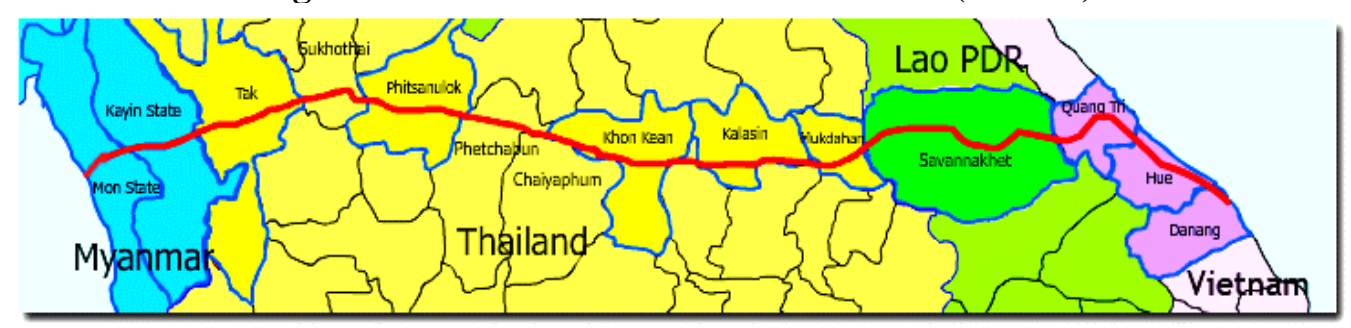

Source: East-West Economic Corridor Business Database (http://www.ewecbiz.com)

Also, Phu Yen sees the opportunity to attract international tourists through $\mathrm{Ha}$ Noi and Ho Chi Minh city. Ninh Thuan, in the near future, expects the number of Russian and Japanese tourists visiting the province will increase thanks to two clean-energy production projects supported by these two countries. These things imply that the less-developed provinces try to approach international markets more indirectly rather than directly.

\subsubsection{Provincial tourism potential and development orientations}

In order to understand the marketing context of each province or group of provinces, their tourism potential needs to be examined. All South Central Coastal provinces share a common potential for tourism development mentioned by interviewees: the long coastlines and beautiful beaches. Interestingly, when being asked about strengths for tourism development, all interviewees mentioned their provinces' marine resources in different ways. Da Nang's representative emphasized that Da Nang's beaches are "beautiful, clean and environment-friendly". Khanh Hoa, on the other hand, has the advantage of sea island tourism with $385 \mathrm{~km}$ coastlines and about 200 islands as well as the diversity of tourism service providers (Khanh Hoa Provincial People's Committee, 2013). Binh Thuan differentiates itself by characteristics of waves 
and its well-known brand name of "Viet Nam resort capital". Meanwhile, although Quang Nam's most important tourism potential is culture, Quang Nam luxury seaside resorts and Cham Island as a world biosphere reserve contribute to the diversity and attractiveness of the province as a destination. Binh Dinh has beaches together with much historical and cultural heritage, especially performing arts like martial arts and Vietnamese traditional opera. Phu Yen focuses on "developing marine tourism with marine culture"; whilst Ninh Thuan's uniqueness is "untouched beaches" and two national parks in the region. Last, but not least, Quang Ngai has Ly Son island with many archaeological attractions and special traditional festivals, especially the Hoang Sa Soldier Feast and Commemoration Festival.

This diversity in coastal tourism enables South Central Coastal provinces to have both competitive and cooperative advantages. In other words, each province is able to provide tourists with different coastal tourism experiences or to cooperate with other provinces to develop trans-region tourism products. Ninh Thuan DCST representative noted:

...tourist demand is diverse. Some tourists like the untouched Ninh Thuan, some like dynamic Da Nang, some like convenient Khanh Hoa. Each province has different strengths... if tourists visit untouched beaches in Ninh Thuan, then they can come to Da Nang to experience luxurious beaches. Tourism marketing needs to be done in that way in order to create a tourism product chain.

Besides the overall common strength of coastal tourism potential, each province is characterized by distinctive strengths which are analyzed together with the typical tourism products developed. In the case of $\mathrm{Da}$ Nang, tourism infrastructure appears to be the competitive advantage that makes the city outstanding. The representative compared the number of four-five star hotels the city has between 2004 and the present:

...In 2004, we had only about 90 hotels with 5000 hotel rooms. Now we have 355 hotels with 11,447 hotel rooms. Before 2004 we only had one 5-star hotel, from 2004 till now we have had eight 5-star hotels; four 4-star hotels and forty three 3-star hotels. Famous international hospitality corporations have been present in Da Nang 
such as Intercontinental, Hyatt, Mercure, Pullman, Novotel, Crown Plaza. These famous brand names automatically make Da Nang different in tourists' eyes (Da Nang DCST)

Table 4.1 also shows that Da Nang has the best tourism infrastructure compared to other provinces. Noticeably, unlike the advantages of other provinces which are more endowed by nature or history, Da Nang's advantages are more strategy-oriented. One respondent commented: “...The city has chosen the right orientation which is to focus on developing infrastructure as the foundation to develop service industries, including tourism. That is why we have large roads, good environmental system, and convenient bridges. Once transportation is convenient, services develop". Similarly, the city chooses to develop MICE tourism as its typical type of tourism because "...Da Nang has a reasonably good infrastructure" and MICE tourism enables Da Nang to "...support or be supported by Hue and Quang Nam". This means Da Nang not just differentiates itself from the two cities of World Heritage Sites - Hue and Hoi An (Quang Nam) but also aims to create complementary products for these three provinces. More importantly, "in that way, tourists can visit Hue, Hoi An for tranquil and ancient experiences, but when they are in Da Nang they experience a modern city with entertainment like karaoke, bars, discotheques...This helps to change tourists' feeling, they can understand deeply about each destination".

Quang Nam is the province that perhaps has the most diverse tourism potential in the region. The representative explained:

...Quang Nam has two World Heritage Sites - Hoi An ancient town and My Son sanctuary; Quang Nam is the meeting place of different cultures, including Champa, China, Japan, the cultures of some ethnic minorities of Vietnam. Quang Nam also has Cham Island the world's Biosphere Reserve; intangible cultures, cuisine, performing arts, traditional occupation villages and folk festivals. So Quang Nam's strength is the diverse tourism potential (Quang Nam TIPC)

Quang Nam is a well-known destination to both international and domestic tourists, but does not have problems like overcharging, stealing, harassment from vendors and beggars. This is clearly another advantage. Typical tourism products of Quang Nam are mainly inspired from cultural heritage. Like Da 
Nang, Quang Nam also develops its own typical type of tourism which is community-based tourism in many of its destinations like community ecotourism in Cam Thanh, Tra Nhieu, Tra Que villages and My Son communitybased tourism village.

The outstanding tourism potential of Quang Ngai is Ly Son island. The representative of Quang Ngai DCST emphasizes special features of this island:

...Ly Son holds traces of prehistoric men about 30,000 years ago on Mount Gieng Tien and Thoi Loi. Ly Son also has precious artifacts of local residents belonging to the Sa Huynh Culture $(2,000-2,500$ years ago)... and many traditional festivals such as boat race festival, An Hai Temple festival, especially the Hoang Sa Soldier Feast and Commemoration Festival. This is a very unique festival, only organized in Ly Son island in order to commemorate the Hoang Sa and Truong Sa soldiers who had fallen to protect the nation sovereignty. (Quang Ngai DCST)

In the future, Ly Son will become the tourist island of Quang Ngai and sea island festival will be held on the island. At the moment, it seems that Quang Ngai does not yet have its typical tourism products.

Like Quang Nam, Binh Dinh also has much tourism potential and "Binh Dinh culture makes it different". More specifically, several typical features of Binh Dinh were identified:

...Firstly, Binh Dinh has many historical and cultural heritage sites...Secondly, Binh Dinh has Quang Trung Museum which preserves unique relics related to the national hero Quang Trung Nguyen Hue and his brothers...Thirdly, the most prosperous period of Champa kingdom occurred in Binh Dinh from the $10^{\text {th }}$ to $13^{\text {th }}$ century. This can still be seen now through 8 zones of temples consisting of 14 temples that are unique in the Southeast Asia. These temples are preserved quite well. Besides, we have other unique potentials such as Tuồng (Dao Duy Tu, Dao Tan), bài chòi, martial arts and Binh Dinh is the place that many famous poets like Han Mac Tu, Xuan Dieu, Quach Tan, Che Lan Vien, Yen Lan were born or lived. (Binh Dinh DCST) 
Although some of these cultural values have been included in the tour itinerary, complete typical products have not yet been developed. Binh Dinh tourism's representative said “...we have lots of tourism potential but not yet tourism products. Tourists' demand for visiting Binh Dinh is still low, so the investment for tourism infrastructure and development is limited. And this is a vicious circle". (Binh Dinh DCST)

Having lots of tourism potential but lacking of attractive tourism products seems to be the main issue with Phu Yen and Ninh Thuan as well. The marine culture of Phu Yen is believed to be different from other provinces because of "the integration between Viet and Cham cultures for hundreds of years". In addition, the province has other unique attractions, including the lithophone, stone horn, Stone Plates rapids and "nui Da Bia" (gravestone mountain). In the case of Ninh Thuan, its living culture of Cham people is something that cannot be found anywhere else. The two national parks of the region - Nui Chua and Phuoc Binh national parks - are located in Ninh Thuan. However, no typical product was mentioned out of the unique potential listed. In contrast, beaches are the most oustanding tourism resource of both Khanh Hoa and Binh Thuan, but these two provinces can successfully develop their typical products in different ways. Khanh Hoa focuses on developing sea-island tourism products like daily tours to islands or luxury seaside resorts. Meanwhile Binh Thuan differentiates its coastal tourism with water sports activities like sailing, sand surfing, hot-air balloon flying.

Also there are cases where provinces turn disadvantages into advantages with appropriate management. Da Nang is an example.

...The problem we met when developing Da Nang is Da Nang is located between Hue and Hoi An and My Son - the World Heritage Sites. This means international tourists know about Hue and Quang Nam but hardly know about Da Nang, so this is our challenge. However, in the challenge we see the opportunities which come from the fact that tourists have to come to Da Nang in order to visit other sites. So if Da Nang can guarantee good infrastructure and high-quality services, tourists can stay in Da Nang to go to other places. They can put their backpacks in Da Nang, then go to Hoi An 
or Hue and then back to Da Nang. That can become our product as well. We can promote that when tourists stay in Da Nang, they can easily visit Hoi An and Hue. This proves that in hardships, there are opportunities that we have not yet explored (Da Nang DCST)

Or there are cases that having too many advantages is not an advantage. For example, Hue has many well-known cultural and historial sites. However, its tourism representative admitted: "Hue has too many things, so we do not know what to focus on". Therefore, it is important to discover not only what provinces have but also what they do to turn potential into actual development. A part of that marketing performance is uncovered by analyzing the marketing orientations South Central Coastal provinces have developed.

The eight provinces in the region have not yet had their own tourism marketing strategy, but they have all identified some sort of marketing orientation through different components such as vision statements, development goals, typical products and target markets. Unsurprisingly, the more developed provinces tend to have clearer marketing orientations. For example, Da Nang has a reasonably clear vision to guide the city's tourism development "Da Nang aims to become a tourist city, an events' city and a tourism centre of the Central and the Central Highlands areas as well as of the whole nation and ASEAN region”. Quang Nam has long positioned their tourism image with the slogan "One destination - Two World Heritage Sites" and the province focuses on combining "cultural strengths (two world cultural heritages) and sea eco-tourism".

Conversely, general goals appear to be the norm for the less developed provinces, as shown in following statements.

... We aim to develop Phu Yen to an attractive and friendly destination. (Phu Yen DCST)

... in 2020, Ninh Thuan will be in the top twenty provinces that have the biggest earnings from tourism development. (Ninh Thuan TIPC)

..To 2020, Quang Ngai tries to be ranked in the group of provinces that have a developed tourism industry in Viet Nam. (Quang Ngai DCST) 
In short, this section shows the eight provinces of the South Central Coast region not only share a common strength based on their coastal tourism potential but also have their own distinctive advantages to develop tourism. However, a development gap between the more tourism-developed and less tourism-developed groups of provinces has been identified. Quang Ngai, Binh Dinh, Phu Yen, Ninh Thuan tend to have general goals for tourism development, which may partly explain why they do not yet have specific tourism products. These provinces mainly attract domestic markets or some near-by international markets indirectly due to a limited marketing budget. In contrast, Da Nang, Quang Nam, Khanh Hoa, Binh Thuan have identified their competitive advantages, developed typical tourism products accordingly and attended largescale tourism events within and outside of Viet Nam to attract both domestic and international tourists.

\subsection{Conclusion}

By analyzing the tourism development situations, tourism potential, marketing orientations and marketing activities done individually, this chapter has described the current tourism development and destination marketing contexts of the South Central Coast region as a whole and of the eight individual provinces. The provincial contexts are discussed based on similarities and differences found in South Central Coast provinces in terms of abovementioned dimensions, rather than province by province. Important similarities shared by South Central Coast provinces include a divese tourism potential and rapid tourism development during recent years. The biggest difference amongst eight provinces is the development gap existing between the more tourism-developed provinces (Da Nang, Quang Nam, Khanh Hoa and Binh Thuan) and the less tourism-developed provinces (Quang Ngai, Binh Dinh, Phu Yen and Ninh Thuan). The former group has received much bigger numbers of tourists, developed their own type of tourism or typical products and targetted both international and domestic markets. The latter group, on the other hand, is characterized by a lower starting point in tourism development, general marketing orientations, a lack of typical products and insufficient marketing budgets to attract international tourist markets. 


\section{Chapter 5: INDIVIDUAL AND JOINT DESTINATION MARKETING ACTIVITIES OCCURING IN THE SOUTH CENTRAL COAST REGION}

\subsection{Introduction}

The previous chapter described the regional and provincial tourism development contexts in which destination marketing activities currently occur. This chapter aims to fully address the first objective regarding the nature and extent of joint destination marketing by examining the actual destination marketing activities that have happened in the region and the patterns of those activities. To begin with, the role of destination marketing perceived by DCSTs/TIPCs representatives is presented. The chapter then examines whether South Central Coast provinces conduct their destination marketing more individually or more jointly by reviewing destination marketing activities through in-depth interview data and content analysis of TIPCs tourism websites and marketing materials. Next, the comparison between joint destination marketing in perceptions and in practices clarifies which stage South Central Coast provinces are in and whether they are shifting from individual to joint marketing. Finally, the extent to which destination marketing activities of the region are conducted jointly is investigated through existing cooperative models established and operated in the South Central Coast region.

\subsection{The role of destination marketing perceived by South Central Coast provinces}

All DCSTs/TIPCs representatives of the eight provinces agreed on the important role of destination marketing to tourism development of their provinces. Ninh Thuan TIPC representative said: “...We consider destination marketing as the top priority." The representative of Khanh Hoa TIPC also emphasized: "destination marketing has a decisive role in attracting tourists to the destinations." Da Nang DCST and TIPC representatives provided further explanation: 
... The nature of tourism activities is to attract tourists towards the products, not bring products to consumers like commercial products. So destination promotion and marketing plays an extremely important role in tourism development. If you do not market your destinations well, you cannot attract tourists to come and thus tourism activities do not develop.

...Marketing is a very important task of all tourism destinations. The characteristic of tourism products is inseparability, so it is fundamental to help tourists acknowledged about the places and decide to visit.

The ways in which the role of destination marketing are perceived by the DMO representatives are quite similar. Perceptions of destination marketing roles do not show the development gaps between the more tourism-developed and the less tourism-developed provinces. For the latter group of provinces, destination marketing is perceivd to have more roles than just attracting tourists:

...Destination marketing has many roles to Phu Yen's tourism. The main role is to introduce the tourist destinations (both developed and potential destinations) to attract more tourists and investors. Destination marketing also helps to improve tourism infrastructure and service quality. (Phu Yen TIPC)

The representative of ITDR affirmed that "marketing is decisive to tourism growth" and "...among contents of cooperation between Central provinces, tourism marketing is the first to be done".

Some provinces also take a broad view towards destination marketing. The Quang Ngai DCST's representative stated: "Destination marketing consists of not only promotional activities but also other activities like tourism image developing, product positioning, destination brand and vision identifying". Da Nang TIPC representative emphasized the necessity of understanding the difference between tourism marketing and product marketing: “...some people suggest applying product marketing to tourism marketing. However, I think it is not enough or it is not accurate to do that...the marketing for each destination needs to be differentiated. We need to understand the nature of tourism marketing in order to have appropriate marketing strategy." 
Amongst South Central Coast provinces, Da Nang approaches destination marketing in a sustainable manner. More specifically, the DCST representative of the city said:

...Destination marketing is done right from socio-economic development and social welfare activities. For example, the city issues the "5-No policy" (no illiteracy, no hunger, no begging, no drugs and no robbers). This is a social welfare program that creates the foundation to build a better destination."

According to this representative, Da Nang has been evaluated as a safe, attractive and tourist-friendly destination and this achievement is resulted from the way they market their city.

...we have to identify that destination marketing cannot focus only on organizing tourism promotional activities. The main thing that has to be done at the same time is to invest in tourism product development in the way that guarantees the quality and special features. Promotion activities also need to be done together with developing the city to become an attractive destination. In destination marketing, there is nothing which is as important as tourists' evaluation and feedback after visiting the destinations. Promotion through communication channels is just the beginning part of destination marketing. Meanwhile, the things that attract tourists to come back are the actual things occurring at the destinations. That is our focus at the moment. Through our evaluation, there are Chinese tourists who have come back to the city 6 times and the main reason of this development is rather through "word-of-mouth" than communication channels.

In sum, South Central Coastal provinces generally showed congruent perceptions toward the role of destination marketing in the development of tourism industry, which is important and decisive. Perceptions of destination marketing by DCSTs/TIPCs' representatives also proved a reasonably high understanding of the nature of tourism marketing compared with product marketing. 


\subsection{Joint destination marketing versus individual destination marketing}

\subsubsection{A mix of individual and joint destination marketing activities in South Central Coastal provinces}

To address the second and third secondary question asking whether South Central Coast provinces do more individual and joint destination marketing and what are those activities, the interviewees were asked to list marketing activities that their provinces conduct both individually and jointly and to evaluate which approach is more common in their provinces (interview question \#6).

The interviewees' responses show that in general South Central Coast provinces currently do destination marketing more individually than jointly. Khanh Hoa TIPC representative expressed this explicitly: "Individual destination marketing still accounts for $70-80 \%$ of destination marketing activities”. Quang Ngai DCST, Binh Dinh TIPC and Binh Thuan TIPC representatives stated that although both exist, individual marketing is still more than the cooperative one. Similarly, two representatives of Phu Yen tourism agreed that they mainly carry out destination marketing activities individually. The only exception they pointed out was in 2011 when the national tourism year promoting the South Central Coast region was organized in Phu Yen by the Ministry of Culture, Sports and Tourism.

Individual and joint destination marketing activities seem to be more balanced in three provinces Da Nang, Quang Nam and Hue. However, the tourism representatives of these provinces were also clear that the close destination marketing partnership is only between these three provinces.

...As mentioned before, the cooperation mainly occurs amongst three provinces - Hue, Da Nang and Quang Nam. Currently all provinces of the region have just started organizing conferences, developing joint definitions. Truly cooperation for the region has not yet been established. (Da Nang TIPC)

...Basically, the destination marketing activities are cooperative in the scale of three provinces. For a larger scale, the cooperation has been expressed in agreements but not yet implemented through 
specific activities like co-attending tourism fairs. (Quang Nam TIPC)

Based on individual and joint destination marketing activities listed by tourism representatives, a list of destination marketing activities that have happened in the region was synthesized (Table 5.1). The collumn of marketing tools provides further insights into the way in which the eight provinces conduct their marketing activities.

Table 5.1: Individual and joint destination marketing activities occurred in South Central Coast provinces

\begin{tabular}{|c|c|c|c|}
\hline Provinces & $\begin{array}{l}\text { Individual } \\
\text { destination } \\
\text { marketing activities }\end{array}$ & $\begin{array}{l}\text { Joint destination } \\
\text { marketing activities }\end{array}$ & Marketing tools used \\
\hline Da Nang & $\begin{array}{l}\text { Marketing activities } \\
\text { for MICE tourism } \\
\text { are organized twice } \\
\text { a year in Ha Noi and } \\
\text { Ho Chi Minh city } \\
\text { Da Nang } \\
\text { international } \\
\text { firework festival } \\
\text { Host Fam trips, } \\
\text { press trips }\end{array}$ & $\begin{array}{l}\text { Attending Leisure } \\
\text { tourism trade fair in } \\
\text { Russia, KOTFA } \\
\text { world travel fair in } \\
\text { Korea, Vietnam } \\
\text { International Travel } \\
\text { Mart in Ha Noi }\left(^{*}\right) \\
\text { Organize regional } \\
\text { tourism fair, } \\
\text { conferences }\end{array}$ & $\begin{array}{l}\text { Tourism fairs/ } \\
\text { exhibitions/conferences } \\
\text { Tourism website, } \\
\text { marketing materials for } \\
\text { our focused markets } \\
\text { Information centers, } \\
\text { tourists support center } \\
\text { Word-of-mouth }\end{array}$ \\
\hline $\begin{array}{l}\text { Quang } \\
\text { Nam }\end{array}$ & $\begin{array}{l}\text { Host Fam trips, } \\
\text { press trips from Ho } \\
\text { Chi Minh city, Ha } \\
\text { Noi, Asean markets } \\
\text { and Russia (since } \\
\text { 2003, Quang Nam } \\
\text { hosts 5 Fam trips } \\
\text { every year) } \\
\text { Organize events: the } \\
\text { Vietnan- ASEAN } \\
\text { Cultural Heritage } \\
\text { Space Exhibition, } \\
\text { Hoi An- Japan } \\
\text { festival }\end{array}$ & $\begin{array}{l}\text { Attend activities in } \\
\text { Thailand and Korea } \\
2013(*) \\
\text { Attend domestic } \\
\text { tourism fairs and } \\
\text { travel expo like } \\
\text { International Travel } \\
\text { Expo (ITE) Ho Chi } \\
\text { Minh, Vietnam } \\
\text { International Travel } \\
\text { Mart (VITM) Ha Noi } \\
(*)\end{array}$ & $\begin{array}{l}\text { Fam trips } \\
\text { Tourism fairs/ } \\
\text { exhibitions/conferences } \\
\text { Thematic festivals } \\
\text { (Quang Nam heritage } \\
\text { festival); Hoi An - } \\
\text { Japan festival } \\
\text { Website } \\
\text { Guidebook,brochures, } \\
\text { leaflets, tourist maps }\end{array}$ \\
\hline
\end{tabular}




\begin{tabular}{|c|c|c|c|}
\hline $\begin{array}{l}\text { Quang } \\
\text { Ngai }\end{array}$ & $\begin{array}{l}\text { Organize } \\
\text { promotional } \\
\text { activities in } \\
\text { Champasak, Laos } \\
\text { Attend tourism fairs } \\
\text { such as Tourism } \\
\text { Day Ho Chi Minh; } \\
\text { International Travel } \\
\text { Expo Ho Chi Minh } \\
\text { Organize the Hoang } \\
\text { Sa Soldier Feast and } \\
\text { Commemoration } \\
\text { Festival } \\
\text { Organize the photo } \\
\text { contest "The Land } \\
\text { and the People of } \\
\text { Quang Ngai" }\end{array}$ & $\begin{array}{l}\text { Attend International } \\
\text { Sea Festival Nha } \\
\text { Trang }\end{array}$ & $\begin{array}{l}\text { Tourism fairs/ } \\
\text { exhibitions/conferences } \\
\text { Brochures, leaflets, } \\
\text { tourist maps, tourism } \\
\text { documentary films } \\
\text { Tourism Magazine, } \\
\text { Television channels }\end{array}$ \\
\hline Binh Dinh & $\begin{array}{l}\text { Organize Fam trips, } \\
\text { press trips from Ha } \\
\text { Noi and Ho chi } \\
\text { Minh city and } \\
\text { Central Highlands }\end{array}$ & $\begin{array}{l}\text { Organize joint } \\
\text { promotional activities } \\
\text { with Quang Ngai, } \\
\text { Phu Yen, Gia Lai, } \\
\text { Kon Tum; } \\
\text { Attend regional } \\
\text { tourism conferences } \\
\text { in Da Nang }\end{array}$ & $\begin{array}{l}\text { Fam trips, press trips } \\
\text { Tourism fairs/ } \\
\text { exhibitions/conferences }\end{array}$ \\
\hline Phu Yen & $\begin{array}{l}\text { Organize promotion } \\
\text { conferences - in Gia } \\
\text { Lai - Dak Lak and } \\
\text { Kon Tum; and in } \\
\text { Ho Chi Minh city }\end{array}$ & $\begin{array}{l}\text { Attend tourism fairs } \\
\text { in Da Nang, attend } \\
\text { Sea Festival } \\
\text { organized in Nha } \\
\text { Trang } \\
\text { Host National tourism } \\
\text { year of South Central } \\
\text { Coast region } \\
\text { organized by the } \\
\text { Ministry of Culture, } \\
\text { Sports and Tourism }\end{array}$ & $\begin{array}{l}\text { Mass media } \\
\text { communication } \\
\text { channels ; } \\
\text { Brochures, leaflets, } \\
\text { tourist maps, } \\
\text { advertising short } \\
\text { movies } \\
\text { Tourism fairs/ } \\
\text { exhibitions/conferences } \\
\text { Fam trips } \\
\text { Online marketing, } \\
\text { On-site promotion }\end{array}$ \\
\hline
\end{tabular}




\begin{tabular}{|c|c|c|c|}
\hline Khanh Hoa & $\begin{array}{l}\text { Attend tourism } \\
\text { fairs: ITB } \\
\text { (Germany); FITUR } \\
\text { (Spain); MITT and } \\
\text { Intourmarket } \\
\text { (Russia); KOTFA } \\
\text { (Korea); JATA } \\
\text { (Japan); Thailand } \\
\text { Travel Mart Plus; } \\
\text { International Travel } \\
\text { Expo (ITE) Ho Chi } \\
\text { Minh, Vietnam } \\
\text { International Travel } \\
\text { Mart (VITM) Ha } \\
\text { Noi } \\
\text { Advertise on } \\
\text { famous magazines } \\
\text { Host Fam trips } \\
\text { Contests within the } \\
\text { tourism industry of } \\
\text { the province }\end{array}$ & $\begin{array}{l}\text { Organize regional } \\
\text { tourism fair, } \\
\text { conferences }\end{array}$ & $\begin{array}{l}\text { Media companies } \\
\text { Travel magazines } \\
\text { Press releases } \\
\text { Fam trips } \\
\text { (Familiarization trips) } \\
\text { Tourism fairs/ } \\
\text { exhibitions/conferences }\end{array}$ \\
\hline $\begin{array}{l}\text { Ninh } \\
\text { Thuan }\end{array}$ & $\begin{array}{l}\text { Promote tourism } \\
\text { through cutural and } \\
\text { sport events } \\
\text { Organize events in } \\
\text { Ninh Thuan rather } \\
\text { than in other places } \\
\text { (more on-site } \\
\text { promotion) }\end{array}$ & $\begin{array}{l}\text { Attend regional } \\
\text { tourism events with } \\
\text { its own booth in Nha } \\
\text { Trang Sea festival in } \\
\text { June } 2013 \text { for the first } \\
\text { time }\end{array}$ & $\begin{array}{l}\text { On-site promotion } \\
\text { Press releases } \\
\text { Through cultural, } \\
\text { sports events }\end{array}$ \\
\hline $\begin{array}{l}\text { Binh } \\
\text { Thuan }\end{array}$ & $\begin{array}{l}\text { Annually attend two } \\
\text { tourism fairs: } \\
\text { International Travel } \\
\text { Expo (ITE) in Ho } \\
\text { Chi Minh city and } \\
\text { Ho Chi Minh } \\
\text { Tourism Day. } \\
\text { Attend some } \\
\text { promotional tourism } \\
\text { activities in Nha } \\
\text { Trang, Russia, } \\
\text { Australia, Japan and } \\
\text { South Korea. } \\
\text { Establish tourist } \\
\text { support center and } \\
\text { training center }\end{array}$ & $\begin{array}{l}\text { Attend promotional } \\
\text { tourism activities in } \\
\text { Da Nang } \\
\text { Attend regional } \\
\text { tourism conferences } \\
\text { in Da Nang, Khanh } \\
\text { Hoa }\end{array}$ & $\begin{array}{l}\text { Through TV channels } \\
\text { (HVT7, VTV1, VTV3, } \\
\text { VTV4) } \\
\text { Tourism fairs/ } \\
\text { exhibitions/conferences } \\
\text { Website }\end{array}$ \\
\hline
\end{tabular}

Note: (*) the joint marketing efforts between Hue - Da Nang - Quang Nam 
As can be seen from the table, the eight provinces in the South Central Coast region implement their destination marketing with a mix of individual and joint marketing activities. Clearly and consistently with the previous point, the eight provinces either organize or attend destination marketing activities individually more than jointly. However, it is important to see the simultaneous existence of two marketing approaches in all provinces and thus in the region as a whole.

The interviewees' responses also show that the decision-making of choosing either individual or joint destination marketing approach needs to be done for specific activities. Sometimes the decision is straightforward because of the nature of marketing activities. For example, Da Nang aims to develop MICE tourism as its typical type of tourism and thus Da Nang organizes MICE marketing activities individually. The city's TIPC representative said: "Marketing activities for MICE tourism are organized independently twice a year in the capital city of Ha Noi and the biggest city of Ho Chi Minh". Also, when provinces organize tourism events to celebrate their local festivals or host familiarization (Fam) trips to introduce their typical tourism products, they tend to market those activities individually. This notion was summarized by Quang Nam TIPC representative: “...there are some activities we need to do on our own...Quang Nam individually organizes local promotional events which occur in the province. Da Nang and Hue also have their own events." At other times, provinces face tensions in their decision-making process because both joint destination marketing and individual destination marketing have their own advantages and disadvantages. The trade-off between individual and joint marketing will be discussed in Chapter 6 together with their benefits and drawbacks as two influencing factors to be considered.

The provincial development contexts and stages also have impacts on destination marketing activities. Table 5.1 also shows differences in the nature of destination marketing activites done by two groups: the more tourismdeveloped provinces (Da Nang, Quang Nam, Khanh Hoa, Binh Thuan) and the less tourism-developed provinces (Quang Ngai, Binh Dinh, Phu Yen, Ninh Thuan). With more favourable contextual factors that have been discussed in 
Chapter Four, the four stronger provinces are more capable of organizing largescale tourism events and then invite other provinces to participate. This notion was emphasized by the ITDR representative:

...Destination marketing activities of the region are done mainly around the events organized in some provinces of the region, such as Quang Nam Heritage Festival, International Sea festival in Khanh Hoa, International Firework festival in Da Nang.

Conversely, weaker provinces have done more individual destination marketing activities which are also on a smaller scale. Four provinces - Quang Ngai, Binh Dinh, Phu Yen and Ninh Thuan- clearly focus more on organizing local tourism events and attending events in near-by provinces rather than marketing abroad. The representative of Phu Yen DCST said:

...When provinces in the region organize tourism-related events, we try to attend. We have not yet organized joint promotional activities abroad because there is a lack of budget... Provinces that are more developed in tourism proactively promote in foreign markets, meanwhile less-developed provinces can not have enough budget to promote abroad.

The tourism promotional activities of Ninh Thuan are perhaps most limited in terms of destination marketing activities. Its tourism representatives described the current tourism marketing situation of the province:

...The province hardly organizes any independent marketing activities, we just attend such events like promotion fairs at Ho Chi Minh, International Travel Expo Ho Chi Minh. In those events, Thuan came to see but not attend the fairs with its own booth. We do not have budget for these activities. Ninh Thuan mainly promotes tourism through press releases before cultural and sports activities organized in the province every year. (Ninh Thuan DCST)

...We are learning from other provinces and focusing on on-site promotion via fam trips, cultural festivals organized in Ninh Thuan and nearby provinces. This is due to our limited funding for promotional activities, especially for activities that occur in other places. (Ninh Thuan TIPC) 
The biggest event that Ninh Thuan attended was said to be the International Sea Tourism Fair organized in Nha Trang city (Khanh Hoa province) in June 2013 where, for the first time, they had their own booth to introduce Ninh Thuan tourism.

In terms of marketing tools that are commonly used in destination marketing activities, the eight South Central Coast provinces seem to have more commonality than differences. The most frequently-used marketing tools include: brochures, leaflets, tourist maps, short tourism movies/clips, images, television channels, newspapers, magazines, information centers, websites, and tourist support centers in some places.

\subsubsection{Provinces' official tourism websites: A tool for individual or joint destination marketing?}

World wide webs have become an increasingly important marketing tool for DMOs (Doolin, Burgess, \& Cooper, 2002; So \& Morrison, 2004). That is also true to DCSTs/TIPCs of South Central Coast provinces of Viet Nam. In the region, seven out of the eight provinces have developed their own websites specialized in providing tourism information. This section examines if TIPCs tourism websites are used more for individual marketing or joint marketing purposes and if there is any evidence of joint destination marketing activities found in these websites. Although several provinces have two official tourism websites designed by DCSTs and TIPCs, the websites of seven TIPCs were chosen for the content analysis of joint destination marketing. The reason for this is because TIPCs websites serve the purpose of providing information and promoting tourism activities.

Table 5.2 shows the findings from the content analysis conducted by checking each TIPC agaist seven criteria indicating evidence of joint marketing between provinces. Generally, in South Central Coast provinces, the TIPCs websites are mainly used for the purpose of marketing provinces individually. 
Table 5.2: Content analysis of Tourism Information and Promotion Centres websites

\begin{tabular}{|c|c|c|c|c|c|c|c|}
\hline \multirow[b]{2}{*}{ Criteria } & \multicolumn{7}{|c|}{ Official tourism websites used for content analysis } \\
\hline & DNTIPC & QNTIPC & BDTIPC & PYTIPC & KHTIPC & NTTIPC & BTTIPC \\
\hline $\begin{array}{l}\text { (1) Having links to tourism } \\
\text { websites of other provinces in } \\
\text { the region }\end{array}$ & $\sqrt{ }$ & $\sqrt{ }$ & $\sqrt{ }$ & $\sqrt{ }$ & $\sqrt{ }$ & $\sqrt{ }$ & $\sqrt{ }$ \\
\hline $\begin{array}{l}\text { (2) Having links to national } \\
\text { tourism websites }\end{array}$ & $\sqrt{ }$ & $\mathbf{x}$ & $\mathbf{x}$ & $\sqrt{ }$ & $\sqrt{ }$ & $\sqrt{ }$ & $\sqrt{ }$ \\
\hline $\begin{array}{l}\text { (3) Updating tourism events of } \\
\text { the whole region or of other } \\
\text { provinces in the region }\end{array}$ & $\sqrt{ }$ & $\mathbf{x}$ & $\mathbf{x}$ & $\sqrt{ }$ & $\mathbf{x}$ & $\sqrt{ }$ & $\mathbf{x}$ \\
\hline $\begin{array}{l}\text { (4) Updating news of joint } \\
\text { tourism activities between } \\
\text { provinces in the region }\end{array}$ & $\sqrt{ }$ & $\mathbf{x}$ & $\sqrt{ }$ & $\mathbf{x}$ & $\mathbf{x}$ & $\sqrt{ }$ & $\mathbf{x}$ \\
\hline $\begin{array}{l}\text { (5) Introducing tourism } \\
\text { products of other provinces in } \\
\text { the region }\end{array}$ & $\mathbf{x}$ & $\mathbf{x}$ & $\mathbf{x}$ & $\sqrt{ }$ & $\mathbf{x}$ & $\mathbf{x}$ & $\mathbf{x}$ \\
\hline $\begin{array}{l}\text { (6) Providing travel } \\
\text { information of the whole } \\
\text { region or other provinces in the } \\
\text { region (brochures/ } \\
\text { travel tips/ images/maps/ } \\
\text { suggestions) }\end{array}$ & $\mathbf{x}$ & $\begin{array}{l}\sqrt{ } \\
\text { (tourism } \\
\text { maps) }\end{array}$ & $\mathbf{x}$ & $\sqrt{ }$ & $\mathbf{x}$ & $\mathbf{x}$ & $\mathbf{x}$ \\
\hline $\begin{array}{l}\text { (7) Publicizing tourism-related } \\
\text { opportunities to other } \\
\text { provinces (job opportunities, } \\
\text { call for event participation) }\end{array}$ & $\sqrt{ }$ & $\mathbf{x}$ & $\mathbf{x}$ & $\sqrt{ }$ & $\mathbf{x}$ & $\mathbf{x}$ & $\sqrt{ }$ \\
\hline
\end{tabular}

Note:

DNTIPC: Da Nang Tourism Information and Promotion Center, www.danangtourism.gov.vn

QNTIPC: Quang Nam Tourism Information and Promotion Center, http://www.quangnamtourism.com.vn

BDTIPC: Binh Dinh Tourism Information and Promotion Center, http://dulichbinhdinh.com.vn

PYTIPC: Phu Yen Tourism Information and Promotion Center, http://www.phuyentourism.gov.vn

KHTIPC: Khanh Hoa Tourism Information and Promotion Center, http://www.nhatrang-travel.com

NTTIPC: Ninh Thuan Tourism Information and Promotion Center, http://www.ninhthuantourist.com

BTTIPC: Binh Thuan Tourism Information and Promotion Center, http://www.dulichbinhthuan.com.vn 
As can be seen, none of the provinces meet all criteria and except for the first two criteria, there are at least 4 out of 7 websites which do not meet the listed criteria for updating, sharing or exchanging joint tourism information with the region and its member provinces. The representative of Binh Dinh TIPC stated: "The on-line cooperation is now at the level of connecting websites through links." Despite having the links to tourism websites of other provinces, the TIPCs websites showed no consistency in terms of which websites the TIPCs websites should link with or in which format. The representative of Quang Nam TIPC touched on this notion in the interview:

... we connect with organizations which are also in tourism industry. We have not yet considered other criteria like website accessibility rate or similar markets. Now we just think that operating in the same industry, we should support each other.

Interestingly, unlike in traditional marketing activities, the weaker provinces of the region seemed to make more attempt to use websites effectively as a tool to market not only themselves but also the region as a whole through sharing and exchanging information. Table 5.2 indicated that Phu Yen TIPC website meets the most criteria (six out of seven listed criteria). In the interviews, the two tourism representatives of $\mathrm{Phu}$ Yen also emphasized the importance of marketing through its website:

... The tourism websites of provinces often have links to tourism websites of other provinces (links are attached through slogans or banners). Some provinces do this in reality, some not. Tourism in Phu Yen is still weak, so we want to do this to set up good example. (Phu Yen DCST)

... The cooperation agreement has been signed and we all can support each other. The online network is now very important to share information. The more information is shared, the more people know and the more effective tourism promotion will be. Now social media like facebook, Youtube are very popular, they are forms of sharing. This is a trend and if you are not willing to share, no one wants to share anything with you. (Phu Yen TIPC) 
Figure 5.1 shows a page in Phu Yen TIPC tourism homepage. This tour page introduces a joint tour between Phu Yen and Binh Dinh named "Tay Son Ghenh Rang - Da Dia cliffs".

\section{Figure 5.1: Tourism website of Phu Yen Tourism Information and Promotion Center}

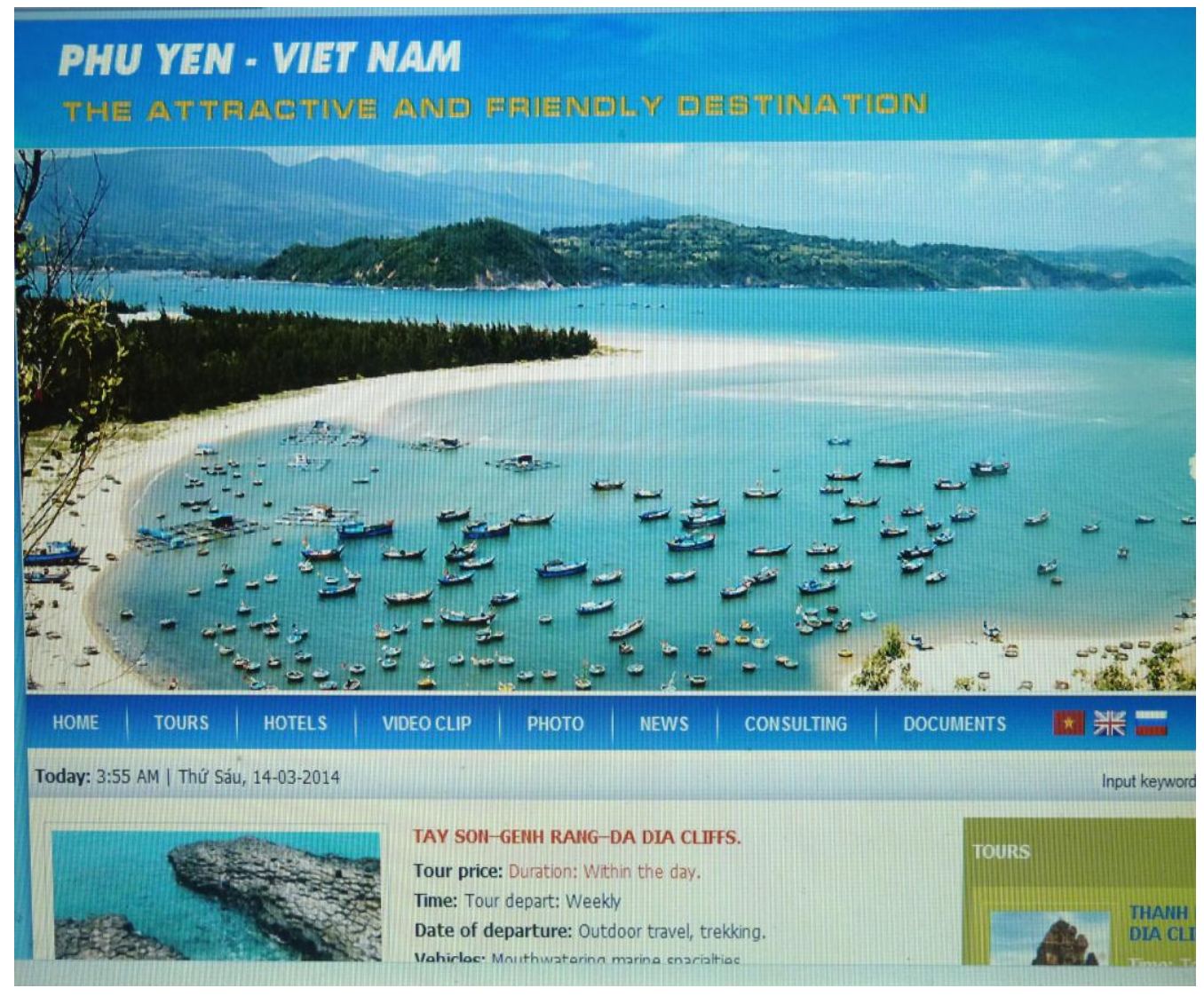

Source: Phu Yen TIPC's website (http://phuyentourism.gov.vn/)

Notably, Ninh Thuan TIPC website shows more evidence of joint marketing activities than websites of stronger provinces like Khanh Hoa or Binh Thuan. Similarly to Phu Yen, Ninh Thuan's representatives expressed:

Ninh Thuan's tourism website has the link with VNAT, which helps us to connect with other provinces as well as international destinations. (Ninh Thuan TIPC)

Information communication technology helps tourism to develop strongly. On-line newspapers become more popular than printed ones, tools like smart phones are very useful to tourists while 
travelling. Tourists very often check travel information on internet. Ninh Thuan now focuses on online marketing, all tourist information like hotel rooms, prices, images of attractions are posted on websites. (Ninh Thuan DCST)

\subsection{Joint destination marketing activities of the South Central Coast region}

\subsubsection{Perceptions versus practices of joint destination marketing}

Partnerships between organizations follow sequential stages (Gray, 1985; Selin $\&$ Chavez, 1995). These stages are differentiated from each other through the awareness and actions of stakeholders towards the common issue that they share. Therefore, this section explores the stage of joint destination marketing process that South Central Coast provinces are in by comparing how joint destination marketing is perceived and how it is currently conducted in the region.

The joint destination marketing of the South Central Coast region currently has the following patterns. First, joint destination marketing is perceived as a new and an increasingly common trend in the South Central Coast region. Some representatives simply said "this is a common trend", while some others connected with what they have observed in the past few years.

... This trend has appeared for about 2-3 years. The national tourism year used to be done for each province, for example the national tourism year of Thai Nguyen. However, in the past two years, the national tourism year is for the whole region although one province is chosen to be the main hosting place. (Phu Yen TIPC)

... In 2006, Hue, Da Nang and Quang Nam were the first provinces in Viet Nam to sign a cooperation agreement. Now this strategy has gradually become a trend and is applied in other provinces. This proves the strategy is suitable; however, all provinces are still in the learning process. (Quang Nam DCST)

The above quotes indicate the suitability of joint destination marketing as a destination marketing strategy given the fact that it has been practised in various regions in Viet Nam. Da Nang DCST representative stated: "Many cooperative arrangements have been established like the model of Hue - Quang 
Nam - Da Nang, Quang Ngai - Binh Dinh - Central Highland provinces, the Northwest, the Mekong Delta, Ho Chi Minh - Lam Dong - Binh Thuan, The Red River Delta...".

Second, according to the representatives, the region is now at the beginning stage of making joint efforts for regional destination marketing. Representatives illustrated this notion through their comments about the type of joint marketing activities, the main purposes of those joint efforts and the level of commitment. For example, ITDR representative stated: “...[South Central Coast provinces] just cooperate in events like conferences and meetings to share information, experiences and solutions. [They] do not have joint marketing programs yet". Similarly, the representative of Binh Thuan TIPC noted:

... Central Coast Cooperation is very recent. The secretaries of the Provincial Party Committee and Chairmen of Provincial People's Committee have signed the cooperation agreement in all areas. However, this is the commitment between leaders, there has not yet been the commitment in specific areas. The directors of DCSTs in the region have not yet gathered to discuss. They have just only come to conferences organized by the Regional Coordination Board. The joint marketing plan has not yet been developed.

In fact, the actual joint activities mentioned by most of interviewees include attending tourism meetings, conferences, fairs and exhibitions together; publishing joint marketing materials and making efforts to develop joint tourism products. These activities are mainly for sharing information, exchanging experiences and learning from each other, as noted in the following statement:

... The cooperation program's activities between provinces have just occurred in terms of sharing experiences. Specific localities that have big culture, sports or tourism events will invite other provinces and give some priorities for other provinces to attend such as free booths in the fairs... That is our current cooperation. (Binh Dinh DCST)

Although being positioned by the representatives at the beginning stage, joint destination marketing between South Central Coast provinces seems to fit the 
second phase of direction-setting in the three-phase model of the collaboration process suggested by Gray (1985):

....in the direction-setting phase, stakeholders articulate the values which guide the individual pursuits and begin to identify and appreciate a sense of common purpose.... One vehicle for directionsetting is the search conference in which participants engage in joint conceptualization of the desired future of the domain (p. 917)

These two features typical of the direction-setting phase can be seen in current joint efforts of the South Central Coast region. First, the common purpose has been identified by the ITDR representative: “... All provinces have same purposes of making tourists satisfied and tourists travel to multiple destinations, not one. So provinces need to shake hands to serve tourists better." Second, three joint tourism conferences of South Central Coast provinces have been organized by the Central Coastal Region Coordination Board.

In addition, current joint activities between South Central Coast provinces also match with actions/steps identified in the direction-setting stage in the work of Jamal and Getz (1995). For example, "collect and share information" and "organize subgroups if required" are named as two direction-setting actions by the authors and these are what are happening at the moment in the region.

The third characteristic of joint destination marketing in the region is being an emerging trend, joint destination marketing of South Central Coast provinces were perceived differently by interviewees. Some representatives claimed that the region has achieved initial successes. One representative considered the Central Coast Cooperation initiative as the first-time-ever achievement of the region: "...[the Central Coast Cooperation initiative is] the first time provincial leaders gather to discuss cooperation between nine provinces. Consequently, the Central Region Research and Development Fund has been formed."

Binh Dinh TIPC representative agreed that initial joint marketing efforts have made certain positive contributions to the increased number of tourists visiting the province: 
...After joint conferences and meetings between Central Coastal provinces, I think this cooperation started to have beginning effects. The most outstanding thing is that in this summer, there are tourists who visited Nha Trang who now come to Qui Nhon (Binh Dinh). This is the result of individual marketing of Binh Dinh, but also thanks to information-sharing between provinces

In contrast, a number of interviewees considered the same joint marketing efforts of the region as being weak and still limited. Cooperative activities between provinces were also acknowledged but limitations seem to outweight achievements:

... In general, cooperation between provinces is still weak. Cooperative activities are still more formalistic rather than having specific activities. The region lacks resources for joint marketing activities...There are some activities in which provinces share information; however, the region has not yet created a joint image. There are still overlapping tourism products in the region. (ITDR)

... The cooperation has been signed on paper, however, what has been done up till now is meetings and conferences. Actual activities of cooperation have not yet happened. (Phu Yen TIPC)

These quotes refer to the Central Coast Cooperation agreement signed by provinces' leaders of nine provinces, including eight South Central Coast provinces and one North Central Coast province - Thua Thien Hue (or Hue). Until now it is the only cooperation initiative that involves all eight provinces but it covers many aspects of socio-economic development of nine provinces, not just tourism.

As discussed above, the initiative was considered as a "first-time-ever" success by some representatives and as "on paper" commitment by others. However, it is normal for such a newly-formed initiative to be perceived in different ways. This notion was futher reinforced by a couple of representatives who stated:

... The current stage of joint destination marketing is mainly inspired by the geographical locations of all provinces in the region. It is also a suitable development at this moment....The cooperation 
has just been mentioned and discussed recently. It needs transitional steps. (Quang Nam DCST)

...Cooperation in destination marketing activities requires a procedure consisting of many stages. For example, at the first stage provinces together attend small activities. At the second stage they start conducting joint activities. It's important to have long-term strategy for joint marketing activities. (Hue TIPC)

These statements imply that destination marketing follows a developmental process and the joint destination marketing between South Central Coast provinces is now perceived to be at the right stage.

The final characteristic of the region's joint marketing is associated with cooperative behaviour and involvement levels of member provinces. More specifically, South Central Coast provinces currently seem to focus on promoting their own tourism images rather than actually making joint efforts to achieve common interests. This is shown clearly by the fact that provinces all have their individual tourism booths in tourism fairs/exhibitions, except for Quang Nam and Da Nang which have promoted their tourism in conjunction with Hue in a shared booth for some years. The representative of Phu Yen reflected the individualistic behaviour of most of the provinces in joint tourism events:

...In joint destination marketing activities, we set up booths in tourism fairs...there is often a program called "buyers and sellers". In our booths, we visualize Phu Yen's tourism potential via images, information of tourism products, specialties of Phu Yen. (Phu Yen TIPC)

Furthermore, some representatives mentioned that their provinces often attend tourism events organized by other localities in the region as a commitment to the cooperation agreement. One example is "...according to the cooperation agreement, a province in the region invites other provinces to participate in tourism events they organize". All these statements imply that currently provinces group together in certain tourism events under the cooperation agreement rather than proactively organizing these events together. 
The involvement level of provinces in joint activities also differs. More developed provinces have a reasonably higher level of involvement in joint activities, which is especially illustrated through regional tourism events they organize and invite other provinces to attend. The four more tourism-developed provinces periodically organize national and international tourism events and invite other provinces to attend. Quang Nam has the Heritage Festival, Khanh Hoa has International Sea festival, Da Nang has International Firework festival and Binh Thuan has international hot balloon festival. Also, the DCSTs/TIPCs of two strong localities - Da Nang and Khanh Hoa - have cooperated with the Central Region Coordination Board to organize two joint conferences that attracted representatives from all eight provinces to attend.

Conversely, the less developed provinces tend to only attend tourism events organized by the national tourism organizations and by stronger provinces, which was mentioned by representatives of Quang Ngai and Ninh Thuan DCSTs:

... Quang Ngai attend tourism fairs, exhibitions together with other provinces or attend culture sports and tourism events organized within and outside Quang Ngai.

... In the past few years, some provinces started organizing some national-level tourism events and they invite other provinces to attend. For example, Khanh Hoa organized the $1^{\text {st }}$ international sea festival and they invited many provinces throughout the country. Provinces like Ninh Thuan attend when receiving the invitation letter from the organizers and guiding letter from the Ministry of Culture, Sports and Tourism.

Representatives discussed the roles of their provinces in joint marketing activities, which indicates the participation level of the provinces. Da Nang and Quang Nam's tourism representatives confidently affirmed that their provinces have important roles in joint activities:

... Da Nang plays an active role to encourage and coordinate the cooperation. It can be said that $\mathrm{Da}$ Nang plays a pioneering role because the city has good infrastructure and many direct flights. (Da Nang TIPC) 
... In tourism cooperation of the central coast region, Quang Nam plays an important role. This can be explained by two main reasons. Firstly, Quang Nam has big potential to develop tourism. Secondly, Quang Nam has achieved positive results in recent years. These two conditions encourage Quang Nam to perform well in the regional cooperation. (Quang Nam DCST)

Meanwhile, less tourism-developed provinces play less important roles in facilitating joint activities. The representative of Binh Dinh DCST said the role depends on each province's capacity. The Phu Yen DCST representative shared this viewpoint: "I guess provinces in the region have similar roles, except for strong provinces who are confident to frequently host many tourism events and invite other provinces to attend." The event organizers have a coordinating role, while other provinces play cooperative roles by attending the events.

Also, provinces that participate in the events also have varied levels of involvement. For instance, some provinces may join in organizing supporting activities within the main events while some others may only assign representatives to come and attend the events:

...Binh Dinh has martial arts, Tuồng (Vietnamese classical opera) and bài chòi (a card game played in huts) which are suitable for the opening ceremony of tourism events, so we are invited to come and perform at some events. (Binh Dinh DCST)

... Ninh Thuan has just attended tourism conferences and fairs to learn from other provinces which have more experiences in developing tourism. (Ninh Thuan TIPC)

\subsubsection{Whole-region versus sub-region joint destination marketing}

In the South Central Coast region, it is more common for joint destination marketing to occur at a sub-regional scale than at the scale of the whole region. This means there are marketing activities conducted jointly by several provinces rather than by the region as a whole. Some frequently mentioned cooperative models include:

- Hue - Quang Nam - Da Nang;

- Quang Ngai - Binh Dinh - Gia Lai - Kon Tum - Phu Yen 
- $\quad$ Phu Yen - Khanh Hoa - Ninh Thuan - Binh Thuan - Lam Dong - Dak Lak

- Binh Thuan - Ho Chi Minh City - Lam Dong.

Figure 5.2: Sub-region destination marketing cooperative models

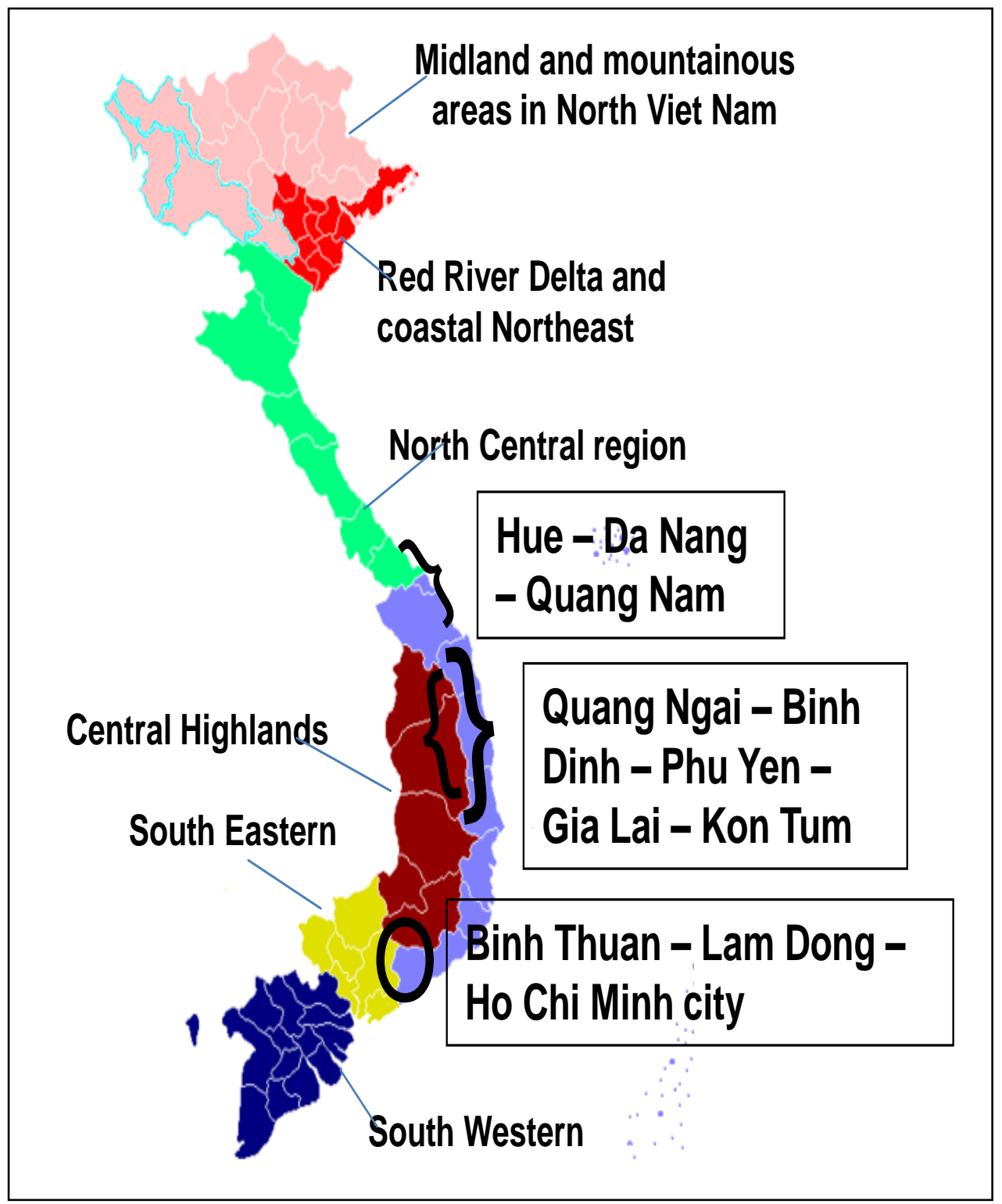

Interestingly, the sub-region cooperations as listed above contain provinces that belong to other regions. For example, Da Nang and Quang Nam have formed a close partnership with Hue - a city of the North Central Coast region. Similarly, Quang Ngai, Binh Dinh and Phu Yen cooperate with two provinces in the Central Highlands of Viet Nam, namely Gia Lai and Kon Tum. The southernmost province of the South Central Coast region - Binh Thuan - also 
has a closer partnership with Ho Chi Minh city and Lam Dong - another Central Highlands province.

The joint destination marketing with provinces outside the region raises the question about the effect of boundaries on the partnership formation. The ITDR representative responded to this question through the specific case of Hue and the cooperation between Hue, Quang Nam and Da Nang

... the boundary has no effect on destination marketing...According to the planning, Hue belongs to the North Central Coast. Cooperation is based on voluntarism and Hue is also a central coastal province. The Central Region is divided into North and South Central Coast because the region is too long. In addition, the Haivan pass between Hue and Da Nang makes the climate of the two region so different - the North is much colder in the winter. Also there should be a balance between regions. Hue is the leading province in the North Central Coast, so it plays an important role to make the North Central Coast region reasonably balanced in the comparison with other regions.

This statement literally means belonging to different regions has no effect on tourism partnership formation. And it implies that belonging to the same region is not a decisive factor in choosing partners and arranging tourism cooperation. As can be seen, this is the case of South Central Coast provinces.

Of the current sub-group cooperative models in the region, cooperation between Hue - Da Nang - Quang Nam was the first to be established and seems to be the most comprehensive as well. This section examines this model in depth in terms of its establishment, its operational mechanism, the joint activities, and the reasons explaining why joint marketing activities are more common and effective in these provinces than in the region as a whole.

The three provinces formed the tourism cooperation initiative in 2006 but this partnership derived from the World Heritage Road initiative started in 2003. This project runs through three provinces and connect three UNESCOdesignated World Heritage sites - Hoi An ancient town, My Son Santuary and the imperial city of Hue. Quang Nam TIPC representative stated: “...now 
although this project has stopped, the cooperation between these three provinces is still maintained. The joint destination marketing between three provinces is still implemented on an annual basis."

In terms of implementing the cooperation initiative, the three provinces take turns at being the group leader. In the year of being the group leader "... that province plays the main role, gets ideas from the other two provinces and then synthesizes these into a joint program. The budget for a joint marketing activity is divided into three". These three provinces have their joint marketing programs which are planned annually in September, then presented and approved in October. They are actively involved in preparing to attend/organize tourism events together. The tourism images of the three provinces are promoted together even though one province may not able to join. The following statements futher illustrate the nature and extent of joint marketing activities co-organized by the three provinces.

...The joint destination marketing activities are implemented in the way that the three provinces co-organize activities. The three provinces all contribute to the marketing budgets, set up only one booth in tourism fairs, co-organize road shows. (Quang Nam TIPC)

...In the 3-province cooperation, Da Nang always go together with the other two provinces even to markets which are not the focus of the city. In programs that Da Nang invite guests to visit the city, Da Nang also takes them to Hue and Quang Nam. (Da Nang DCST)

These three provinces are also involved in the process of publishing joint marketing materials. Hue TIPC representative described the way the three provinces prepare and co-publish the annual tourism event calendars:

...We often have the list of all tourism events throughout the year, then the three provinces discuss on which events they can attend...the group leader has the role to accomplish the final program, then send the plan to the three provinces for discussion and suggestion.

While attending tourism events in other places, the three provinces make efforts to promote their joint slogan - "Three localities - One destination". Annual activities that the three provinces conduct jointly include: 
- Attending promotion activities within Viet Nam and abroad (Leisure tourism trade fair in Russia, KOTFA world travel fair in Korea, International Travel Expo in Ho Chi Minh, Vietnam International Travel Mart in Ha Noi)

- Publishing joint marketing materials (maps, leaflets, brochures, tourism films)

- Developing joint tourism promotion clips, movies

- Hosting Fam trips

- Exchanging the managerial experiences between provinces

- Organizing tourism events at different time

- Organizing joint inspection of tourism activities

Joint activities are also shown in tourism websites of the three provinces. According to Quang Nam tourism's representative, “...the main function of websites is for exchanging information. It's important to update and diversify tourism information by posting each other's information...For example, Quang Nam festivals are introduced on websites of Hue and Da Nang...”. Figure 5.3 shows a tourism event of Quang Nam (International Choir competition) posted on Da Nang TIPC website.

Figure 5.3:Quang Nam's tourism event on Da Nang TIPC's website

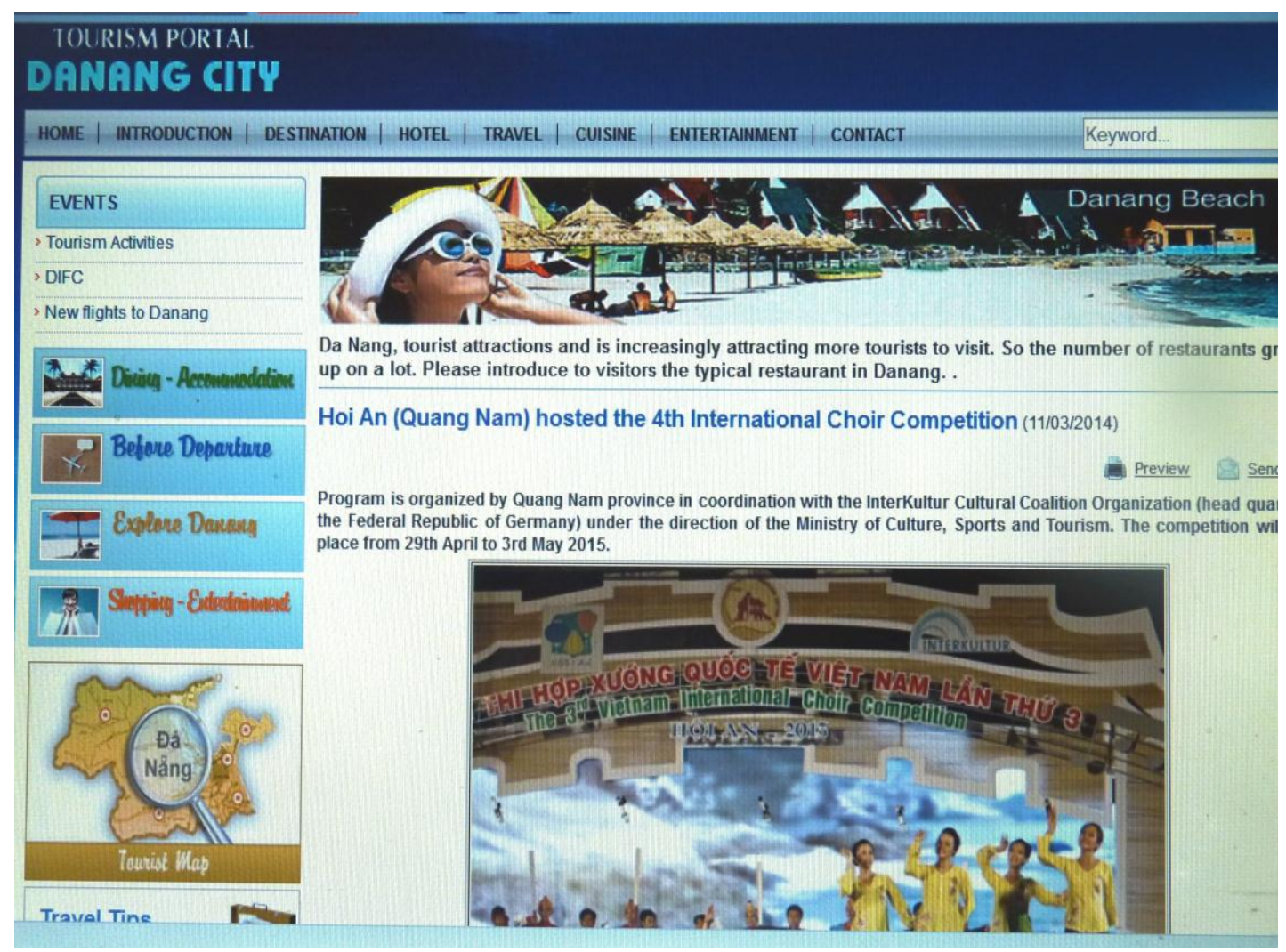

Source: Da Nang TIPC website (http://www.danangtourism.gov.vn/) 
It can be seen that joint marketing activities between these three provinces are more diverse and comprehensive than joint actions for the region as a whole. This is due to several reasons. Firstly, the three provinces have formed and maintained tourism cooperative activities for a longer period of time. Secondly, "Hue, Da Nang and Quang Nam belong to one zone for tourism development. Da Nang is the gate to the region, Hue and Quang Nam are two destinations of World Heritage". Da Nang has good tourism infrastructure, meanwhile Hue and Quang Nam are famous for cultural heritage. This different but complementary tourism potential obviously supports cooperation. Furthermore, "Da Nang and Quang Nam used to be one province, therefore it's convenient to implement cooperative plans". Thirdly, joint activities between three provinces have received strong support from their leadership. Tourism representatives of these provinces acknowledge leadership support as a key success factor of cooperative activities:

...Leaders of the provinces and tourism industry in three provinces have supported a lot of the three-province cooperation. That's why we can implement the cooperation for such a long time. (Quang Nam TIPC)

...[the success factors are] the reasonably consistent awareness of leaders, DCSTs and enterprise communities in the three provinces. That is why in our annual budget, we set a certain amount for joint destination marketing. (Da Nang DCST)

Fourth, the "active and enthusiastic involvement of tourism enterprises" partly explains why joint activities between the three provinces are more comprehensive than the ones between eight provinces. Tourism enterprises in these three provinces even motivate state tourism organizations to have favourable policies for cooperation, as stated by Quang Nam DCST representative: "there are many tour companies running businesses in these three provinces. And when enterprises have a demand for cooperation, the public sector has to support it".

From the analysis above, it can be seen clearly that joint marketing activities are more commonly conducted between small groups comprising three to five 
provinces that do not necessarily come from the same region. The most frequently practised joint marketing activities in sub-group cooperative models are still conferences and Fam trips in order to exchange information, experiences and attract each other's markets. The only exception found is the cooperation between Hue - Da Nang - Quang Nam which actually coorganizes their joint actions based on their annual joint marketing programs.

\subsection{Conclusion}

This chapter has presented the nature and extent to which joint destination marketing activities occur between South Central Coast provinces. The findings show that although tourism representative express a reasonably high awareness of joint marketing's benefits, South Central Coast provinces currently practise destination marketing individually more than jointly. Being an emerging phenomenon, joint destination marketing is characterized with initial achievements (joint conferences, Fam trips, joint brochures), a low level of assertive involvement and higher priority for self-interests rather than common ones. More cohesive joint marketing activities occur between small groups of provinces which also include provinces from other regions. In sum, the current picture of joint destination marketing of the region has been drawn, however, the whys of such situation remain unclear. The following chapter investigates factors that influence the joint destination marketing decision-making. 


\section{Chapter 6: JOINT DESTINATION MARKETING: FACTORS INFLUENCING}

\subsection{Introduction}

The previous chapter revealved the nature and extent of joint destination marketing in the region through current patterns of marketing activities. This chapter analyzes factors that account for the phenomenon, including preconditions facilitating joint destination marketing activities, benefits and drawbacks perceived from joint activities and motives for and barriers to implementing joint marketing activities in the context of the South Central Coast region. The chapter then ends by concluding which factors were perceived to be the most important in making decisions on destination marketing partnership formation and joint destination marketing practice.

\subsection{Conditions favoring joint destination marketing in the region}

Drawing from the literature about the preconditions of cooperative destination marketing (Wang \& Fesenmaier, 2007), representatives were asked about factors that favor joint destination marketing between provinces in the region. The factors mentioned by the interviewees were classified into two groups: factors from the internal environment of South Central Coast provinces and factors from the provinces' external environment. The former includes three factors: (1) provinces share similarities and differences in their tourism potential; (2) provinces are connected by the transportation system and (3) provinces receive leadership support. The latter group include the multidestination travel demand of tourists and fierce competition in the marketplace.

Chapter Four showed that South Central Coast provinces have geographical and topographical similarities and these features are commonly mentioned again in this chapter as a condition for the DCSTs/TIPCs of eight provinces to work together. Quite a few representatives specifically identified that their similar tourism potential of coastlines and heritage is the catalyst for cooperative 
efforts because they all share the common interest of developing coastal and cultural tourism based on their potential. The representative of Binh Thuan TIPC said: "All provinces have similar natural conditions. Central Coast means provinces along the coastline in the Central region. So they should gather to conduct joint destination marketing". The representative of the national tourism organization - ITDR- also held the same view: “...the desire for cooperation is inevitable. Many provinces have things in common, so they want to pool resources together, which is better than doing it individually".

Furthermore, the condition of sharing certain similarities was emphasized by DCSTs/TIPCs representatives as an important criteria in selecting partners for tourism events. The following statements clarify this point:

...Khanh Hoa just organized the International Sea Travel Expo and Khanh Hoa invited Quang Nam because Quang Nam is one of the provinces that have potential and have develped coastal tourism products. (Quang Nam TIPC)

... Quang Ngai chooses partners based on similar natural, cultural and historical resources to be stronger in order to develop transregion tourism products such as eco-tourism or sea island tourism products. The province also chooses partners that have geographical similarities like provinces in the South Central Coast region or provinces along the East and West Economic Corridor to develop caravan tours. (Quang Ngai DCST)

Interestingly, in the case of the South Central Coast provinces, both commonalities and differences contribute to the cooperation between provinces.

Binh Dinh TIPC's representative pointed this notion out:

...One more special feature of the Central Region is that each province has its own culture. This is a very favourable condition for joint marketing activities between provinces. This feature makes it easier to develop trans-region products. If these provinces all have beaches and the same culture, it is very hard to cooperate.

Also according to Da Nang DCST's representative, cultural differences of provinces were actually perceived positively because they offer the potential to develop regional tourism products: 
... The local culture is very important because tourists are especially interested in the culture of each destination. For example, the accent, the lifestyle, the art of all provinces are different. The food is also different. Hue food is a little bit sweet and spicy; Da Nang food is a little bit saltier. In common things, there are still differences. So we have to exploit these cultural differences in order to express typical features of each locality. (Da Nang DCST)

With similar and distinctive tourism potential, clearly the South Central Coast provinces can develop common but complementary tourism products which are very attractive to today's tourists. Based on Da Nang's experience in developing complementary products with Hue and Quang Nam, Da Nang DCST representative believed all provinces in the region can develop and benefit each other in the same way:

...Tourists visit Hue, they have tranquil experiences. Tourists visit Da Nang, they have dynamic experiences. Tourists visit Hoi An, they have a memory of the ancient time. When tourists travel towards the South (Binh Dinh, Ninh Thuan, Binh Thuan), the Champa culture become clearer. Thus coming to these places, tourists can experience the living Champa culture.

Transportation connections between localities are another important condition favouring the implementation of joint destination marketing activities. The representative of Phu Yen DCST said that the region is well connected by the Highway No.1 and all provinces also have "systems of rivers, lakes and bays". Another representative agreed with the important role of transportation in connecting provinces and thus in facilitating destination partnerships:

...Transportation is another thing that requires provinces in the region to cooperate. Especially for air transport, only Da Nang, Hue, Nha Trang have big airport infrastructure which are able to welcome international flights. Therefore, other provinces like Quang Ngai, Binh Dinh, Phu Yen need to cooperate with those provinces to have bigger and further gateways to get tourists. (Binh Dinh TIPC)

Although this statement indicates that some provinces have better transportation infrastructure than others, the feature creates the condition for provinces to exploit tourism resources more efficiently by working jointly rather than individually. 
At the same time, a lack of convenient transportation system does discourage cooperative activities. Binh Dinh TIPC representative actually mention distance with unconvenient transportation as a challenge:

... The second challenge is the distance between Binh Dinh and important destinations of the region like Da Nang, Hue, Hoi An, Nha Trang. For example, the distance between Binh Dinh and Da Nang is $300 \mathrm{~km}$ which takes about 5-6 hours of travelling by bus or by car in the current transportation conditions. Tourists normally donot want to visit destinations which require them to spend a lot of time and money on means of transportation, especially in the condition that there are no must-see tourism products between those destinations. (Binh Dinh TIPC)

In the South Central Coast region, proximity and convenient transportation are actually decisive factors for destination partnership formation. As can be seen from the sub-region cooperative models analyzed in chapter Five, provinces in the region now have closer partnerships with their nearby provinces although some of them belong to other regions. For example, Da Nang shares borders with Hue and Quang Nam and "the distance from Da Nang to World Heritage Sites is very near $-30 \mathrm{~km}$ to Hoian, $60 \mathrm{~km}$ to My Son and 100km to Hue". These conditions make it obvious that the three provinces should definitely cooperate although Hue is not in the same region.

...Tourists visit Da Nang but then also visit the other two provinces; they hardly only stay in Da Nang. And visiting the other two places, tourists still need to visit or stop at Da Nang because we have international airport and seaport. (Da Nang DCST)

Ninh Thuan entered the partnership with Lam Dong- a province that belongs to the Central Highlands region- with a similar reason:

...Ninh Thuan cooperates with Lam Dong because we are close. The road between two cities - Ninh Thuan and Da Lat- is being improved. After it is finished, it will take only about 2 hours to travel from Ninh Thuan to Da Lat. So tourists staying in Ninh Thuan can visit Da Lat within a day. (Ninh Thuan TIPC) 
Provinces that are close to each other tend to focus in particular on improving the transportation between them. Consequently, they have a better transportation system, which further enhances their cooperative relationship and joint activities. This situation occurs between Ninh Thuan and Lam Dong, as reflected in the above statement. A similar thing happens between three neighbouring provinces of Hue, Da Nang, Quang Nam. Since its opening in 2005, the longest Southeast Asia tunnel - Hai Van tunnel - shortens the distance between Hue and Da Nang by $20 \mathrm{~km}$ and thus reduces the travelling time by 30 minutes to one hour. According to Da Nang DCST's representative, the other two tunnels through Phu Tuong and Phu Gia passes are being constructed. When they are finished, the travelling time between Hue and Da Nang will be reduced from three hours to only one hour.

Some representatives whose provinces do not conduct joint activities with certain provinces in the region also identified distance and inconvenient transportation as their reasons. Binh Thuan TIPC representative said: "There are activities where Binh Thuan cooperates with Ho Chi Minh city instead of Da Nang because Da Nang is further...”. Another representative supported the view: "...with joint marketing, the further the distance, the less cooperative relationships are established."

The final internal factor favouring joint destination marketing between South Central Coastal provinces is the support from their provinces' leaders. This notion was acknowledged by tourism representatives of the eight provinces, especially when they mentioned the Central Coast initiative between the nine provinces (eight South Central Coast provinces and Hue province in the North Central Coast). One representative noted:

...Leaders of nine provinces in the central coast region signed the commitment to cooperate, which proves the determination and consistent management of provinces. In this way, resources will be concentrated for the planned joint activities. (Quang Nam DCST)

Clearly, the initiative of Central Coast Cooperation could not have been possible without the support and commitment between the provinces' leaders. 
Leadership support is the prerequisite for executing joint marketing activities in the case of South Central Coast provinces and probably in the case of Viet Nam as a whole. This fact was reflected in one comment about the administrative system at provincial level in Viet Nam: "everything we do, we need to ask for the agreement and the budget approval from Provincial People Commitees. So support from leadership level of each province is fundamental".

There are also several conditions favouring joint destination marketing that come from the external environment. One is the multi-destination travel demand of tourists which was commonly agreed among the interviewees as a "push factor" for DCSTs/TIPCs of South Central Coast provinces to work together. This notion was represented by the following comments:

...This is because no one is interested in an individual destination. When visiting a country, tourists want to understand and experience destinations in a large area. (Quang Nam TIPC)

...tourists have increasing demand for diverse products. If we work individually, it is clear that the province cannot meet demands of today tourists. (Binh Dinh TIPC)

Deriving from tourists' demand, big tour operators in origin markets were said to be more interested in joint marketing done by multiple provinces. This partly explains why joint marketing is a better solution.

Another external condition encouraging provinces to cooperate is competition. The representative of Quang Ngai DCST explained this: "the fierce competition for tourist markets requires each locality not only to improve the quality of tourist activities but also to "shake hands", especially in exchanging information and enhancing the financial capability." Competition favors provinces working in partnership in order to pool resources together and better leverage them to achieve common goals.

In short, the South Central Coast provinces share several preconditions from both the internal and external environment. Joint marketing activities between provinces are conditioned by similar tourism resources, transportation connections, leadership support and commitment. External forces pushing 
South Central Coast provinces to conduct destination marketing together include tourists' needs to travel to multiple destinations and the increasing competition in the market.

\subsection{Benefits and drawbacks perceived from joint destination marketing}

Representatives of South Central Coast provinces are highly aware of the benefits their provinces receive from joint destination marketing activities. The benefits of joint activities mentioned in the interviews can be classified into three categories - benefits for participating provinces, benefits for the whole region and benefits for tourists.

Cost saving and creating a stronger budget for promotional activities are among the first benefits that joint marketing activities were perceived to offer participating provinces directly. Binh Dinh DCST representative said: “...Clearly, when provinces jointly make tourism brochures or tourism maps or jointly introduce tours, the costs are reduced for each province." Specifically, Hue, Quang Nam, Da Nang have implemented joint marketing for about ten years and thus have experienced this cost-effectiveness for themselves. Da Nantg DCST representative affirmed: "in short, we tend to cooperate in activities that we cannot afford to conduct individually". Khanh Hoa TIPC representative also stated: "joint destination marketing become increasinly popular because it helps to save costs, enhance the relationships as well as increase the tourist arrivals for the region". According to many representatives, joint destination marketing activities are more cost-effective as well as more efficient than individual marketing activities.

Joint marketing provides not just cost savings but also opportunities for provinces to support each other. This can be done through exchanging tourism information and experiences. Phu Yen TIPC representative explained through an example: 
...The advantages of cooperation are too clear. By carrying out jointly, we can support each other in promoting tourism products. For example, tourists visiting Binh Dinh, they can know information about Rapids of Stone Plates or Xuan Dai Bay in Phu Yen and book daily tours to visit these destinations in Phu Yen.

Through supporting activities, provinces can enhance their mutual understandings and thus reduce competitive behaviour. This notion was expressed in the following statement:

...the cooperation helps to limit competition because cooperation occurs with the appropriate allocation of resources between provinces. The cooperation encourages discussion, sharing and sympathy between provinces. (Quang Nam DCST)

...Every province has strengths and weaknesses, so by doing marketing jointly we can support each other better. (Ninh Thuan DCST)

In other words, joint activities enable provinces who are stronger at certain aspects of marketing or have more experiences in accessing certain markets to share experiences with other provinces. For example, “...Da Nang has experiences in promoting in the Thailand market, Da Nang can support other provinces. Or Nha Trang often promotes in the Russia market, Nha Trang can support Da Nang or go together so that we can make promotional campaigns more effective." (Da Nang DCST)

Interestingly, the support from joint marketing activities is not just one way from more tourism-developed provinces to less tourism-developed provinces. More developed provinces can benefit from sharing tourists and developing new products that bring tourists to various places in the region. Khanh Hoa TIPC's representative said: “...currently there are too many Russian tourists in Khanh Hoa, through cooperation Khanh Hoa will share Russian tourists to Phu Yen, Binh Dinh." Another representative explained how joint destination marketing can benefit overloaded destinations:

...some famous destinations like Da Nang, Nha Trang, Binh Thuan are overloaded in high seasons, which may lead to the unsustainable development. So cooperation also helps to reduce the pressure for 
some places by sharing tourists to other provinces. (Binh Dinh TIPC)

With joint marketing activities, South Central Coastal provinces clearly have more opportunities to diversify products, avoid duplicated ones and develop trans-region tourism products to the whole region. Khanh Hoa TIPC representative mentioned the connection between creativity and cooperation in tourism development: "If done individually, programmes lack creativity because there is no participation from other provinces. For example, Khanh hoa has beaches but cannot have as good "mực một nắng" (sun dried squid) as Phan Thiet (Binh Thuan)." Furthermore, by combining to develop multi-destination tour itineraries, the region can prolong the average stay of tourists. Binh Dinh TIPC's representative said: "Tourists can stay 10 days but they may leave after 3 days staying in only one place. If we want to lengthen tourists' stay, we have to cooperate."

Cooperation between DCSTs/TIPCs was also generally considered as a tool to better manage tourism activities in the provinces. One representative noted:

...DCSTs aim to cooperate so that they have better control or management of tourism activities. For example, when one province organizes tourism events, the prices of tourism in that place often increase. With cooperation, the organizers need to guarantee that the prices for their partners remain stable. (Binh Dinh DCST)

Provincial representatives also discussed quite a few benefits that joint destination marketing activities bring about for the whole region, not just for their provinces. As mentioned in one statement before, cooperation helps to reduce competition through more discussion and mutual understanding between provinces. As a result, the whole region can concentrate resources and "develop a regional tourism brand, avoid the overlap in tourism product development and create competitive strengths compared with other regions" (Quang Ngai DCST). In this way, the tourism image of the region is improved and the relationships among provinces are enhanced. Most importantly, joint destination marketing enables the region to attract more tourists at the same time with satisfying them: "...More cooperation creates the product chains, which enhances the 
professionalism and satisfies tourists' demand. Consequently, this brings more tourists to all participating provinces." (Quang Nam DCST)

The third group of joint destination marketing benefits is for tourists whose satisfaction was widely acknowledged as the common purpose of the tourism industry of South Central Coast provinces. Practising marketing activities jointly helps provinces to reach this goal in a number of ways, including providing tourists with value-added products and diverse experiences. Several representatives stated:

.. When conducting joint destination marketing activities, the value of tourism products has been enhanced. (Da Nang TIPC)

... we can focus on our strengths (through promoting our typical features) and can make the whole package more attractive with diverse products from different provinces. If we promote our heritages individually, tourists may not like it. But while doing it jointly with one dynamic Da Nang and one tranquil Hue; we clearly have more diverse products. (Quang Nam TIPC)

... it's convenient to transfer tourists and it's easy for tour operators to develop tours. (Phu Yen TIPC)

Besides, the cooperation among provinces makes multiple destinations of the region more tourist-friendly. Being partners, provinces can help each other in introducing destinations to tourists. At the moment, tourists tend to visit more well-known places and this is partly due to the fact that tourism enterprises have not yet cooperated. One representatives explained the situation:

...Tourism facts and figures show that tourists do not stay long in the region and often stay in one destination and then leave. The reason is because international tour operators only take tourists to specific destinations as the result of not knowing about cooperating destinations. (Ninh Thuan DCST)

Binh Dinh TIPC representative gave one example illustrating how lack of cooperation can affect tourists' benefits: 
...tourists visit Nha Trang (Khanh Hoa) but they want to discover other parts of the region. If tourism enterprises in Nha Trang are not determined to cooperate with enterprises in Binh Dinh, tourists will not visit Champa temples and the martial-art villages of Binh Dinh.

Clearly, these statements emphasize the importance of cooperation, especially between tour operators, in marketing new destinations of the region to tourists.

Despite many benefits, drawbacks of joint destination marketing were also well acknowledged by the tourism representatives. The interviewees were asked to describe their experiences of conducting destination marketing jointly versus individually. The reponses pointed out that both joint destination marketing and individual destination marketing have benefits and drawbacks and thus provinces face tensions in their decision-making process. For instance, attending tourism fairs jointly is more cost-effective but less flexible for participating provinces.

...If we attend a tourism exhibition individually, a province can only afford a 9 meter booth; meanwhile in Vietnam International Travel Mart in Hanoi three provinces had the 36 meter booth. We both can share the costs and have a bigger space, which is clearly better. (Hue TIPC)

... we are unable to be active because we have to ask for opinions from each other. (Quang Nam TIPC)

Similarly, regarding joint efforts to develop and market trans-region tourism products, Phu Yen DCST representative pointed out: “...joint marketing activities create stronger promotion effects, regional tourism products can attract more tourists, especially international markets". However, at the same time, that also means provinces probably lose the opportunity to enjoy benefits of individual destination marketing activities, including "to be able to target their main markets" or "to have lots of freedom to choose the content to promote".

Another example is that provinces can support each other in promoting tourism products with joint marketing but their own products and brand name may 
receive less attention. The trade-offs between individual and joint destination marketing were actually clearly described by a number of interviewees:

... Individual marketing has advantages to make tourists pay attention to local tourism products. But it does not meet the tourists' requirement for product diversity. For example, Binh Dinh does not have entertainment areas, when tourists ask; we have no such products to introduce. (Binh Dinh TIPC)

... The advantages of individual marketing activities are being able to introduce the destination images and promote the tourism brand and products of the province in a detailed and adequate way. However the disadvantage is not being able to cooperate with other provinces to develop the trans-region tourism products and to prosper the holistic strengths of the region to compete with other regions. (Quang Ngai DCST)

...with individual activities, we do not share time and space with other provinces. But too much information can also become a disadvantage where tourists feel confused and thus not pay attention. The cost is high. The attractiveness is lower. (Quang Nam TIPC)

As indicated in the above statements, tourism representatives of provinces took the individual and joint marketing approaches into considerations by balancing their benefits and drawbacks. And the ways in which provinces view and weight the pros and cons of individual and joint destination marketing activities differ. Consequently, their decisions are different. For example, within the three provinces of Da Nang, Hue, and Quang Nam, the effectiveness resulting from making joint efforts to market their tourism products and destinations was felt to outweigh the drawbacks. However, this may not be the case with Khanh Hoa and Binh Thuan who decided to organize both large-scale domestic and international tourism fairs on their own.

Also, the trade-off between individual and joint destination marketing activities is made for specific activities. For example, in tourism fairs organized in Russia, Hue decided not to join Da Nang and Quang Nam because Russia is not Hue's target market. In this case, Hue perceived too little value from marketing activities in Russian market to actually make joint efforts. 
This section discussed the benefits and drawbacks of joint destination marketing and the associated tensions between them. Investigating the benefits and drawbacks of joint destination marketing sheds some light on understanding the decision-making process in which joint marketing activities occur. The chapter continues with the examination of other influencing factors of joint destination marketing, including motives, barriers and decision-making factors.

\subsection{Motives for joint destination marketing to South Central Coast provinces}

Motives reflect the benefits that tourism organizations seek when entering certain partnerships (Wang \& Fesenmaier, 2007). Some motives of joint destination marketing perceived by South Central Coast provinces' representatives derived from recognizing the benefits of collective actions. For instance, provinces recognize that joint destination marketing activities are less costly, so they are motivated to join to save costs. Similarly, provinces are aware of the trend that tourists want to visit multiple destinations and have different experiences during their trips, so they are motivated to work together.

However, it is also common that provinces have different motives for conducting joint destination marketing. One example is Da Nang city. Being the biggest city in Central Viet Nam, Da Nang aims to meet the goal that the Central Government has identified to become the socio-economic centre of the central region of Viet Nam. This is clearly one motive for the city to coordinate all provinces in the region, as shown in the following statement.

...Da Nang is the pioneer in both 3-province cooperation and 9province cooperation. The Central Government has identified Da Nang as the socio-economic and motivational centre to develop the economy of the Central region. With that role, Da Nang has to make great efforts all the time and pioneer in facilitating cooperative activities. (Da Nang DCST)

When provinces aim to attract certain markets, they also tend have more motivation to work together. Hue, Da Nang and Quang Nam are the only three 
provinces that really co-organize their joint marketing activities, which can be done because they share similar tourist markets. Interviewees' responses show that the three provinces agree to attract domestic tourists from Ha Noi and Ho Chi Minh city. For the international markets, they aim to attract tourists who are interested in culture, heritage and beach tourism such as retired tourists from European countries. Other provinces, including Quang Ngai, Binh Dinh, Phu Yen also have the same target markets which are tourists from Central Highlands provinces and nearby markets like Laos and Thailand. That is one reason motivating them to cooperate with each other and with Gia Lai and Kon Tum in the Central Highlands region.

Next, provinces are motivated to cooperate if they can clearly perceive the mutual benefits. The cooperation between Binh Thuan, Ho Chi Minh city and Lam Dong is a good example to illustrate this notion. The representative of Binh Thuan tourism explained:

... Binh Thuan's cooperation with Ho Chi Minh and Lam Dong has been discussed and implemented since 2007. This cooperation is the result of the interdependence of the three provinces. Binh Thuan needs to attract international tourists and investors, many of them come from Ho Chi Minh city. Ho Chi Minh city also needs beaches to diversify their tourism products. Binh Thuan is the beach city, so it needs a highland city with cool climate like Lam Dong.

Similarly, Binh Dinh cooperates with Central Highlands provinces of Gia Lai and Kon Tum in order to exchange markets and mutually benefit each other.

...Clearly, Central Highlands provinces do not have beaches, tourists in those provinces want to go to the beaches. Tourists in Binh Dinh are also attracted by the typical culture of Central Highlands like Gongs culture and forests. (Binh Dinh TIPC)

So coperative activities are normally formed and maintained between provinces that can benefit each other to a certain extent. For example, Hue tourism's representative commented “...Da Nang, Quang Nam and Hue cooperate when they see cooperation is the right direction...". His counterpart in Quang Nam tourism shared similar thoughts: "the cooperation between Quang Nam and Quang Ngai is not as effective as the cooperation with Hue and Da Nang”. 
From the above examples, it seems that mutual benefits are considered as the motive for joint destination marketing more by strong provinces than the weaker ones. Weaker provinces, on the other hand, are motivated to cooperate in order to be supported by stronger partners. This motive was clearly seen by both groups of provinces as follows:

...Binh Thuan is not capable of organizing marketing activities alone. Meanwhile Ho Chi Minh city has had much experience in attracting tourists, Binh Thuan will benefit when joining with Ho Chi Minh, especially for promotional activities abroad. (Binh Thuan TIPC)

...Everything is done because of the objectives and benefits for each province. Some provinces in the region have recently focussed on developing tourism. Those provinces have not been known much, so they cannot do effective marketing if they do individually. And even if tourists know, normally they do not come to visit that place alone. For example, Japanese tourists may visit Hue, Danang, Hoi An and Quang Ngai. They normally do not visit only Quang Ngai, except for business purposes. So those provinces have a demand for cooperation. (Quang Nam TIPC)

Another motive that also has a very important role in joint marketing is the compatibility of tourist destinations and products. The Da Nang representative mentioned that their cooperation with Hue and Quang Nam depends on ompatible tourism products. The Da Nang tourism representative also suggested South Central Coast provinces should provide tourists with beach and cultural experiences with differences:

... Each province has to find a balance in developing new products in order to avoid repeated products. For example we can build golf courses in Phu Yen, while Binh Dinh chooses another type of tourism product to invest in, like casino. (Da Nang DCST)

As can be seen from the above analysis, South Central Coast provinces are not only aware of joint destination marketing benefits but they also have practical reasons that motivate them to implement marketing activities jointly. 


\subsection{Barriers to implementing joint destination marketing}

Despite preconditions, benefits and motives, the implementation of joint destination marketing is currently hindered because of many barriers. This section discusses barriers that provinces face in doing destination marketing jointly. The barriers are classified into three groups: resource-based barriers, administrative/managerial barriers and socio-cultural barriers.

The resource-based barriers refer to all inhibitors related to certain resources which are important in carrying out joint marketing activities. Financial barriers were amongst the first to be mentioned. The representative of Ninh Thuan DCST stated: “...the budget for promotional activities for the whole nation is limited, let alone for each province. Compared with countries like Singapore, Malaysia and Thailand, we spend too little for tourism promotional activities." His colleague in Ninh Thuan TIPC also claimed their limited funding as the reason explaining why the province mainly promote through cultural events organized in Ninh Thuan or nearby provinces.

Another financial barrier is the inability of provinces to provide equal financial contributions to joint marketing activities. A number of representatives showed their concern about this issue.

...the marketing budget of each province is not equal. Binh Dinh have 1 billion VND, your province has three billion, the other has 5 billion for example. So when doing joint marketing, Binh Dinh cannot meet the required budget. How would the joint destination marketing be done between these three provinces? (Binh Dinh DCST)

...Ho Chi Minh spends $\$ 100$ for the cooperation, Binh Thuan can only spend \$1. (Binh Thuan TIPC)

Some representatives also mentioned that at the moment participating provinces are expected to contribute certain fixed amounts in cooperative efforts to organize joint activities. Some provinces, especially the less developed ones, may not enter into the partnership of joint destination marketing simply because they cannot afford the cost. 
In practice, the effectiveness of joint activities can also be affected because each province has different financial capability:

...There are some inconsistencies amongst participating provinces. For example, Quang Nam and Da Nang cooperate to dredge and clean Co Co river for socio-economic development, including tourism activities. Da Nang is committed but Quang Nam meets more financial difficulties. Therefore, the implementation is not consistent. (Quang Nam DCST)

Beside financial difficulties, the lack of a suitable mechanism for operating joint destination marketing activities in the South Central Coast region was also described as a main barrier. Several practical issues, which mainly concern how to implement destination marketing jointly, were raised:

... All provinces recognize the benefits of cooperation but the problem here is how to implement that cooperation. Are they all equally enthusiastic with cooperating; are the budgets equal and affordable; how to achieve the agreement on how to implement? Each province has its own thoughts, orientations and budgets. Tourists also have different tastes. Some like coming to Quang Nam but not Binh Dinh or Thailand tourists may say they like Binh Dinh but not Kon Tum. How to manage this issue in cooperating? (Binh Dinh DCST)

...there are still many issues around the cooperation. We do not receive funding for cooperative activities and the benefits are not clear. They call for cooperation but how to implement it is not clarified. (Binh Thuan TIPC)

The region faces other resource-based difficulties, including a lack of human resources, lack of common voices, no joint marketing plan, limited information exchange and limited tourism planning. Binh Dinh DCST representative noted: “...We still cannot establish the regional coordinator/ team which is responsible for judging and exchanging information... Now the information is reported and exchanged only at the end of the year." This viewpoint received the support from Binh Thuan TIPC representative who said: “... Exchange of information is still limited. The benefits for each province are still more important and at higher priority than for the whole region." A couple of other representatives said that the eight provinces have not yet achieved common voices and they 
lack the leadership and support from national-level tourism management organizations. In fact, South Central Coast provinces have not yet had a joint plan for destination marketing activities, which clearly hinders the joint marketing implementation in reality.

Moreover, the representative of ITDR suggested that the South Central Coast provinces, like many provinces in Viet Nam as well as the country as a whole, lack a thorough understanding of tourism marketing and destination marketing. As a result of this, tourism marketing activities are not as efficient and effective as they should be. The ITDR representative observed two issues from the current destination marketing activities of Viet Nam:

...Awareness of tourism in general and of marketing in particular is not deep. It is not clear what to market, where to emphasize. What they think beautiful, maybe tourists do not like. What they take for granted, tourists may like. Awareness on market segmentation is also low. Clearly there is no research on what different types of tourists like in Viet Nam.

...Destination marketing activities are still not considered as investing activities to add more value to tourism products. We have not understood that marketing is an inseparable part of the whole process of creating value. Vietnam now just simply invite tourists to come like "Welcome to Vietnam", which is not enough. We have to make tourists understand our value, which require investment, especially in information.

These statements indicates that tourism marketing in Viet Nam has not been done seriously from the tourists' perspectives. In other words, the market-based approach in tourism marketing is still limited. This reflects the situation in which Viet Nam's transition from a centrally-planned to a socialist-oriented market economy has not yet been completed.

In terms of administrative and managerial aspects, the South Central Coast region meets quite a few constraints. They include the cumbersome administrative system, the limited support from other industries as well as not having enough agreement and commitment from all provinces to implement joint destination marketing: 
...based on the national administrative system, each province has its own department of trade, tourism and investment. This means that resources are fragmented. This situation also leads to the so-called "provinciality", which is clearly a constraint to cooperation. (Da Nang TIPC)

...there is already the agreement between provinces, however, it is not enough to implement in reality. All provinces have found the orientation and started relevant discussions to find solutions...some joint conferences have been organized to find common voices. However, we need a higher agreement in order to implement in reality. (Da Nang DCST)

...the relationship between tourism and related industries. Tourism depends a lot on other related industries. Supporting policies for tourism from other industries are still limited. (ITDR)

In addition, differences in the administrative system of each province can cause difficulties in implementing joint destination marketing activities. One representative noted:

... good relationships between leaders do not mean that they have good cooperation. State organizations are tied by many factors, especially the bureaucratic mechanism. Also tourism in Vietnam is still tied by administrative boundaries, not like Thailand where thorough management is guaranteed. (Binh Thuan TIPC)

Another representative claimed VNAT was not doing its job well and identified several important tasks which VNAT have not done:

- VNAT is late in preparing marketing plans.

- VNAT has not synthesized tourism events throughout the year. This locality does not know the plan of other localities, so it is harder to cooperate with other localities or with VNAT.

- Viet Nam tourism does not have representative office in foreign countries. In 2013, one representative office was established but we have not known anything about it. Meanwhile Malaysia has two representative offices - one in Ha Noi and another one in Ho Chi Minh city, which help Tourism Malaysia to organize impressive promotion events in Viet Nam. Because we do not have representative offices in 
our target markets, it is very hard to organize marketing activities abroad.

Finally, the region faces socio-cultural barriers. The eight provinces are different in terms of tourism development levels. Consequently, consistency in service quality is not always guaranteed. Quang Ngai DCST's representative considered the fact that each province delivers tourist services in different way as a big challenge to joint destination marketing. Also because of the development gap, the desire for cooperating with other provinces is not the same. One representative shared the view that:

....in the condition of similar tourism products, provinces with more advantages find no motivation to cooperate with provinces having fewer advantages. For example, why Nha Trang has to cooperate with Ninh Thuan? (Binh Dinh DCST)

Ninh Thuan DCST representative also expressed his doubt: “...we know we are weak, so we hope we can cooperate with other provinces. We want to cooperate but we are not sure if other provinces want and know how to cooperate."

Another issue is "the cooperating ability of Vietnamese and between provinces is very weak. Team-work culture is weak". This clearly affects the effectiveness of cooperation. It seems that all provinces have recognized the benefits but 'no organization leads the initiative to carry out destination marketing jointly". Referring to barriers of joint destination marketing, the representative of ITDR said: "The problem is who is mainly responsible, all care for their own benefits first". Also, another representative commented: "Vietnam is very feeling-based in our actions, not reason-based like many foreign countries". With this comment, he implied some provinces have their preferred partners. However, as can be seen from previous sections, preferences for provinces were well explained by benefits and motives, rather than by "feelings".

In the South Central Coast region, DCSTs/TIPCs representatives especially expressed their concerns towards the cooperative culture of tourism enterprises. More specifically, the interviewees seemed to agree that weak cooperation 
between tourism enterprises limits the actual joint marketing activities of provinces.

Such activities like introducing joint destinations, organizing joint conferences and meetings are done quite well, which means state management organizations have started to cooperate. However, in reality the difficulty is that tourism enterprises have not shaken hands for cooperation (Ninh Thuan DCST)

The difficulty is that the cooperation between tourism enterprises is still weak although state management organizations have been very determined (Binh Dinh TIPC)

Although having recognized benefits and being motivated by different reasons, South Central Coastal provinces are currently faced with many barriers that prevent them from actually conducting marketing activities jointly. Three types of barriers discussed in this section are resource-based barriers, administrative and sociol-cultural barriers. Some provinces may meet more barriers of certain type than others, however, the representatives of eight provinces generally agreed on barriers above.

\subsection{Conclusion}

This chapter has presented explanatory factors of the current joint marketing activities discussed in the previous chapter. As shown in the conceptual framework, South Central Coast provinces are influenced by various factors preconditions, benefits, drawbacks, motives and barriers. These factors do not exist exclusively but complement each other. Consequently, destination marketers of provinces face tensions which require them to balance one factor against others in making destination marketing decisions.

Of all influencing factors discussed above, there are some factors that are more important than others in the joint destination marketing decision-making of South Central Coast provinces. This explains why the sub-group cooperative arrangements are currently more common than cooperation of the whole region. Especially, the existence of decision-making factors can be seen in the cases where provinces in the region cooperate with specific provinces outside the region. In particular, partnership arrangements currently exist between 
provinces that share boders, have convenient transportation, perceive clearly the mutual benefits, target similar markets and enable to provide compatible tourism products. 


\section{Chapter 7: DESTINATION MARKETING INTER-RELATIONSHIPS \\ OF SOUTH CENTRAL COAST PROVINCES: COOPETITIVE PRESENT AND COOPERATIVE FUTURE}

\subsection{Introduction}

Being a continuous, sequential process (Morrison, 2013), destination marketing can be better managed if its key issues and challenges are diagnosed. Thus, this chapter presents the existing marketing relationships between provinces perceived by DCSTs/TIPC representatives. Subsequently, this chapter examines future patterns of joint destination marketing in the South Central Coast region and then summarizes what should be done to achieve the prospects through two sets of structural and operational suggestions made by the interviewees.

\subsection{Destination marketing relationships between South Central Coast provinces: A coopetitive present}

Relationships between organizations can take various forms, which are required to be managed differently (Bengtsson \& Kock, 2000). This section examines how representatives of DCSTs/TIPCs perceive the forms of destination marketing relationships that their provinces have developed with other provinces in the region. As explained in the conceptual framework as well as in the methodology chapter, interviewees were introduced to the continuum consisting of four forms of interorganizational relationships - competition, coopetition, cooperation and collaboration and were asked to choose the one that reflects most accurately their provinces' marketing relationship with other provinces. The findings are summarized in Figure 7-1 (next page). 
Figure 7.1: The destination marketing relationships between South Central Coast provinces

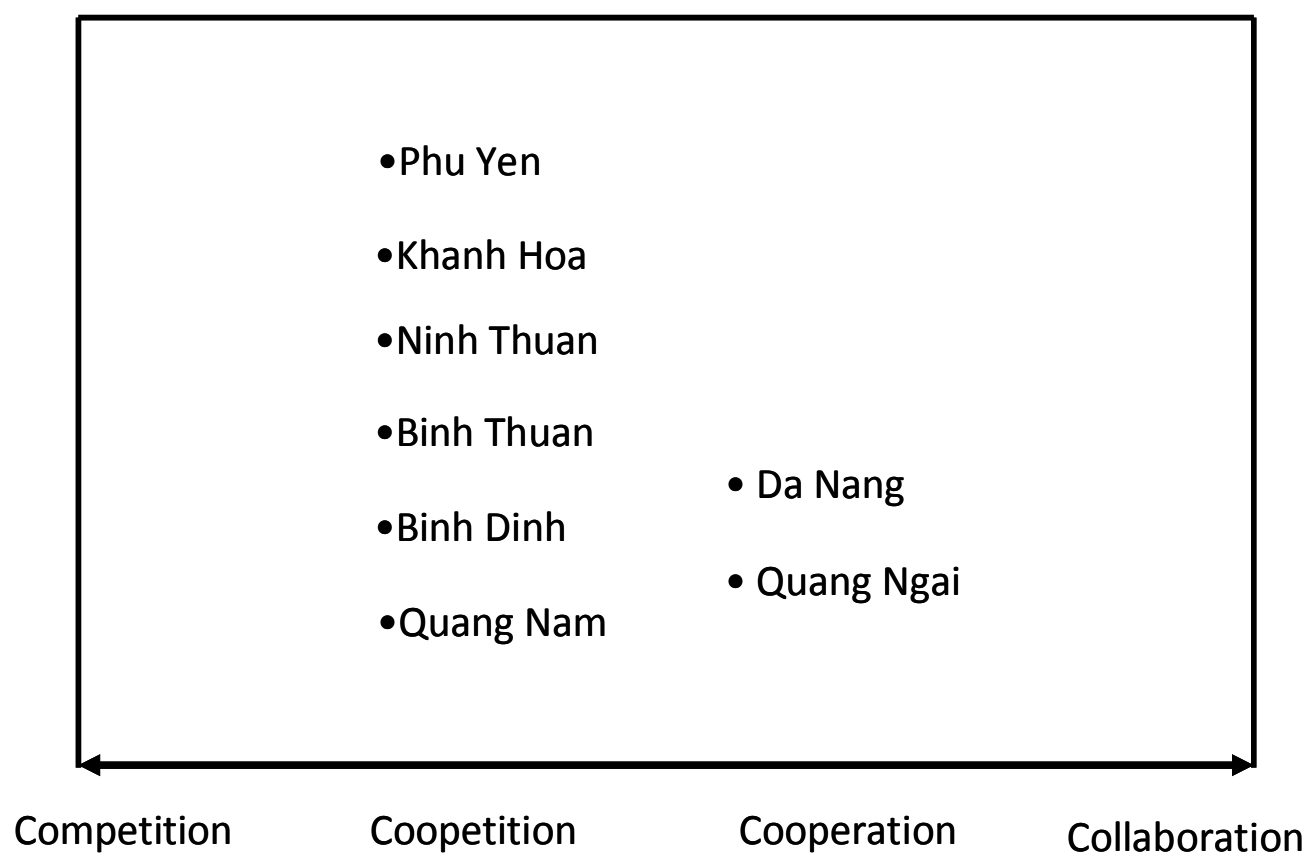

As can be seen, six out of eight South Central Coast provinces were placed at "coopetition", which means DCSTs/TIPCs representatives perceived that their provinces have developed competitive and cooperative relationships with other provinces at the same time. These representatives also expressed reasonably similar explanations for the co-existence of competition and cooperation in their provinces. Some explained that coopetition enables them to achieve their own targets as well as shared interests:

... Cooperative efforts are made to create trans-region tourism products. We also compete in a healthy way in order to achieve better quality. (Binh Dinh TIPC)

... We cooperate to achieve common goals and benefits but we also develop our own ways to attract more tourists. It is like in a Miss World competition, all candidates show solidarity and take part in humanitarian projects but everyone wants to make themselves outstanding. (Quang Nam TIPC)

According to others, competition naturally exists in the marketplace. Binh Thuan TIPC representative commented: “...Binh Thuan mainly considers provinces in the region as partners and wants to develop cooperative 
relationships with them. We do not consider others as competitors although competition still exists.". Similarly, Ninh Thuan TIPC representative said: "this form has some characteristics of the other form. There is no absolute cooperation or competition".

Interestingly, many of interviewees perceived competition in positive ways. The Quang Nam TIPC representative observed: “...competition in terms of quality of services, tourism products, it's not "bad competition". This viewpoint was supported strongly by the representative of Binh Thuan TIPC:

...competing does not mean taking tourists from other provinces. We are well aware that "where the land is good, birds reside". Tourists who like beaches and water sports will come to Binh Thuan and tourists who like beaches and islands will come to Khanh Hoa.

Meanwhile, Binh Dinh TIPC representative also said that they compete in a healthy way in order to achieve better service quality: "if we see Nha Trang has good tourism human resources, we also try to enhance the quality of our tourism staff'. At the same time, Ninh Thuan TIPC representative described competition as a motive for development:

...If we do not create a competitive picture, we will lag behind...If we are all surrounded by nice houses, we definitely desire to build another nice house to contribute to the general picture. So at the same time we consider other provinces as competitors and friends in order to develop.

These statements indicate that competition to some extent is an important incentive for development. At the same time, cooperation in some respect enables provinces to achieve common goals which then contribute to the development of the whole region. So the hybrid mode comprising competition and cooperation appears to be the preferred one in the South Central Coast region at the moment.

The only two provinces that were placed by their representatives at "cooperation" were Da Nang and Quang Ngai. Their representatives provided different reasons underpinning the perceived cooperative relationships. In the 
case of Da Nang, aiming to attract similar tourist markets motivates the city to cooperate with others, whereas, the Quang Ngai DCST representative defined cooperation as a useful way to improve its paradoxical situation:

...We have much tourism potential but this is not outstanding compared to other provinces, so our attractiveness is low... With its tourism potential and the current status of tourism development, Quang Ngai needs to cooperate with neighbouring provinces to exchange experiences and learn from other provinces, especially in tourism marketing and management.

The reasons presented by the representatives proved that there are different motives that can lead provinces to the same configuration of relationships cooperation in this case. This means that cooperative relationships do not prevent provinces from fulfilling their own interests.

It is interesting to note that although the DCSTs/TIPCs representatives positioned their provinces on either coopetition or cooperation, their responses reflected more diverse relationships from the point of view of a "passiveassertive" continuum. This notion was illustrated through the differing capacity to compete and cooperate of stronger and weaker provinces. The former seem to be more proactive in making their decisions about what to compete on. Quang Nam DCST representative stated: “...We tend to compete for new elements. For example, Quang Nam has initiated developing community-based tourism and now this has become a strength of Quang Nam tourism. Meanwhile Da Nang focuses on investing in tourism infrastructure." On the other hand, representatives of weaker provinces like Phu Yen and Binh Dinh explained the practices of coopetition as the result of not being able to only compete or only cooperate given their current limitations. Phu Yen's tourism representative commented: "We consider them both as partners and as competitors because our cooperation has not yet clearly established...the province is not strong enough to develop its own special tourism products". The Ninh Thuan representative even made this point clearer by saying: "Ninh Thuan is at the stage of coopetition however Ninh Thuan compete in a passive way. Meanwhile other more tourism-developed provinces compete in a proactive way." This 
finding is congruent with the findings of different roles and levels of involvement of South Central Coast provinces in joint destination marketing discussed before in section 5.2.2. It may also indicates that relationship experienced in the terms shown in Figure 7-1 (i.e., competition, coopetition, cooperation and collaboraion) are inadequate to reflect all inter-relationships that may exist between tourism organizations.

During the interviews, the DCSTs/TIPCs representatives generally referred to the marketing relationships between provinces but they also made several comparisons about the cooperative behaviour of state tourism organizations and of tourism entrepreneurs. Many representative agreed that state tourism organizations (DCSTs and TIPCs) tend to cooperate while tourism enterprises tend to compete. The representative of Da Nang DCST said: "DCSTs are state management organizations, we are the same. We are not like businesses, so there is no competition here." He then explained the reason:

...We need to cooperate because each place has its own typical features and problem-solving experiences. We need to exchange ideas and experiences to do the state-management tasks better. In addition, there are issues that relate to many provinces, which require the agreement before implementation. That is the relationship at the level between DCSTs.

This viewpoint was further supported by some other representatives. Ninh Thuan DCST representative stated: “...the main barrier is from tourism enterprises. All state management organizations want cooperation...". Binh Dinh TIPC representative also said that the main difficulty is caused by weak cooperation between tourism enterprises although state management organizations have been very determined. From a national tourism organization perspective, the ITDR representative observed that there was a generally low level of involvement of tourism enterprises in joint marketing activities all over the country:

... Joint destination marketing of the whole country, regions and localities have not yet attracted much attention from enterprises. Consequently, many enterprises do not contribute to destination 
marketing activities and thus there are not enough resources for professional marketing.

However, further research on destination marketing relationships between tourism businesses in multiple provinces need to be done before any firm conclusion can be made.

\subsection{Destination marketing relationships of the South Central Coast provinces: A cooperative future}

This section explores how South Central Coast provinces will develop their destination marketing relationships with other provinces within the region in the future. According to interviewees' responses, the most frequently-chosen relationship forms between provinces in the future will be coopetition and cooperation. This means coopetition will continue to be popular. However, there are changes in the degree of competitive and cooperative behaviour shown by provinces in the future. More specifically, local DMOs' representatives shared the viewpoint that cooperative relationships will become more and more common although competition still exists:

...Partnerships and cooperation with other provinces are what we want. The competition still exists but will become less and less. (Quang Nam DCST)

...In the future, we want to develop circuits to attract tourists from Khanh Hoa, then travel to Ninh Thuan, Binh Thuan and finally visit Lam Dong before coming back to Khanh Hoa. In order to reach that goal, we need to develop cooperation between provinces. This does not mean that there is no competition. Each form has some characteristics of the other. (Khanh Hoa TIPC)

Multi-destionation marketing relationships of the future will also become more professional and specialized. The representative of Quang Nam DCST believed: "The cooperation will become more professional, at a bigger scale, with more commitment and responsibility from participating provinces." Similarly, the representative of Vietnan ITDR emphasized the specialization of future destination marketing relationships: “... cooperation will go into more specialized directions like sea tourism promotion cooperation or MICE tourism 
promotion cooperation or rural and mountainous tourism promotion cooperation....The sea tourism travel expo organized in Nha Trang in June is one example". Another representative suggested that specialized marketing is suitable in the short-term, while cooperative efforts to develop the regional brand of coastal tourism should be done in the long term.

... the orientation to develop sea tourism may be only suitable for the long term. For the short term, it is impossible for all provinces to just focus on sea tourism. Each province needs to identify its own strengths to develop because not all provinces can have appropriate infrastructure, accessibility and complementary products for sea tourism. (Quang Nam TIPC)

Also in the near future, the sub-group cooperative models in destination marketing will continue to be popular in the South Central Coast region. It was suggested that sub-group cooperation should be established and operated effectively before the whole region cooperates. The representative of Da Nang DCST advised the region to first divide into sub-groups to work together based on similar target markets. Specifically, Khanh Hoa and Binh Thuan focus on the Russia market; Da Nang and Quang Nam focus on the Korean and China markets. Others like Phu Yen, Binh Dinh, Quang Ngai should focus on domestic market and nearby markets like Thailand, China, Asean countries. Marketing materials and programs will be designed to suit identified tourist markets. The eight provinces then will cooperate, learning from experiences and best practices of the sub-groups. The representative of Phu Yen TIPC shared the same view:

...In the future, provinces should be grouped into sub-zones such as Binh Dinh - Phu Yen - Khanh Hoa or Ninh Thuan - Khanh Hoa Phu Yen. I think other provinces will also form similar tourism triangles because in that way, they are able to exploit their favorable geographical conditions and attract suitable target markets.

Also the future will witness the narrowing of the development gap between the two groups of provinces. The representative of Vietnam ITDR commented: 
$\ldots$ in the future when the accessibility is better, tourists will search for new destinations. Quang Ngai, Phu Yen are destinations with new outstanding features that are more attractive to tourists than the developed provinces which are coming to the decline stage.

The tourism representative of Ninh Thuan province also expressed the view that:

...Tourists from Ho Chi Minh have known a lot about Binh Thuan, Vung Tau. From psychological aspects, they will want to find a new destination. Ninh Thuan is an ideal new destination.

Because the marketing behaviour and forms depend on the development stages of the destinations (Prideaux \& Cooper, 2002), less developed provinces of the South Central Coast region will probably become more proactive in joint marketing programmes in the future when their destinations are more visited.

The two provinces, which positioned themselves at "cooperation" on the continuum (Figure 7-1) consistently mentioned "collaboration" as their desired form of marketing relationship with other provinces in the future. Quang Ngai DCST representative explained that they "will collaborate with other provinces in order to develop sustainable tourism". Meanwhile, Da Nang's tourism representative confirmed that the city now cooperates and will collaborate in the future:

...We aim to collaborate in the future. This is the lesson learnt from other countries, especially from Thailand who cooperates very closely in each group, zone and throughout the whole country, not within each locality anymore. In the national tourism strategy, they have good supporting policies for the whole system. That is why they have good products with competitive prices. The 3-star hotel rate in Thailand is lower than the 3-star hotel rate in Viet Nam or flying to Thailand is cheaper than flying domestically. That happens thanks to the harmonization from other related areas like commerce, airlines, transportation, entertainment...

The statement indicates that collaboration has helped Thailand tourism become very competitive and attractive, even more than Vietnam tourism from the perspective of domestic tourists. It also implies that the successful collaborative 
story of Thailand tourism is due to support from national tourism organizations and relevant industries.

Generally speaking, the tourism representatives agreed that joint destination marketing would gain increasing significance, moving from a coopetitive present to a cooperative future. Competition still co-exists but the South Central Coast provinces show more cooperative behaviour and higher commitment for joint destination marketing in the future. Sub-region cooperative models will continue to be common in the near future, which provides provinces with experiences to form destination partnerships at a larger scale in the long term.

\subsection{Joint destination marketing at regional level: What should be done?}

\subsubsection{Structural suggestions}

Different interorganizational structures represent different levels of cohesiveness of regional destinations and affect the delivery of integrated tourist experiences (Scott, Cooper \& Baggio, 2008). Given such an important role, tourism representatives were asked which interorganizational structure is appropriate for South Central Coast provinces in order to co-organize their joint marketing activities more effectively. Generally, representatives suggested the region forms a regional tourism coordinating organization. The representative of Quang Nam TIPC affirmed: “...There must be a regional organization in charge of tourism development management for the whole region. Such an organization is able to facilitate tourism cooperation in the region. Tourism can not exist independently.” Da Nang TIPC representative also said: “...In order to be successful, the cooperative structure must have a conductor for the Central Coast tourism's orchestra."

In terms of the structure of the regional tourism coordinating organization, representatives discussed several possibilities. First, the region should form a joint team which consists of representatives from each province. The representative of Binh Dinh TIPC said: “..there should be a group or a team in which each province assigns at least one person to be a member". His fellow in 
Phu Yen TIPC also noted: “...there must be a person or a group of people who are mainly responsible for managing this cooperation and all participants have to work in a team". Similarly, Ninh Thuan DCST representative expressed: "...there must be contact points to attend in discussions for cooperation, like standing committee - those are people who advise provinces to implement the cooperation programmes." This option receives support from a considerable number of provincial tourism representatives because it creates an environment for all provinces to be actively and fairly involved in co-organizing joint activities. In addition, it was said to guarantee more discussion and negotiation and thus more common voices between provinces.

Another possibility is to outsource to a professional consulting team which is mainly responsible for preparing joint programs and facilitating joint activities. The representative of ITDR recommended: “...Provinces should have a joint fund for destination marketing activities so that they can hire a professional consulting and destination marketing organization to help prepare the plan." Clearly, this possibility emphasizes objectivity and effectiveness. The representative explained:

The problem is who is mainly responsible? All care for their own benefits first. That is why I suggest to hire a consulting group which is not in the region so that they can view things objectively and consult on joint activities that the region can conduct together.

The representative of Binh Dinh DCST agreed that the region needs technical help from a professional consulting team which firstly prepares the joint plan. However, this organization has to work closely with provincial tourism representatives to find the answers for questions like "who pays for developing the plan? The MCST or VNAT or provinces contribute? And after having the plan, do you have enough capability to implement the plan and how to do that?".

In either case, it was said that the regional organization should belong to the ministry so that it has enough real power and has the right to make strategic decisions quickly and effectively. 
The possibility of a turn-taking mechanism to bring all eight provinces together was mentioned by one representative. However, at the same time it was said to be inappropriate for the whole region because of possible inequality and ineffectiveness in exchanging the information.

...The take-turn cooperation mechanism shows the commitment of each province, however, more priorities are still given to the localities which host the joint marketing activities. Therefore, the results from the cooperation are not as convincing as they should be. (Da Nang TIPC)

... It is already hard for three provinces to manage the information. So how to guarantee the information is delivered well between nine provinces? (Hue TIPC)

Another representative suggested: “...the Central Region Research and Development Fund is the suitable organization for facilitating the cooperation in the region. They have both financial resources and capacity." However, this organization also has limitations which were mentioned by the representative of Ninh Thuan DCST as follows:

...The Coordination board is based in Da Nang. Southern provinces of the region seem to receive less attention, especially provinces that have less potential and bring less benefits.

From the strengths and limitations of possible interorganizational structures discussed above, it seems to be most sensible for the region to establish the regional tourism coordination team which administratively belong to the Central Region Coordination Board and thus under the management of the Central Region Research and Development Fund. The ITDR representatives suggested that "TIPCs should assign representatives who establish a joint organization which help leaders to make decision on joint destination marketing plan". In that way, such joint organization between TIPCs acts as a bridging organization connecting their provinces and the regional tourism coordination team. 


\subsubsection{Operational suggestions}

Regarding turning cooperative plans into actions, tourism representatives of South Central Coast provinces also shared common concerns and suggestions. Firstly, they emphasized the importance of having a joint fund. The representative of Da Nang DCST stated: “...Before doing anything, you must have the budget. So we need to have a joint marketing fund." This view was agreed by Quang Nam DCST representative who considered a common fund as the key success factor of joint marketing activities. At the moment, provinces that participate in certain joint activities need to contribute first and then report later. Together with the lack of a joint marketing program, this indefinite way of raising funds for joint activities does not enable provinces to manage the necessary budget for marketing activities in advance.

The contributing mechanism of the fund is also important and attracted some discussion. Some representatives reflected the inequality of the current mechanism. The ITDR representative noted: "In the story of cooperation, provinces that contribute more funds often have bigger roles. This is clearly not yet suitable." The representative of Binh Thuan TIPC also stated that "...in joint destination marketing, the equality between provinces is only reasonable. Strong cities like Ho Chi Minh and Da Nang have economic advantages, thus their voices are listened to more; while other provinces participating in the joint activities should follow". The role and voice of each locality are not identified clearly. One representative suggested to fix the rate that each province contributes to the joint marketing fund based on the province's tourism revenue. A fixed amount of contribution was perceived to be unfeasible by the same representative because provinces have different levels of development.

Secondly, in order to implement marketing tasks together, the region needs to have a joint marketing programme which all provinces agree upon. Preparing the joint plan is one important task of the proposed regional tourism coordinating organization. This regional tourism organization is responsible for organizing annual meetings between the provinces' leaders to discuss joint marketing programmes and joint action plans. The marketing plan needs to be 
done three to four years in advance, which requires market research to be done. In addition, in order to avoid the duplication between joint and individual marketing activities, the ITDR representative suggested choosing different themes for the annual marketing program. Also in joint destination marketing, each province can be in charge of certain activities based on their strengths. Provinces then can individually do their own marketing activities which are different from what has been done jointly.

Thirdly, to implement joint actions, the South Central Coast provinces need to be aware that tourists coming to one province benefit other provinces in the region. Thus, provinces need to think about the joint benefits first. The representative of Da Nang DCST expressed the viewpoint:

We should not say each province needs to have an airport because Da Nang has an airport. Instead, they should invest in other things like train system, road system, other infrastructure. We have to consider how far there should be an airport or a seaport, which suit tourists demand. It is unreasonable that tourists just stop at Hue's airport, then they stop again at Da Nang airport and then Chu Lai airport of Quang Ngai province.

The ITDR representative also said that provinces should not learn mechanically from each other. Clearly, how can eight provinces cooperate if they all try to develop golf courses. Instead, each province can exploit their typical tourism potential to develop unique products. Another representative noted: "For example I think Phu Yen can develop a casino; if they develop a casino strongly they can attract tourists from Nha Trang and other places. Similarly, Phu Yen or Ninh Thuan can build horse-racing or motor-racing centres to attract tourists." These statements imply that in order to aim for a collaborative future, individual provinces need to find a balance between self and common interests.

Finally, a certain level of flexibility in joint marketing program is required for successful implementation. Being autonomous organizations with different conditions and capability, member provinces are not always able to implement all cooperative items regulated in the cooperation agreement. Instead, the agreement is more for guidance purposes; provinces need to be flexible in 
solving problems when they occur. In the cooperation between Hue, Quang Nam and Da Nang, such flexibility enables Hue - the province that does not aim to target the Russian market - to not attend costly tourism fairs in Russia although their images are still promoted thanks to close tourism partnerships with Quang Nam and Da Nang.

\subsection{Conclusion}

This chapter has presented the existing marketing relationships between provinces. Based on the positioning of tourism representatives, the most common form of marketing relationships between eight provinces is coopetition, which implies provinces compete and cooperate at the same time. The chapter also examined the future patterns of joint destination marketing between South Central Coast provinces. In terms of inter-destination marketing relationships, the eight provinces will aim for a collaborative future in which cooperation becomes increasingly significant despite the co-existence of competition. Joint marketing of the region in the future will become more specialized as a result of a regional strategy of pursuing several types of niche tourism, including coastal eco-tourism, MICE and mountainous tourism. The chapter has also presented the suggestions of the provinces' tourism representatives regarding how to achieve a collaborative future in joint destination marketing. Most importantly, the region needs to establish a regional tourism coordination organization, which specializes in facilitating joint tourism and marketing activities between provinces. 


\section{Chapter 8: DISCUSSION, RECOMMENDATIONS AND CONCLUSION}

\subsection{Introduction}

There is little research on destination marketing activities between tourism organizations of multiple destinations, especially in developing countries. This thesis has contributed to fulfil this gap by examining the nature and extent of destination marketing activities that occur jointly between the eight provinces of the South Central Coast region of Vietnam and their perceived destination marketing interrelationships. The study has also provided explanations for joint marketing decisions-making processes through the investigation of influencing factors. In particular, the study has three objectives as following:

- Examine the nature and extent of current destination marketing activities that occur jointly between the eight South Central Coast provinces of Viet Nam

- Analyze the factors that influence joint destination marketing decisionmaking in the South Central Coast region

- Investigate the destination marketing relationships between DMOs of the eight provinces in the region

The study achieved its objectives by formulating research questions and then searching for answers to address those questions. The main findings have been presented in four findings chapters. Chapter 4 dealt with the regional and provincial tourism development and destination marketing contexts; Chapter 5 focused on destination marketing activities that currently occur individually and jointly in the region; Chapter 6 analyzed factors that influence the joint destination marketing decision-making; and finally Chapter 7 presented the perceived destination marketing relationships between the DMOs of the eight provinces in the South Central Coast region at the present and in the future. This final chapter will once again bring all the findings together to provide a 
clear picture on joint destination marketing activities, destination marketing interrelationships between DMOs and the explanatory factors for joint destination marketing decision-making.

\subsection{Joint destination marketing activities of the South Central Coast region}

The objective of understanding the nature and extent of joint destination marketing activities has been achieved by examining the actual marketing activities that have occurred and their characteristics. In the South Central Coast region, individual destination marketing activities were found to be more common than joint ones, which was stated by most of the interviewed representatives of DCSTs/TIPCs. The content analysis of seven TIPCs' websites also showed that currently South Central Coast provinces use their tourism websites mainly to provide tourists with tourism information of individual provinces. However, both individual and joint destination marketing exist simultaneously in the eight provinces with different degree of dominance. Although the adoption of individual or joint approach differ from one activity to another, stronger provinces in the region are generally capable of organizing or attending larger-scale tourism events which involve more joint elements. As shown in Table 5-1, the four more tourism-developed provinces, Da Nang, Quang Nam, Khanh Hoa and Binh Thuan, all attended many important domestic and international tourism fairs; hosted national and international tourism events and invited other provinces to participate. Whereas, weaker provinces are characterized by organizing smaller tourism events and attending activities organized by nearby provinces.

Joint destination marketing activities in the South Central Coast region were revealed to be an emerging and increasingly common trend in the region as well as throughout the country. Cooperative models involving multiple provinces have been established in different parts of the country. Considering the joint marketing efforts of the region as a whole, the findings showed that the South Central Coast provinces have identified and agreed on the common purpose of working together and have organized three joint conferences, what might be 
called "search conference", in Gray's terms (1985). These current joint destination marketing efforts indicate that the region is now at the second stage of direction-setting on the three-stage process model (Gray, 1985; Jamal \& Getz, 1995). In this study, the joint destination marketing was also perceived as a process that consists of several sequential stages. This is congruent with the findings of previous studies on partnership models (Darrow, 1995; Wang, 2008; Gray, 1985; Selin \& Chavez, 1995; Jamal \& Getz, 1995).

The study also showed that the overall cooperative behaviour and involvement level of South Central Coast provinces in joint activities are rather low. Most of the provinces attend each other's events as commitment to the cooperation agreement or attend the same national tourism events rather than actually coorganizing activities. Only two provinces - Da Nang and Quang Nam - have conducted more comprehensive joint marketing activities but these activities are also organized at a smaller scale (between Hue, Da Nang and Quang Nam). Since being signed in 2011, the Central Cooperation Agreement formed the basis for cooperative activities, especially for joint activities in tourism. For tourism partnership models that involve multiple destinations, such an agreement has a fundamental role in the collaboration process (Wong, Mistilis \& Dwyer, 2010). However, there are differences in involvement level and thus in the effectiveness of cooperative activities when participants only comply with the cooperation agreement rather than engage in joint activities. Therefore, it is also important to have enforcement mechanisms and policies to motivate member provinces to actively engage in implementing marketing activities together.

Current joint destination marketing activities of the South Central Coast region were also found to more commonly occur at a sub-regional scale rather than at the scale of the whole region. All provinces in the region are now involved in cooperative models that consist of a smaller number of participants (three to five provinces), which do not necessarily belong to the same region. This feature leads to two further conclusions for the study. First, in the case of the South Central Coast region, belonging to different regions has little effect on 
tourism partnership formation. Second, influencing factors that lead a group of provinces in the region to decide to establish cooperative models with provinces outside the region (not with other provinces within the region) are decisionmaking factors of joint destination marketing.

The above discussion shows that although destination marketing activities in the South Central Coast region now adopt more individual marketing approach, joint destination marketing co-exists in the region and has become an increasingly common trend. The mix of individual and joint marketing activities also varies from one province to another, depending on various factors. In order to achieve the common goals to develop and market the regional tourism, it is crucial for relevant tourism organizations to understand what factors that influence the joint destination marketing decision-making in the regional context.

\subsection{Joint destination marketing: Influencing and decision-making factors}

In the existing literature, tourism partnership formation between multiple tourism organizations have been studied in terms of various explanatory factors, including preconditions (Wang \& Fesenmaier, 2007; Selin \& Beason, 1991); benefits and drawbacks (Jamal \& Getz, 1995; Palmer \& Bejou, 1995; Fyall, Oakley \& Weiss, 2000); motives and barriers (Saxena, 2005; Selin \& Chavez, 1995; Naipaul, Wang \& Okumus, 2009); and decision-making factors (Hill \& Shaw, 1995; Wang \& Krakover, 2007). This study also examined the role of these factors in explaining joint destination marketing activities in the South Central Coast region and shared similar findings.

The environmental preconditions (Wang \& Fesenmaier, 2007) found in this study are classified into two groups: preconditions from the internal environment and preconditions from the external environment of regional destinations. The first internal-environment precondition is derived from similarities and differences in the diverse tourism potential of the eight South Central Coastal provinces. The study of Teye (1988) also indicates the diversity of tourism resources as incentives for regional cooperation. Furthermore, similarities and differences in nature and culture form favourable conditions to 
develop common but complementary tourism products, which are in turn the facilitating factors for regional cooperation (Naipaul, Wang \& Okumus, 2009).

In the South Central Coast region, transportation connections are another precondition favouring the partnership between the eight provinces. Actually, there are reciprocal effects between transportation and regional cooperation. Transportation systems form the basis for cooperative activities while tourism cooperation also enhances the convenience and efficiency of transportation. For example, the national highway No.1 connects the Central Coast provinces and makes cooperation easier. Conversely, the cooperation enables provinces without international airports to receive foreign tourists and the more cooperative practices between provinces, the better the transportation systems are.

The third precondition deriving from the internal environment of destinations is the leadership support, which is in line with the study of Wang and Fesenmaier (2007). Joint activities between the eight South Central Coast provinces were committed in the general socio-economic cooperation agreement signed in 2011, and tourism was chosen as one of the first five areas for implementing cooperative actions. In the study of tourism collaboration between Southeast Asia countries, tourism is also the specific area for cooperation within the ASEAN general economic cooperation framework (Wong, Mistilis \& Dwyer, 2010). Long before that Teye (1988) stated "tourism marketing has provided the primary reason for whatever regional cooperation exists in developing countries" (p.222). Being one of the first fields of cooperation within a general socio-economic cooperation framework is a typical feature of inter-destination marketing.

The external-environment preconditions include the multi-destination travel trend of today's tourists and the increasingly fierce competition in the market place. DMO representatives of the South Central Coast provinces are well aware that tourists demand to visit multiple places and have multiple travel experiences during their trips. This is especially true for long-haul travellers. Destinations therefore enter partnerships to provide multiple-destination programmes for tourists (Tussyadiah, Kono \& Morisugi, 2006). The present 
study concludes that competition is a precondition for joint destination marketing, which is similar to the findings of Wang and Fesenmaier (2007).

In terms of the benefits of joint destination marketing, the study shares a number of findings with previous studies. Joint marketing activities are clearly more cost-effective because the costs are shared (Naipaul, Wang \& Okumus, 2009; Fyall, Garrod \& Wang, 2012). Joint activities provide an environment for supporting and transferring skills and knowledge (Saxena, 2005). Joint marketing enables product diversification, develops a regional tourism brand and creates competitive advantage compared with other regions (Pearce, 1992). The joint marketing benefits perceived by the DMOs representatives in this study were categorized into three groups: (1) benefits for participating provinces; (2) benefits for the whole region; and (3) benefits for tourists. This classification provides a comprehensive view of the benefits of joint destination marketing, which can be useful for conveners to persuade multiple tourism stakeholders to participate in cooperative activities.

The study also highlights the tradeoffs with regard to the benefits and drawbacks of individual and joint destination marketing activities. In the South Central Coast region, joint destination marketing activities were perceived to bring about cost effectiveness and efficiency but also to reduce flexibility and freedom of individual provinces. Similarly, individual activities maximize provinces' independence but limit their attractiveness and are more costly. This observation is in line with Wood and Gray's (1991) discussions about shared versus individual control and self-interests versus the collective interests of collaborative alliances. Given these tensions, DMOs need to make sense of their decisions by balancing the benefits and drawbacks of individual and joint marketing for specific destination marketing activities.

Regarding motives for joint destination marketing activities, it is important to identify that provinces often have their own motives in conducting destination marketing activities jointly besides common incentives of cost savings or meeting the multi-destination travel demand of tourists. Some motives found in this study include attracting similar/same target markets, perceiving mutual benefits and being able to produce compatible tourism products. These findings 
are similar to facilitating factors named "homogeneity of target market", "common but complementary products" and "fair share of benefits and responsibilities" in the study of Naipaul, Wang and Okumus (2009). The motives can be very specific. For example, Da Nang is motivated to conduct and facilitate joint marketing activities as the biggest city and the centre of the region. The less tourism-developed provinces are motivated to cooperate in order to be supported by stronger partners.

Barriers to joint destination marketing activities were also grouped into resources-based barriers, administrative/managerial barriers and socio-cultural barriers. Again, this provides comprehensive insights into possible barriers that constraint the implementation of joint destination marketing and thus provides DMOs with better directions to overcome these obstacles. Some barriers are shared with previous studies such as a lack of funding, tight budget, weak cooperation from tourism businesses (Blumberg, 2005); and limited human and financial resources (Naipaul, Wang \& Okumus, 2009). Other barriers appear to reflect the specific contexts of the South Central Coast region and probably Viet Nam more generally, like the cumbersome administrative system or weak cooperating ability and team-work culture. Fyall and Garrod (2005) identify several barriers to destination collaboration such as the inability of stakeholders to work together due to excuses of a political, economic and administrative nature and cases where particular stakeholders fail to recognise the real value of collaboration. Barriers found in this study appear to be congruent with those findings but indicate the issues more specifically.

The final group of factors were examined in the study is the decision-making ones. Despite being influenced by a wide variety of factors, South Central Coastal provinces have established sub-group cooperative models, consisting of provinces that have convenient transportation, mutual benefits, similar target markets and compatibility of tourism products and are close to each other. Hill and Shaw (1995) show some similar findings in their study about strategic alliance formation between two countries. In particular, close proximity and compatible tourist attractions are two decision-making elements when a pair of countries consider an alliance to market their tourism products to a third 
country. Also their study examines cooperative marketing alliances at international level, which probably explains why other decisive factors of the alliances like en route air service connections and many multinational tourism enterprises are not in line with the present study.

\subsection{Destination marketing interrelationships between South Central Coastal provinces}

As discussed in Chapter Two, the interrelationship between tourism organizations can take different forms (Wang \& Krakover, 2007; Timothy, 1999; Elbe, Hallén, \& Axelsson, 2008; Watkins \& Bell, 2002). These studies observed the simultaneous existence of competitive and cooperative behaviour at the destinations concerned. In line with these findings, this study's findings showed the co-existence between competition and cooperation and also indicated competition was a natural feature of the marketplace. Grängsjö (2003) also concludes that it is hard to separate competition from cooperation and the two forms need to be balanced against each other.

The DMO representatives of the South Central Coastal provinces perceived that coopetition and cooperation will be their destination marketing interrelationships in the future. Cooperation will become more and more common but competition and cooperation will still co-exist at destinations. Serveral studies have similar findings. Fyall, Leask and Garrod (2001) include collaboration as one of 15 issues that will have a significant impact on the future of destination marketing. According to these authors, "collaboration is not viewed as a luxury, but as a necessity for destinations to survive..." (p.61). Similarly, Bennett (1999) suggests destination marketers work in partnerships if they wanted to achieve success in destination marketing this century. In order to achieve the a cooperative future in destination marketing, it is crucial for destinations to establish a regional cooperative marketing body (Cox \& Wray, 2011). All DMO representatives in this study suggested forming a regional tourism coordinating organization to facilitate cooperative destination marketing. 


\subsection{Implications and recommendations for tourism organizations in}

\section{Viet Nam}

The findings show that the South Central Coast provinces' tourism representatives perceived joint destination marketing as an emerging and indispensable trend. The eight provinces also aim to work together for a collaborative future in the field of destination marketing. This section presents several implications drawn from the findings and accordingly provide recommendations for destination marketing organizations, including the Vietnam National Tourism Administration (VNAT), the Institute of Tourism Development Research (ITDR) and the Central Region Development Fund (CRDF) and provincial DCSTs and TIPCs.

\subsubsection{Implications and recommendations for national tourism organizations}

The first implication for VNAT is that the organization plays a very important role in facilitating joint destination marketing activities between provinces in a region. VNAT plays an orienting role for joint destination marketing activities, providing basic orientations for product development, target markets and marketing strategies for each region. These aspects form the contexts in which joint destination marketing activities occur. Therefore, VNAT should consult provinces and the region to develop master plans of tourism development and marketing strategies in a consistent and complementary manner. The region also needs special support from VNAT to develop their joint marketing programme with detailed action plan for implementation. The national organization should also provide the South Central Coast provinces with further leadership support in both domestic and international destination marketing campaigns. Also there is an agreement amongst DMO representatives that funding from national tourism organizations are limited. VNAT should support the provinces to diversify ways to raise funds for marketing activities (i.e. socialize marketing activities).

The second implication for VNAT is that there are development gaps between two groups of provinces in the region. Accordingly, provinces need different 
support. VNAT should support poorer provinces to attract more investment for tourism infrastructure development. Meanwhile, stronger provinces are probably more in need of support in terms of favourable policies, human resources and destination marketing training. Tourism enterprise communities in South Central Coast provinces are perceived by DMO representatives to have a reasonably low involvement in cooperative marketing activities. As a statemanagement organization in tourism, VNAT should lobby activities for suitable tax-support policies to be developed to clarify benefits that tourism enterprises receive as a result of attending joint marketing efforts. The support of VNAT to improve the quality of tourism human resources and the quality of managing and marketing tourism activities is crucial. Calling for assisstance and cooperation from other industries like transportation, immigration, foreign affairs, environment is also the responsibility of VNAT.

The third implication for VNAT and ITDR is that it is currently not just the South Central Coast region but also Vietnam tourism as a whole is weak at marketing research. This area should be improved if Viet Nam wants to attract the appropriate tourist markets and satisfy them. In particular, market research should be done to understand what kind of tourism information tourists need when they visit a region. Also market research should measure travel motivations, satisfaction levels and evaluate the effectiveness of joint marketing plans as well as do research on new travel trends of both domestic and international tourists.

\subsubsection{Implications and recommendations for the regional cooperation organization}

The first implication for the current regional cooperation organization - the Central Region Research and Development Fund (CRDF) - is the lack of an appropriate mechanism as the main barrier for South Central Coast provinces to implement marketing jointly. DMOs of the eight provinces have recognized the benefits of joint destination marketing but without coordination and enforcement mechanisms, actual measures will not be implemented. The CRDF should establish the regional tourism coordinating organization to facilitate 
joint marketing activities between provinces. It is also important for CRDF to ensure the regional tourism coordinating organization has necessary credibility, fairness, influence and knowledge (Wood \& Gray, 1991) in order to function effectively as a convener of the destination marketing partnership between the eight South Central Coast provinces.

Second, South Central Coast provinces have their own strengths and weaknesses for tourism development. Those provinces are also in different tourism development contexts and stages. Consulting groups of the regional cooperation organization need to help each province to identify comparative and competitive strengths and develop typical but complementary tourism products.

\subsubsection{Implications and recommendations for provincial DMOs of South Central Coast provinces (DCSTs/TIPCs)}

The study has several implications for the DCSTs/TIPCs of the South Central Coastal provinces. First, all provinces should have destination marketing strategies and action plans. Da Nang is a good example of how a strategic marketing plan helps the city to develop tourism in an effective and sustainable manner. DCSTs/TIPCs should work with each other and with national and regional tourism organizations to develop joint destination marketing programmes on an annual basis. To optimize similarities and differences in tourism potential, South Central Coast provinces should develop trans-region tourism products based on themes such as beach, food or folk festival tours.

Second, the study findings show that cooperation between the eight provinces now mainly occurs at managerial levels. At the tourism industry and DCST level, the determination has not yet been realized into action. In the future, DCSTs should make further efforts to turn commitments into actions. Also, DCSTs/TIPCs need to maintain annual meetings of provincial leaders between provinces to discuss cooperation programs. There must be contact points for discussions relating to cooperation, like a standing committee - those are people who advise provinces to implement the cooperation programs. There 
must be the evaluation of what has been actually done by provinces in reality. The issue is to evaluate how much effectiveness has been gained compared to the investments and efforts provinces have spent in order to optimize the tradeoffs they make.

Third, the roles and functions of TIPCs as the bridging organizations should be enhanced. A joint team could be established between provincial TIPCs and this team works as a contacting point between regional tourism organization and provinces. At the same time, leaders of DCSTs/TIPCs need to be aware of facilitators and inhibitors that arise during the process of joint marketing so that they are able to implement appropriate actions.

Fourth, DCSTs/TIPCs in the region should suggest a mechanism for cooperation and issue supporting policies for tourism enterprises that participate in the cooperation. For example, if a tour operator has trans-region products, what support does the operator receive from the provinces? Without a supporting mechanism and without benefits, enterprises do not have motivation to cooperate. Further training for tourism businesses is also crucial so that they can be familiar with cooperation process and understand the benefits and have motivations to involve in cooperative activities.

\subsection{Implications for future research}

As mentioned before, in the destination marketing literature, most of the studies look at destination marketing within a destination rather than between destinations. Thus, many questions in this problem domain remain to be answered.

Futher research should focus on evaluating the effectiveness and examining the decision-making process of joint destination marketing. Researchers could also conduct similar comparative studies in other parts of the world to find out both similarities and differences, which can be compared with this study and thus enhance the generalization of research in this specific area. There is also much 
room for comparing the joint marketing domain between tourism and other sectors.

This study also indicated that tourism enterprises have a decisive role in destination marketing relationships between provinces. However, the involvement of tourism enterprises has not been examined in this study due to constraints of time and budget. Therefore a similar study could be done from the perspective of tourism enterprises to understand how tourism businesses might be involved in destination marketing activities between provinces and how they perceive their relationships with other businesses in the region. There is also a call for research to study the trade-offs destination marketers face in making decisions on conducting marketing either individually or jointly.

The study confirms the important role of the convener in facilitating joint actions between provinces. It is also important for the convener to be unbiased and have enough power as well as ability and resources to induce multiple stakeholders to participate. These characteristics of the converner are congruent with the findings of Gray (1989). However, the ways in which the convener can effectively convene in the cooperation process remain unclear.

Further research is needed into factors that contribute to partner satisfaction. Some representatives in this study provided the information indicating that teamwork, a clear vision and objectives contributed to the sucessful cooperative model of Hue - Quang Nam- Da Nang. Research is required to show how joint destination marketing at the regional level can be formed and maintained and to figure out the best ways to mobilize the DCSTs/TIPCs of multiple provinces to become actively involved and committed. 


\subsection{Conclusion}

This thesis was inspired from a practical issue of regional tourism development in Viet Nam as well as from research gaps identified in the existing literature. The study has made both theoretical and practical contributions. First, regionalization in tourism development is important (Teye, 1988; Pearce, 1992) but has attracted less and less research attention (Naipaul, Wang \& Okumus, 2009). By examining destination marketing activities that occur jointly between provinces, this study has contributed to the inter-destination marketing literature. Also, by focusing on the activity dimension of destination marketing, the study has demonstrated how destination marketing is actually implemented in the local and regional contexts. Second, the study contributes specifically to the research on destination marketing partnerships which are also fundamental because most destinations now compete on a global level (Soteriades, 2012). Applying a comparative research approach, the research has been able to provide comprehensive views of joint actions and destination marketing interrelationships and underlying explanatory factors from the perspectives of DMOs at provincial, national and inter-provincial levels. Although the study looks at joint destination marketing in a specific region of Viet Nam, its conceptual framework and research design can be useful for similar studies on destination marketing partnerships at a regional level in other regions.

In terms of practical contributions, the study has drawn several important conclusions on the practice of joint destination marketing not only at present but also in the future. First, marketing multiple destinations in a region jointly is an increasingly common trend and thus requires destination marketers to understand its nature and the ways in which they can work well in partnership. Second, despite the popularity of cooperative destination marketing, destinations practice a mix of both individual and joint destination marketing activities, depending on their decision-making that involves consideration of various factors. Fuller awareness of the factors that influence joint destination marketing is needed so that informative and thoughtful tradeoffs can be made. Similarly, most destinations compete and cooperate at the same time. Destination marketers need to practice balancing acts between individual and 
joint marketing activities, between seft-interests and common interests and between competition and cooperation. 


\section{Appendices}

\section{Appendix 1: Interview schedule for DCSTs/TIPCs representatives}

Representatives of Department of Culture, Sports and Tourism (DCST)/provincial tourism information and promotion centres (TIPCs) are indentified from the official websites of these organisations. Letters will be firstly sent by email and then by post to ask for and arrange interviews.

Starting the interviews, the researcher will describe the main points of the project to interviewees. The information sheet and consent form then will be explained and provided. The participants are asked to sign the consent form if they agree to participate in the project voluntarily. Then the in-depth interviews will be conducted with following questions.

1. How do you evaluate the growth of tourism development in your province? How does the Department of Cuture, Sports and Tourism contribute to that development?

2. What is the role of destination marketing to tourism development in your province?

3. How do you compare the role of destination marketing with other roles of DCST?

4. What is the organizational structure of the DCST?

5. Does the province/city have its own marketing strategy? If yes, can you describe the marketing strategy in terms of its objectives, activities and action plans?

6. What marketing activities do you carry out individually and what activities do you carry jointly with other provinces or organizations? Do your province conduct destination marketing activities more individually or more jointly?

7. What are the provinces or organizations that your DCST often has joint activities with? Any localities within the region that your province does not have joint marketing with? Why not?

8. On your organization's tourism promotion website, is there any connection with other provinces/cities? If yes, why there are those connections?

9. How often do you carry out joint marketing activities with other provinces? What do these activities involve? Who are the main organizers? What are organizations participating in these activities? what marketing tools do you use?

10. Who initiates these joint activities, your organization or the other organizations? If your organization does, how do you choose your partners in joint destination marketing? If other organizations initiate the joint marketing, why do you think they include you? 
11. What are the distinctive tourism potential of your province compared to other provinces/cities? How your province develops its competitive advantage while carrying out destination marketing activities jointly?

12. Why do you carry out joint marketing activities with other localities?

13. What are the ways in which your destination is involved in or contributes to those marketing activities?

14. How would you evaluate your experiences when DM activities are conducted individually and when they are done jointly?

15. What are benefits of joint destination marketing with other localities?

16. What conditions favor the joint destination marketing between provinces in the region? If the province has the joint DM with any province outside the region, what conditions did favor that relationships?

17. What are the constraints to joint DM between provinces?

18. Are there threats that you perceive from joint DM between provinces? Does JDM present any challenge for you?

19. What factors have contributed to the success or failure of past joint marketing activities with other destinations?

20. Do you consider other destinations and other DCSTs in the region as partners or competitors? Why? What are factors affecting that perception?

21. In describing the relationships between destinations, there is the continuum Competition - Coopetition - Cooperation - Collaboration. So where should you place yourself in that continuum concerning your destination marketing relationships with other provinces in the region? Why that is the case?

22. What forms of DM relationships have been used in previous joint marketing activities between destinations in the region? Why do you think those forms have been chosen? How do they work? How effective they are?

23. What destination marketing relationships would your destination like to develop with other localities? Why?

24. Which structures are most appropriate for the proposed form of relationship? In your opinion, what are their key success factors?

25. JDM in Viet Nam is still a relatively new concept, from your perspective how would you summarize joint destination marketing?

26. Do you have any other comment or suggestion regarding destination marketing relationship between localities (inside or outside the region)? 


\section{Appendix 2: Interview schedule for the national tourism organization's representatives}

Representatives of the national tourism organizations are indentified from the official websites of these organisations. Letters will be firstly sent by email and then by post to ask for and arrange interviews.

Starting the interviews, the researcher will describe the main points of the project to interviewees. The information sheet and consent form then will be explained and provided. The participants are asked to sign the consent form if they agree to participate in the project voluntarily. Then the in-depth interviews will be conducted with following questions.

1. How do you evaluate the tourism potential of South Central Coastal provinces?

2. Are you aware of destination marketing activities in the South Central Coast region? What are they?

3. How do you evaluate destination marketing efforts in South Central Coast region compared with tourism potential of the region?

4. Does national tourism strategy encourage destination marketing in the region? In what ways?

5. What are the ways in which VNAT is involved in or contribute to destination marketing activities in the region?

6. Does VNAT play its role in destination marketing with each province or with groups of province or with the whole region? Why? Which factors lead to that decision?

7. According to you, what destination marketing activities each province should carry out individually and what activities the province should do it jointly?

8. Is joint destination marketing or individual destination marketing more suitable for South Central Coast provinces? Why?

9. What are benefits of joint destination marketing?

10. What conditions favor or limit the joint destination marketing between provinces?

11. What are threats from joint destination marketing between provinces? What are the challenges to which provinces in South Central Coast region must face in joint destination marketing with other provinces?

12. How does the region's boundary affect the joint destination marketing in the South Central Coast region? What conditions favor or limit the joint destination marketing outside the region? 
13. What are the success or failure factors of joint marketing activities with other destinations?

14. How South Central Coast provinces develop its competitive advantage if they carry out destination marketing activities jointly?

15. In your opinion, the South Central Coast provinces consider each other as partners or competitors? Why? What are the factors affecting that perception?

16. In describing the relationships between destinations, there is the continuum - Competition - Coopetition - Cooperation - Collaboration. Where do you think is the position of destination marketing relationships of the South Central Coast provinces at the moment? Why? And where they should be (if the current one is not ideal)? Why?

17. Which structures are most appropriate for joint destination marketing relationship in the South Central Coast region? Why do you think it is appropriate?

18. Joint destination marketing in Viet Nam is still a relatively new concept, from your perspective how would you summarize joint destination marketing? How would you evaluate its opportunities and its feasibility in the South Central Coast region in particular and in Viet Nam in general?

19. Do you have any other comment or suggestion regarding destination marketing relationship between localities (inside or outside the region)? 


\section{References}

ASEAN. (2012). Tourism statistics. Retrieved 4 December, 2013, from http://www.asean.org/news/item/tourism-statistics

Augustyn, M. M., \& Knowles, T. (2000). Performance of tourism partnerships: A focus on York. Tourism Management, 21(4), 341-351.

Baker, M. J., \& Cameron, E. (2008). Critical success factors in destination marketing. Tourism and Hospitality Research, 8(2), 79-97.

Bengtsson, M., \& Kock, S. (2000). "Coopetition" in business networks - to cooperate and compete simultaneously. Industrial Marketing Management, 29(5), 411-426.

Bennett, O. (1999). Destination marketing into the next century. Journal of Vacation Marketing, 6(1), 48-54.

Blumberg, K. (2005). Tourism destination marketing - A tool for destination management? A case study from Nelson/Tasman Region, New Zealand. Asia Pacific Journal of Tourism Research, 10(1), 45-57.

Buhalis, D. (2000). Marketing the competitive destination of the future. Tourism Management, 21(1), 97-116.

Butler, R. (2006). The tourism area life cycle: Applications and modifications. Clevedon, Buffalo: Channel View Publications.

CIA. (2013). The world factbook: Vietnam. Retrieved 21 November, 2013, from https://www.cia.gov/library/publications/the-worldfactbook/geos/vm.html

CNN. (2013). World's 100 best beaches. Retrieved 5 May, 2013, from http://edition.cnn.com/2013/05/28/travel/100-best-beaches/

Cox, C., \& Wray, M. (2011). Best practice marketing for regional tourism destinations. Journal of Travel \& Tourism Marketing, 28(5), 524-540.

CRDF, \& DNPPC. (2013). Investment promotion for the Central Coastal region of Vietnam. Da Nang: Central Research Development Fund.

d'Angella, F., \& Go, F. M. (2009). Tale of two cities' collaborative tourism marketing: Towards a theory of destination stakeholder assessment. Tourism Management, 30(3), 429-440.

Darrow, K. (1995). A partership model for nature tourism in Eastern Caribbean Islands. Journal of Travel Research, 33(3), 47-51.

Decrop, A. (1999). Triangulation in qualitative tourism research. Tourism Management, 20(1), 157-161.

Doolin, B., Burgess, L., \& Cooper, J. (2002). Evaluating the use of the web for tourism marketing: A case study from New Zealand. Tourism Management, 23(5), 557-561.

Elbe, J., Hallén, L., \& Axelsson, B. (2008). The destination-management organization and the integrative destination-marketing process. International Journal of Tourism Research, 11(3), 283-296.

Forbes. (2005). World's most luxurious beaches. Retrieved 5 May, 2013, from http://www.forbes.com/2005/06/01/cx_sb_0602featslide_5.html

Fyall, A., \& Garrod, B. (2005). Tourism marketing: A collaborative approach. Portland: Channel View Publications.

Fyall, A., Garrod, B., \& Wang, Y. (2012). Destinational collaboration: A critical review of theoretical approaches to a multi-dimensional phenomenon. Journal of Destination Marketing and Management, 1(1- 
2), 10-26.

Fyall, A., \& Leask, A. (2006). Destination marketing: Future issues -strategic challenges. Tourism and Hospitality Research, 7(1), 50-63.

Fyall, A., Leask, A., \& Garrod, B. (2001). Scottish visitor attractions: A collaborative future? International Journal of Tourism Research, 3(3), 211-228.

Fyall, A., Oakley, B., \& Weiss, A. (2000). Theoretical perspectives applied to inter-organisational collaboration on Britain's inland waterways. International Journal of Hospitality \& Tourism Administration, 1(1), 89-112.

Grängsjö, Y. v. F. (2003). Destination networking co-opetition in peripheral surroundings. International Journal of Physical Distribution \& Logistics Management, 33(5), 427-448.

Grängsjö, Y. v. F., \& Gummesson, E. (2006). Hotel networks and social capital in destination marketing. International Journal of Service Industry Management, 17(1), 58-75.

Gray, B. (1985). Conditions facilitating interorganizational collaboration. Human Relations, 38(10), 911-936.

GSO. (2012). Area, population and population density of Viet Nam's provinces in 2012. Retrieved from 15 October 2013 from http://www.gso.gov.vn/default.aspx?tabid=387\&idmid=3\&ItemID=146 32

GSO. (2013). Social economic status in 2013. Retrieved 15 October 2013, from http://www.gso.gov.vn/default.aspx?tabid=403\&\&ItemID=14769

GSO. (2013). Vietnam - destination of the new millennium. Retrieved 17 October, 2013, from http://www.gso.gov.vn/default.aspx?tabid=507\&ItemID=13966

Guest, G., Namey, E. E., \& Mitchell, M. L. (2013). Collecting qualitative data: A field manual for applied research. Thousand Oaks, Californa: SAGE Publications.

Hague, R., \& Harrop, M. (1982). Comparative Government: An Introduction. London: Macmillan.

Hawes, D. K., Taylor, D. T., \& Hampe, G. D. (1991). Destination marketing by states. Journal of Travel Research, 30(1), 10-17.

Hill, T., \& Shaw, R. N. (1995). Co-marketing tourism internationally: Bases for strategic alliances. Journal of Travel Research, 34(1), 24-32.

Hennink, M., Hutter, I., \& Bailey, A. (2011). Qualitative research methods. London: SAGE Publications.

Horner, S., \& Swarbrooke, J. (1996). Marketing tourism hospitality and leisure in Europe. London: International Thomson Business Press.

Hsu, C., Killion, L., Brown, G., Gross, M. J., \& Huang, S. (2008). Tourism marketing: An Asia-Pacific perspective. Milton: John Wiley \& Sons Australia.

ITDR. (2012). Ninh Thuan tourism development plan to 2020, with the vision to 2030. Ninh Thuan: Ninh Thuan Department of Culture, Sports and Tourism.

Jamal, T. B., \& Getz, D. (1995). Collaboration theory and community tourism planning. Annals of Tourism Research, 22(1), 186-204.

McCann, J. E. (1983). Design guidelines for social problem-solving interventions. Journal of Applied Behavioral Science, 19(2), 177-192. 
Meriläinen, K., \& Lemmetyinen, A. (2011). Destination network management: A conceptual analysis. Tourism Review, 66(3), 25-31.

Middleton, V. T. C., \& Clarke, J. (2001). Marketing in travel and tourism (3rd ed.). Oxford: Butterworth-Heinemann

Miles, M. B., \& Huberman, A. M. (1994). Qualitative data analysis. Thousand Oaks, California: SAGE Publications.

Ministry of Home Affairs. (2005). Guiding on functions, duties, power and organizational structure of the specialized agency helping the provincial People's Committee in state management on tourism. Retrieved 4th June, 2013, from http://www.moj.gov.vn/vbpq/Lists/Vn\%20bn\%20php\%20lut/View_Det ail.aspx?ItemID $=18389$

Morrison, A. M. (2013). Marketing and managing tourism destinations. New York: Routledge.

Murphy, P., Pritchard, M. P., \& Smith, B. (2000). The destination product and its impact on traveller perceptions. Tourism Management, 21(1), 43-52.

Naipaul, S., Wang, Y., \& Okumus, F. (2009). Regional destination marketing: A collaborative approach Journal of Travel \& Tourism Marketing, 26(56), 462-481.

NCHMF. (2014). Map from Da Nang to Binh Thuan. Retrieved 12 December 2013, from http://www.nchmf.gov.vn/web/viVN/61/21/map/Default.aspx

Nguyen, P. N., \& Le, T. G. (2013). Tourism development on the Central region from a value chain perspective. Paper presented at the Investment promotion for the Central Coastal region of Vietnam, Da Nang.

Palmer, A. (2002). Cooperative marketing associations: An investigation into the causes of effectiveness. Journal of Strategic Marketing, 10(2), 135156.

Palmer, A., \& Bejou, D. (1995). Tourism destination marketing alliances. Annals of Tourism Research, 22(3), 616-629.

Parker, S. (1999). Collaboration on tourism policy making: Environmental and commercial sustainability on Bonaire, NA. Journal of Sustainable Tourism, 7(3-4), 240-259.

Pearce, D. (1989). Tourist development. London: Longman.

Pearce, D. (1992). Tourist Organizations. Harlow, England: Longman.

Pearce, D. G. (1993). Comparative studies in tourism research. In D. G. Pearce \& R. W. Butler (Eds.), Tourism Research: Critiques and Challenges (pp. 21). London: Routledge.

Pike, S. (2008). Destination marketing: An integrated marketing communication approach. Oxford: Elsevier.

Prideaux, B., \& Cooper, C. (2002). Marketing and destination growth: A symbiotic relationship or simple coincidence? Journal of Vacation Marketing, 9(35-51).

Ragin, C. C. (1994). Constructing social research: the unity and diversity of method. Thousand Oaks, California: Pine Forge Press.

Rubin, H. J., \& Rubin, I. (1995). Qualitative interviewing: the art of hearing data. Thousand Oaks: Sage Publications.

Saxena, G. (2005). Relationships, networks and learning regions: case evidence from the Peak District National Park. Tourism Management, 26(2), 277289. 
Scott, N., Cooper, C., \& Baggio, R. (2008). Destination networks: Four Australian cases. Annals of Tourism Research, 35(1), 169-188.

Selin, S., \& Beason, K. (1991). Interorganizational relations in tourism. Annals of Tourism Research, 18(4), 639-652.

Selin, S., \& Chavez, D. (1995). Developing an evolutionary tourism partnership model. Annals of Tourism Research, 22(4), 844-856.

Selin, S. W., \& Myers, N. A. (1998). Tourism marketing alliances: Member satisfaction and effectiveness attributes of a regional initiative. Journal of Travel \& Tourism Marketing, 7(3), 79-94.

So, S.-I. A., \& Morrison, A. M. (2004). Internet marketing in tourism in Asia: An evaluation of the performance of East Asian National Tourism Organization websites. Journal of Hospitality and Leisure Marketing, 11(4), 93-118.

Soteriades, M. (2012). Tourism destination marketing approaches improving effectiveness and efficiency. Journal of Hospitality and Tourism Technology, 3(2), 107-120.

Teye, V. B. (1988). Prospects for regional tourism cooperation in Africa. Tourism Management, 9(3), 221-234.

Timothy, D. J. (1999). Cross-border partnership in tourism resource management: International parks along the US-Canada border. Journal of Sustainable Tourism, 7(3-4), 182-205.

Tran, L. D., \& Consultative group. (2013). Development of tourism products in the Central Coastal provinces. Paper presented at the Conference on tourism product development for the Central Coastal region of Viet Nam, Khanh Hoa.

Travers, M. (2010). Qualitative interviewing methods. In M. Walter (Ed.), Social research methods. Australia: Oxford University Press.

Tussyadiah, I. P., Kono, T., \& Morisugi, H. (2006). A model of multidestination travel: Implications for marketing strategies. Journal of Travel Research, 44(4), 407-417.

UNESCO. (n.d.). Properties inscribed on the World Heritage List - Viet Nam. Retrieved 18 October, 2013, from http://whc.unesco.org/en/statesparties/VN/

UNWTO. (2007). A practical guide to tourism destination management. Madrid: World Tourism Organization.

UNWTO. (2011). Tourism and poverty alleviation. Retrieved 17 June, 2013, from http://step.unwto.org/content/tourism-and-poverty-alleviation-1

VNAT. (2005). Non nиос Viet Nam. Ha Noi: Vietnam National Administration of Tourism.

VNAT. (2012). Vietnam tourism development strategy until 2020, vision to 2030. Ha Noi: Vietnam National Administration of Tourism. Retrieved from http://itdr.org.vn/an-pham/mainmnu-anphamkhac/700-an-phamchien-luoc-2020.html.

VNAT. (2013). Tourism statistics. Retrieved 12 April, 2013, from http://www.vietnamtourism.gov.vn/index.php?cat=2020

Wang, Y. (2008). Collaborative destination marketing: Understanding the dynamic process. Journal of Travel Research, 47(2), 151-166.

Wang, Y., \& Fesenmaier, D. R. (2007). Collaborative destination marketing: A case study of Elkhart county, Indiana. Tourism Management, 28(3), 863-875. 
Wang, Y., \& Krakover, S. (2007). Destination marketing: Competition, cooperation or coopetition? International Journal of Comtemporary Hospitality Management, 20(2), 126-141.

Wang, Y., \& Xiang, Z. (2007). Toward a theoretical framework of collaborative destination marketing. Journal of Travel Research, 46(1), 75-85.

Watkins, M., \& Bell, B. (2002). The experience of forming business relationships in tourism. International Journal of Tourism Research, 4(1), 15-28.

Wong, E. P. Y., Mistilis, N., \& Dwyer, L. (2010). Understanding ASEAN tourism collaboration - Preconditions and policy framework formulation.

International Journal of Tourism Research, 12(3), 291-302.

Wood, D. J., \& Gray, B. (1991). Toward a comprehensive theory of collaboration. The Journal of Applied Behaviour Science, 27(2), 139162.

World Bank. (n.d.). GDP growth (annual \%). Retrieved 4 December, 2013, from http://data.worldbank.org/indicator/NY.GDP.MKTP.KD.ZG?page=4\&o rder=wbapi_data_value_2009\%20wbapi_data_value\%20wbapi_data_va lue-first\&sort=asc

World-bays. (n.d.). The most beautiful bays in the world. Retrieved 5 May, 2013, from http://www.world-bays.com/nha-trang-bay-47-70.html

WTTC. (2013). Travel and tourism economic impact 2013: Vietnam. Retrieved 21 June, 2013, from http://www.wttc.org/site_media/uploads/downloads/vietnam2013.pdf

Yin, R. K. (2009). Case study research: design and methods. Los Angeles, Calif: Sage Publications.

Zajac, E. J., \& Olsen, C. P. (1993). From transaction cost to transactional value analysis: Implications for the study of interorganizational strategies. Journal of Management Studies, 30(1), 131-145. 